\section{COMUNICACIONES ORALES}

\section{APLICABILIDAD DE LA ELASTOMETRÍA DE TRANSICIÓN (FIBROSCAN®) EN LA CONSULTA EXTERNA DE UN SERVICIO DE MEDICINA INTERNA}

Bermúdez Ramos M, Macía-Rodríguez C, Antela López A, Martínez de Rituerto ST, Losada Arias E, Otero Antón E. MEDICINA INTERNA, CLINIICO UNIVERSITARIO DE SANTIAGO DE COMPOSTELA.

INTRODUCCIÓN: La elastometría de transición (ET) permite una estimación de forma no invasiva del grado de fibrosis hepática. Actualmente es fundamental para la valoración de la necesidad de tratamiento en las hepatitis víricas. Su limitación fundamental consiste en que no permite obtener en todos los casos una medición fiable.

OBJETIVOS: Estudiar la aplicabilidad de la ET (Fibroscan®) en la práctica diaria en consultas externas de un servicio de Medicina Interna, en base al porcentaje de exploraciones exitosas, el tiempo empleado en la exploración, y la variabilidad interoperador.

MATERIAL Y MÉTODO: Se recogieron todos Ios estudios de rigidez hepática mediante ET realizados en el servicio de Medicina Interna del CHUS entre el 12/1/2015 y el 11/5/2015. Los operadores que realizaron las exploraciones desconocían que eran objeto del presente estudio. En todos los casos se empleó una sonda M. Todos los parámetros se obtuvieron del archivo de registro automático del aparato (FibroScan 402) empleado en las exploraciones. Se analizaron el porcentaje de exploraciones válidas, el tiempo empleado en las mediciones y su variabilidad interoperador. De acuerdo con los estándares internacionales se consideró que un estudio era válido cuando se obtuvieron un mínimo de 10 valores, con un porcentaje de éxito $>60 \%$ y un $I Q R /$ medM $<0.3$

RESULTADOS: Durante el tiempo del estudio 6 operadores realizaron un total de 264 exploraciones, con una mediana de 36 exploraciones por operador (rango 18-112). La mediana de edad de los pacientes fue de $50 \pm 11$ años, y de ellos el 29. 2\% eran mujeres. En 198 pacientes (75\%) se obtuvo un estudio válido. El porcentaje de éxito de la exploración fue similar para todos los operadores (71 . 4-75. 9\%) independientemente del número de exploraciones que habían realizado durante el tiempo del estudio. La mediana de duración de las exploraciones fue de 164 segundos (rango intercuartílico 115-251 segundos), con una correlación negativa entre el IQR/medM y la duración de la exploración (coeficiente de Pearson -0. 15, $\mathrm{p}<0$. 05). El número de intentos de medición fue menor cuando la exploración fue válida que en los casos en que fracasó la exploración (IC95\% para la media 15-17 vs. 20-26; $p<0$. 001)

CONCLUSIONES: La ET permite estimar el grado de fibrosis hepática en el 75\% de los pacientes explorados con escasa dependencia del operador y una curva de aprendizaje breve. La exploración es más rápida en los casos en los que se obtiene una medición válida.

\section{AUSENCIA DE HIPERTENSIÓN ARTERIAL PULMONAR SINTOMÁTICA EN LOS PACIENTES CON EMTC EN EL ÁREA SUR DE PONTEVEDRA}

Vázquez-Triñanes $C^{\prime}$, Sopeña $B^{2}$, Villaverde-Álvarez $I^{\prime}$, Sousa-Domínguez $A^{1}$, Lorenzo-Castro $R^{1}$, Argibay $A$

Freire $M^{1}$, RiveraA

MEDICINA INTERNA-UNIDAD TVY, COMPLEJO HOSPITALARIO UNIVERSITARIO DEVIGO', COMPLEJO HOSPITALARIO UNIVERSITARIO DE SANTIAGO DE COMPOSTELA'

INTRODUCCIÓN: La enfermedad mixta del tejido conectivo (EMTC) es una entidad poco frecuente que se caracteriza por títulos elevados de anticuerpos anti-RNP y la combinación de manifestaciones clínicas comunes a otras enfermedades del tejido conectivo (ETC): esclerosis sistémica (SSC), artritis reumatoide, polimiositis y lupus eritematoso sistémico. Clásicamente se consideraba que la hipertensión arterial pulmona (HAP) en estos pacientes era muy frecuente. Sin embargo, aunque se sabe que es una de sus complicaciones más graves, la verdadera prevalencia de la HAP en la EMTC sigue siendo desconocida. Las diferentes series dan cifras que oscilan entre 3,4\% y 23,4\%[1]. De ahí que en las guías para el screening de HAP en las ETC no se hayan podido establecer recomendaciones al respecto con suficiente grado de evidencia[2] OBJETIVOS: Determinar la incidencia acumulada de HAP sintomática en los pacientes con EMTC en el área sur de Pontevedra tras un largo periodo de seguimiento.

MATERIAL Y MÉTODO: Se revisaron las historias clínicas de los pacientes con al menos 1 determinación de antiRNP positiva a título elevado entre ene-2006 y dic-2012 en el CHUVI (hospital de 3er nivel, área de 300. 000hab). Se seleccionaron los que cumplían criterios de EMTC (Kanh o Alarcón-Segovia). Se recogieron las características clínicas, analíticas y los datos de capilaroscopia, ecocardiograma y cateterismo derecho(CD). Se definió HAP como PAPm >25mmHg en CD y HAP probable como PSAP >30mmHg 0 dilatación de cavidades derechas en ecocardiograma. Se consideró como tiempo de seguimiento el periodo entre la primera valoración clínica por ETC y la última valoración antes de dic-2014.

RESULTADOS: De 89 pacientes con antiRNP positivo, 16 (18\%) cumplian criterios de EMTC, edad media 53ะ12,9años, 15 mujeres, con un seguimiento medio de 11,8+8,50años. Todos tenían fenómeno de Raynaud y 5 (31\%) cumplían además criterios para SSc. Solo 1 paciente refirió disnea en algún momento de la evolución, clase II (EMTC con enfermedad pulmonar intersticial). Ninguno manifestó signos de fallo cardiaco derecho. A 9 pacientes (56\%) se les realizó al menos 1 capilaroscopia: solo 1 presentaba patrón esclerodermiforme, 7 presentaban un patrón inespecífico y 1 tenía una exploración normal. 7 pacientes (43\%) tenían al menos 1 ecocardiograma realizado, todos ellos con cavidades derechas normales y PSAP normal o indetectable; en ningún caso se realizó CD. 2 pacientes (13\%) fallecieron durante el seguimiento, por causas no relacionadas con la EMTC.

CONCLUSIONES: Ningún paciente con EMTC en el área sur de Pontevedra presentó HAP sintomática en un periodo de seguimiento medio mayor de 10 años.

\section{ENFERMEDAD POR ARAÑAZO DE GATO (EAG) \\ EN ADULTOS DEL ÁREA NORTE DE PONTEVEDRA}

García JC', Núñez MJ', Matilde Trigo ${ }^{2}$, Marta Rodrígez

MEDICINA INTERNA ${ }^{\top} Y$ MICROBIOLOGI'A ${ }^{2}$, COMPLEJO HOSPITALARIO UNIVERSTARIO DE PONTEVEDRA.

INTRODUCCIÓN: La EAG es una enfermedad de distribución universal. El 80\% de casos aparece en pacientes menores de 18 años. El 5-20\% son formas atípicas/sistémicas. La incidencia en EFUU es de 0,8 x105/año en pacientes hospitalizados y 9,3x105/año en ambulatorios. En Dinamarca es de 2,6x105/año. En España no hay datos nacionalesdeincidencia. En la Comunidad Valenciana 0,07×105/año (2009-2012). Tampoco se dispone de datos nacionales sobre prevalencia que varía entre regiones de un 6,4-7,9\% en Cataluña al 24,7\% enSevilla.

OBJETIVOS: Describir la incidencia y características clínicas de la EAG en los adultos diagnosticada en el área sanitaria Norte de la provincia de Pontevedra

MATERIAL Y MÉTODOS: Estudio retrospectivo de 2009-2014. Partiendo de las serologías positivas a Bartonellahenselae. Se recogieron datos epidemológicos, clínicos y evolutivos. Se incluyeron aquellos con un título único $>1 / 800$,seroconversión,mantenimiento de títulos $>$ 1/200 oelevación de títulos en fase de convalecencia en presencia de datos clínicos y/o histológicos y/o evolutivos concordantes.

RESULTADOS: 453 muestras, 65\% Medicina interna. 13 casos en adultos. 8 hombres (61\%); 5 mujeres (38\%). Edad media (DE) 44(21,6),rango 16-86 años. Todos inmunocompetentes. Las incidencias anuales se recogen en figura $1.77 \%$ casos en otoño e invierno. Todos los pacientes tenían contactos con gatos pero el arañazo sólo 62\%. En la presentación 69\%adenopatías,en evolución 100\%. Fiebre 46\%. Lesiones cutáneas 38\% . El 31\% fueron formas atíicas. Analítica anodina. Histología 2 casos.: linfadenitis y mastitis granulomatosa necrotizante. TincióndeWharthin-Starry negativa en ambas. PCR en 3 casos: todas negativas. El 38\% ingresaron; la estancia media (DE) fue de $12,75(1,70)$ días. El tiempo medio hasta $1^{\mathrm{a}}$ consulta fue 23,6 (24,7) y el de diagnóstico de 14,9 (6,9) días. El 77\% recibió tratamiento antibiótico, la mayoría con azitromicina. Evolución: curación en todos los pacientes.

CONCLUSIONES: La EAG es una enfermedad de baja incidencia en nuestra área pero,extrapolando datos similar a la de otros países europeos. Aparece en paciente jóvenes y su distribución estacional es similar al resto del mundo. La presentación es atípica en un tercio de pacientes, dato comprensible porque estas formas son más frecuentes en adultos aun siendo inmunocompetentes. Los tiempos hasta primera consulta y diagnóstico parecen prolongados y hacen pensar en un bajo índice de sospecha. El tratamiento fue adecuado en la mayoría de casos y la evolución (espontánea o con tratamiento ) fue buena.

\section{FIBROSIS HEPÁTICA EN PACIENTES CO-INFECTADOS POR EL VIH Y EL VHC: VARIABLES ASOCIADAS}

Vilariño-Maneiro $L^{2}$, Valcarce-Pardeiro ${ }^{3}$, Mariño-Callejo ${ }^{\dagger}$, Álvarez-Díaz $\mathrm{H}^{1}$, García-Rodríguez JF', SesmaSánchez $P$

UNIDAD DE ENFERMEDADES INFECCIOSAS', SERVICIOS DE MEDICINA INTERNA ${ }^{2}$ F FARMACIA HOSPITALARIA ${ }^{3}$, COMPLEXO HOSPITALARIO UNIVERSITARIO DE FERROL.

INTRODUCCIÓN: Existen varios factores determinantes de la evolución hacia la fibrosis hepática en los pacientes infectados por el VHC, dependientes del virus y del huésped. En sujetos con infección por el $\mathrm{VIH}$ se asocian, además, otras variables que pueden modificar la historia natural de la enfermedad y su progresión hacia la fibrosis avanzada.

OBJETIV0: Conocer las variables asociadas a la progresión de la hepatitis $\mathrm{C}$ en una cohorte de pacientes co-infectados por el VIH y el VHC.

MATERIAL Y MÉTODOS: Análisis retrospectivo de variables dependientes de la infección por el VIH y el VHC que pueden estar relacionadas con la progresión hacia la fibrosis hepática (medida a través de elastografía FibroScan $($ ). La información sobre aspectos epidemiológicos, clínicos y analíticos se recogió de forma prospectiva en una base de datos específica para los pacientes co-infectados por el VIH-VHC en seguimiento regular durante el año 2014 en la consulta monográfica de VIH. Para comparar las variables cualitativas se utilizó la prueba Chi-cuadrado y para las variables cuantitativas el test de la T de Student. RESULTADOS: Acudieron a la consulta monográfica de VIH un total de 469 pacientes durante el año 2014. 109 estaban co-infectados por el VHC. De los 109, disponemos de datos en 75 pacientes con seguimiento protocolizado. 57 (76\%) eran varones y la mediana de edad 49 años (intercuartil 46-53). Cinco pacientes consumían $>30 \mathrm{~g}$ de alcohol/día y 24 otras drogas. La vía de transmisión fue el UDVP en el 78,7\% de los casos y sexual en el 10,7\%. Transcurrió una media de 19,7 $\pm 6,4$ años desde el diagnóstico de la infección por el VIH. Según la clasificación de los CDC, 30 pacientes (40\%) estaban en estadio A, 15 (20\%) B y $30(40 \%)$ C. Los linfocitos CD4+ fueron $>200$ células/ $/$ l en 70 casos $(93,3 \%)$. 69 pacientes (92\%) tenían CV de VIH $\leq 50 \mathrm{cp} / \mathrm{ml} .73$ pacientes (97,3\%) recibían tratamiento antirretroviral (TAR). El 97,3\% de los pacientes en TAR tenían CV de VIH $\leq 50 \mathrm{cp} / \mathrm{ml}$. La media de años transcurridos desde el diagnóstico de la infección por el VHC fue 16,2 $\pm 6,2$. El genotipo (Gt) del VHC fue Gt 1 en 41 pacientes $(54,7 \%)$, Gt 3 en $14(18,7 \%)$ y Gt 4 en $20(26,7 \%)$. La carga viral de VHC era $>6.000 .000 \mathrm{UI} / \mathrm{ml}$ en 13/75 pacientes $(17,3 \%)$. El grado de fibrosis fue avanzado ( $\geq$ F3) en $30 / 75$ pacientes (40\%) y ligero-significativo (F0-F1 o F2) en $45 / 75(60 \%$ ). Al analizar qué variables se asocian a fibrosis hepática avanzada por el VHC, sólo encontramos significación estadística en el caso de la edad ( $50,6 \pm 3,7$ vs $47,9 \pm 5,7$ años, $p=0.028)$, el estadio B-C de la infección por el VIH ( $76,7 \%$ vs $48,9 \%, p=0.018)$ y el genotipo $1(91,3 \%$ Gt 1 vs $8,7 \%$ Gt $3, p=0.025$ )

CONCLUSIONES: Casi todos nuestros pacientes estaban en TAR y tenían la viremia de VIH suprimida. En nuestra serie las variables que se asocian con una fibrosis hepática avanzada por el VHC son la edad, el estadio avanzado de la infección por el VIH y el genotipo 1 del VHC.

\section{MANTENSE 0 EFECTO DA CONSULTA MONOGRÁFICA DE INSUFICIENCIA CARDÍACA MÁIS ALÓ DE 1 ANO DE SEGUIMENTO?}

López-Reboiro ML, Ventura-Valcárcel P, Piñeiro-Fernández JC, Romay-Lema EM, Suárez-Gil R, Rubinos-Chaos P, Cerqueiro Gonzalez JM.

MEDICINA INTERNA, HOSPITAL UNIVERSTTARIO LUCUS AUGUST

INTRODUCIÓN: Os pacientes con insuficiencia cardíaca (IC) supoñen unha elevada carga asistencial debido ó elevado número de ingresos fundamentalmente por IC. Manter a estabilización mediante un programa de seguimento adaptado ás súas necesidades é a única medida que demostrou reducir ingresos. Sen embargo, ata agora os estudos só valoran este efecto nun prazo máximo dun ano de seguimento. № HULA dispoñemos dunha consulta monográfica, o que nos levou a facer o seguinte estudio para ver o seu impacto sobre os doentes con IC, que teñen un seguimento maior a 1 ano.

OBXECTIVOS: Caracterizar a poboación seguida na consulta monográfica de IC, durante $>1$ ano, e 0 impacto sobre os ingresos e consultas a urxencias por IC.

MATERIAL E MÉTODOS: Realizamos un estudio retrospectivo, seleccionando ós pacientes seguido na Consulta Monográfica de IC de Medicina Interna do HULA, dende setembro do 2013 a setembro do 2014 Excluímos aqueles doentes que teñan menos dun ano de seguimento. Sobre esta poboación recollemos datos de filiación (idade e sexo), características da cardiopatía de base e co-morbilidades. En canto a seguimento recollemos os ingresos por insuficiencia cardíaca as chegadas a urxencias por IC. E comparámolo cun estudio realizado polo grupo de IC dea SEMI, cunha poboación similar seguida só ata un ano. Os datos foron almacenados e analizados nunha base de datos de Excell 2013

RESULTADOS: Obtemos unha mostra de 142 pacientes, de 82 anos de idade media con 60\% de varóns, dos cales $074 \%$ ten máis de 80 anos. 0 factor de risco cardiovascular máis importante foi a HTA (76\%), DM (41\%) e DLP (38\%). As co-morbilidades más frecuentes foron a FA (64\%), IRC (45\%), EPOC (34\%) e Anemia (30\%). A cardiopatía estrutural máis prevalente foi a hipertensiva (36\%) e a isquémica (23\%); e na maioría dos casos a FEVI > 35\% (60\%). En canto á clínica $087 \%$ dos pacientes están en NYHA II-III e 0 $88 \%$ no estadio C da ACC/AHA. Destes 142 pacientes, faleceron 25 (mortalidade do 17\%). Estes pacientes xeraron 87 eventos por insuficiencia cardiaca, 39 ingresos (27\%) e 48 (33\%) chegadas a urxencias. Os 39 ingresos foron xerados por 29 pacientes, permanecendo 113 estables e sen ingresar, e $048 \%$ dos ingresos foron orixinados por pacientes que acabaron falecendo. A poboación do estudo realizado polo grupo de ICC da SEMl é de 338 pacientes dos que faleceron 0 17\%, cunhas características moi parecidas á da nosa polo que son poboacións superpoñibles. Xeran 92 ingresos por insuficiencia cardíaca (27\%) e 120 chegadas a unxencias (35\%), resultados similares ós obtidos nos noso análise.

CONCLUSIÓNS: Os resultados obtidos máis aló de un ano de seguimento son superpoñibles ós presentados durante $01^{\circ}$ ano. Polo que o impacto nos ingresos por IC mantense maís ala do ano. Pero hai que ter en conta que estamos ante unha poboación moi maior, con moita comorbilidade. Onde unha minoría xerea a maioría dos Ingresos por IC e temos unha alta mortalidade.

\section{MEDICACIÓN POTENCIALMENTE INADECUADA (MPI) SEGÚN CRITERIOS STOPP}

Domínguez Rodríguez T, Suárez Fuentetaja R, Porto Pérez AB, Díaz Díaz JL, Martín Malmierca N, Penas Ríos JL, Ruanova Suárez $S$

MEDICINA INTERNA, CHUAC.

INTRODUCCIÓN: Los criterios STOPP (Screening Tool of Older Persons' Potentially inappropiate Prescriptions), son una herramienta diseñada para la detección de MPI en pacientes mayores de 65 años, con el 
objetivo de modificar uno de los predictores de reingreso hospitalario modificables, como es la polifarmacia mejorando la calidad asistencial, el gasto sanitario y la seguridad del paciente anciano.

OBJETIVOS: - Valorar el grado de implementación de criterios STOPP, comparando la incidencia de MP al ingreso y tras el alta de hospitalación en un S. de Medicina Interna de un Hospital Terciario, previo a la implantación de criterios STOPP en dicho servicio.

MATERIAL Y MÉTODO: Estudio observacional transversal, que incluye 200 pacientes consecutivos mayores de 65 años, dados de alta entre el 1 junio 2014 y el 19 de julio de 2014, del S. de Medicina Interna del Complejo Hospitalario Universitario A Coruña. Se excluyeron los pacientes de los médicos que llevaron a cabo este estudio y que por tanto conocían los criterios STOPP. Para el análisis estadístico se empleó el programa SPSS v. 18

RESULTADOS: Pacientes con 1 o más MPI al ingreso 114 (57\%), al alta 92 (46\%). Por tanto, MPI por paciente (media +/- DT) $0.9+/-1$ al ingreso y $0.77+/-1.05$ al alta $(p<0.05)$.

Índice MPI $0.13+/-0.17$ al ingreso y $0.1+/-0.14$ al alta $(p<0.001)$.

CONCLUSIÓN: Se ha observado una reducción significativa en la MPI por paciente tras el alta del $\mathrm{S}$.

Medicina Interna. Esta reducción podría ser mayor, con la aplicación sistemática de los criterios STOPP.

Habrá que valorar la posible repercusión sobre la tasa de reingreso y la mortalidad.

\section{MENINGITIS TUBERCULOSA. DUDAS DIAGNÓSTICAS Y PRONÓSTICO}

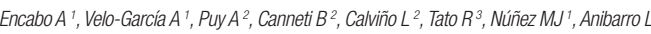

MEDICINA INTERNA', UNIDAD DE TB. NEUROLOGI'A². MICROBIOLOGIIA33, COMPLEXO HOSPITALARIO UNIVERSITARIO DE PONTEVEDRA.

INTRODUCCIÓN-OBJETIVOS: La tuberculosis meníngea (TBM) es la forma más grave de localización de esta enfermedad, alcanzando una mortalidad del $100 \%$ en casos sin tratamiento. Debido a la escasa carga bacilar y a la necesidad de instauración de tratamiento precoz, el diagnóstico y tratamiento inicial es frecuentemente empirico. En ol presente estudio analizamos los pacientes que iniciaron y mantuvieron de forma prolongada tratamiento espećífico de TBM, intentando identificar variables asociadas al diagnóstico final de TBM y factores asociados al pronóstico a largo plazo.

MATERIAL Y MÉTODOS: Revisión de los casos que iniciaron tratamiento específico de TBM desde 1996 (año de creación del Programa Gallego de TB) en el área de Pontevedra. Se analizaron las variables asociadas al diagnóstico final (TBM segura, posible-probable, o diagnóstico final no TB según criterios de Thwaites 2012) y factores predictores de mal pronóstico (mortalidad o secuelas neurológicas permanentes según escala de Rankin). Para el análisis estadístico se emplearon las pruebas de chi-cuadrado o Fisher para variables categóricas y T o Mann-Whitney para continuas. Las variables con significación estadística en el análisis univariante se incluyeron en análisis de regresión logística.

RESULTADOS: 47 pacientes iniciaron tratamiento especíico de TBM y lo mantuvieron durante al menos 6 meses o fallecieron precozmente. $66 \%$ eran varones y el $8,5 \%$ inmigrantes. La edad media de $43 \pm 23$. 8 años. 17 pacientes (36\%) presentaban algún tipo de inmunodepresión previa al diagnóstico. 25 enfermo (53\%) presentaron convulsión o focalidad neurológica. Solo se obtuvo confirmación microbiológica (PCR y/o cultivo) en el $28 \%$ de los pacientes. 39 enfermos (83\%) completaron tratamiento Tras el seguimiento clínico, resultados microbiológicos y otras pruebas complementarias, el diagnóstico final fue TBM segura en 13 pacientes y posible-probable en otros 28 . En 6 pacientes (13\%) se consideró que finalmente no habían padecido TB meníngea. Tras el análisis multivariante, de entre las 35 variables clínico-analítico-radiológicas estudiadas, solamente la presentación TAC y/o RM patológica se asoció con el diagnóstico definitivo de TBM (83\% en los pacientes con TB definitiva vs $50 \%$ en No TB definitivas; $p==.046$ ).

6 pacientes (13\%) fallecieron antes de finalizar el tratamiento. Entre los 39 enfermos que finalizaron correctamente el tratamiento, se realizó seguimiento mínimo de 2 años a 35, detectándose otros 5 fallecimientos. 12 pacientes presentaban algún déficit neurológico al final del seguimiento.

Las variables relaciones con la mortalidad durante el tratamiento fueron la edad (63,7 vs 39,1 años; $p=0$. 02), el deterioro de nivel de conciencia, los valores elevados de proteínas y ADA en LCR y glucorraquia baja. En el seguimiento a largo plazo, las variables relacionadas con mala evolución (mortalidad o secuelas permanentes) fueron los mismos que los relacionados con la mortalidad precoz y valores bajos de $\mathrm{Hb}$ basales. CONCLUSIONES: Ante la sospecha inicial de TBM, únicamente la presencia inicial de patología en TAC o RM pueden ser predictoras de diagnóstico final de certeza de la enfermedad. El tratamiento inicial de TB meníngea implica un alto grado de incertidumbre. Los valores bioquímicos alterados en LCR, la edad y la situación clínica basal son predictores de mortalidad y de secuelas neurológicas permanentes.

\section{PACIENTES CENTENARIOS INGRESADOS \\ EN LA COMUNIDAD AUTÓNOMA DE GALICIA}

Romay-Lema E, Piñeiro-Femández JC, Ventura-Valcárcel P, López-Reboiro ML, Suárez-Gill R, Rabuñal-Rey $R$. MEDICINA INTERNA, HOSPTTAL UNIVERSITARIO LUCUS AUGUSTI.

INTRODUCCIÓN: El aumento de la esperanza de vida en las últimas décadas dio lugar a una población más Iongeva y consecuentemente a un incremento de la demanda sanitaria de este colectivo. El objetivo de este estudio es conocer el perfil de los centenarios que ingresan en los hospitales gallegos.

MÉTODOS: Se obtuvieron de forma retrospectiva mediante el CMBD (Conjunto Mínimo Básico de Datos) los datos al alta hospitalaria de todos los pacientes mayores de 100 años de la población gallega desde el año 2004 al 2013 (ambos incluidos). Se recogió el sexo, la edad y la provincia de procedencia, y se identificó para cada paciente un GRD (Grupo Diagnóstico Relacionado). Asimismo, se recogió el servicio de ingreso el carácter del mismo (urgente ó programado), la tasa de reingresos y el tipo de alta.

RESULTADOS: Se registraron 1373 ingresos con una edad media de 101,2 $\pm 1,4$, siendo casi el $74 \%$ mujeres. El número de centenarios atendidos por año se incrementó de forma progresiva en el tiempo, duplicándose el número de ingresos a lo largo de los diez años descritos (6,6\% en 2004 versus 14,6\% en 2013). Este aumento fue independiente del número de ingresos de la población total gallega, que se mantuvo estable en la década analizada.

La provincia con mayor incidencia de ingresos de centenarios fue Ourense $(0,09 \%)$, seguida por Lugo $(0,07 \%)$, Pontevedra $(0,04 \%)$ y A Coruña $(0,02 \%)$ en orden decreciente.

La mayoría de los pacientes ingresaron con carácter urgente, y lo hicieron de forma predominante en el Servicio de Medicina Interna (54,4\%), seguido por los Servicios de Geriatría y de Traumatología, que asumieron un $13,8 \%$ y $10,3 \%$ de los ingresos respectivamente.

Las patologías que se hallaron más frecuentemente en esta población sin diferencias entre sexos fueron las correspondientes al sistema circulatorio $(34,8 \%)$, seguidas de las del sistema respiratorio $(17,3 \%)$ y musculoesquelético (11,7\%), similares a lo descrito en análisis previos. En los varones hubo una mayor incidencia de enfermedades del tracto urinario y enfermedades del aparato digestivo, mientras que las mujeres presentaron mayor incidencia de enfermedades musculoesqueléticas.

El motivo de ingreso en la mayoría de los casos fue de causa médica (84,7\%), constituyendo el GRD más frecuente la neumonía simple y otras infecciones respiratorias. Los GRDs quirúrgicos más frecuentes fueron los procedimientos sobre cadera y fémur.

a estancia media fue de 8,6 7 días, alcanzando una mortalidad de casi el 30\% y la tasa de reingresos al año fue del 7,8\%.

CONCLUSIONES: Se observa un incremento progresivo del número de ingresos de pacientes centenarios en los últimos años. La mayoría de ingresos son de causa médica, siendo el diagnóstico más frecuente la infección respiratoria. Presentan una mortalidad elevada y reingresan con alta frecuencia.

\section{PALUDISMO IMPORTADO EN GALICIA}

Macia-Rodríguez $C^{1}$, Barreiro Rivas $A^{2}$, Dubois Silva $A^{3}$, Estevez Gil $M^{4}$, Lijó Carballeda $C^{5}$, Ríos Prego $M^{6}$ Suárez Gill $R^{7}$, Val Domínguez $N^{8}$, Campos Franco $J$

MEDICINA INTERNA, COMPLEXO HOSPITALARIO UNIVERSITARIO SANTIAGO DE COMPOSTELA', COMPLEXO HOSPITALARIO UNIVERSITARIO DE OURENSE ${ }^{2}$, COMPLEXO HOSPITALARIO UNIVERSITARIO DE A CORUÑÄ ${ }^{3}$, HOSPITAL MEIXOEIRO DE VIGO ${ }^{4}$, COMLEXO HOSPITALARIO UNIVERSITARIO DE FERROL ${ }^{5}$, COMPLEXO HOSPITALARIO DE PONTEVEDRA ${ }^{6}$, HOSPITAL UNIVERSITARIO LUCUS AUGUSTP, HOSPITAL XERAL-CIES DE VIGO ${ }^{8}$

INTRODUCCIÓN: La malaria es la enfermedad parasitaria más importante a escala mundial. Pese que el último caso endémico en España se produjo en 1961, en los śltimos años se ha observado un aumento de los diagnósticos de paludismo secundario a la inmigración y a los viajes internacionales.

OBJETIVO: Analizar las características clínicas y epidemiológicas, el diagnostico, el tratamiento, el uso de profilaxis y las complicaciones de los pacientes diagnosticados de paludismo en la Comunidad Autónoma de Galicia.

MATERIAL Y MÉTODOS: Estudio multicéntrico retrospectivo en los que se incluyeron los pacientes diagnosticados de malaria que ingresaron en los hospitales públicos de Galicia entre el 1 de enero de 2005 y el 31 de diciembre de 2014. Se recogieron las variables epidemiológicas, clínicas, analíticas y pronosticas y se realizó un estudio descriptivo de las mismas.

RESULTADOS: Se incluyeron 79 pacientes ( $79,7 \%$ varones) con una edad media de 38,5 $\pm 12,5$ años. La mayoría de los pacientes eran de nacionalidad española (53,2\%), seguida de la nigeriana (13,9\%). El continente más visitado fue África $(84,8 \%)$, siendo el país más visitado Guinea Ecuatorial $(35,1 \%)$. El motivo del viaje fue laboral en el $47,8 \%$, eran trabajadores de la construcción un $35,5 \%$ y marineros un $32,3 \%$. El 18,8\% eran inmigrantes que visitaron a familiares y el $15,9 \%$ eran inmigrantes que acaban de Ilegar a Galicia. El área sanitaria con más casos fue la de Santiago de Compostela (30,4\%), seguida de Lugo (20,3\%), Vigo (20,3\%), Coruña (19\%), Ferrol (6,3\%) y Ourense (3,8\%). El 32,9\% de los pacientes había sufrido por lo menos un episodio de malaria previamente. Sólo el 22,7\% habían tomado profilaxis y sólo 7 pacientes lo hicieron correctamente. El síntoma más frecuente fue la fiebre $(96,2 \%)$, seguida de las artromialgias $(53,2 \%$ y ye la cefalea $(51,9 \%)$. En el $88,6 \%$ de los casos el diagnostico se hizo con gota gruesa, en el 17,7\% se realizó además antígeno parasitario y se confirmó el diagnóstico con PCR en el $41,7 \%$. La especie protozoaria más frecuente fue P. falciparum $(86,1 \%)$, seguida de P. ovale (4\%) y P. vivax (3\%). El índice de parasitemia fue bajo $(<1 \%)$ en el $46,8 \%$ de los pacientes, moderado $(1-5 \%)$ en el $127 \%$ y elevado (>5\%) en el $16.5 \%$. El tratamiento más utilizado fue Quinina asociada a Doxiciclina (45,6\%) seguido de Atovacuona-Proguanil (25,3\%). Se tardó en comenzar tratamiento una media de 6,4 días $\pm 4,9$ desde el comienzo de los síntomas. Presentaron complicaciones graves el $21,6 \%$, necesitando ingreso en UCl el 11,4\%. Fallecieron 2 pacientes.

CONCLUSIONES: - Los casos de malaria han aumentado en los últimos años en Galicia sobretodo relacionado con gallegos que van a trabajar países endémicos.

- La mayoría de los pacientes no realiza profilaxis o lo hace de forma incorrecta.

Muchos pacientes presentaron complicaciones graves, pero la mortalidad fue baja.

\section{PESO DE LA COINFECCION POR VIRUS DE HEPATITIS C EN UNA COHORTE DE PACIENTES CON INFECCION POR VIH. IMPACTO EN LA MORBILIDAD Y MORTALIDAD DE LOS PACIENTES COINFECTADOS}

Meijide H, Mena A, Rodríguez-Osorio I, Castro A, López S, Vázquez P, Pernas B, Poveda E, Pedreira JD. GRUPO DEVIROLOGÍA CLIINICA, INIBIC. SERVICIO DE MEDICINA INTERNA, CHUAC.

INTRODUCCIÓN: La enfermedad hepática continúa siendo una de la mayores causas de hospitalización y muerte en pacientes coinfectados VIH-VHC. El objetivo del estudio fue evaluar el impacto de la infección por VHC en la morbi-mortalidad en una cohorte de pacientes VIH en seguimiento en nuestra institución en los últimos años.

MATERIAL Y MÉTODOS: Análisis retrospectivo de una cohorte de pacientes VIH seguidos entre 19962013 en el Hospital de A Coruña. Se recogieron datos epidemiológicos, clínicos, de laboratorio, de hospitalización y muerte. Se compararon dichas variables en pacientes mono y coinfectados y se realizó un análisis de supervivencia comparando los dos grupos.

RESULTADOS: Se incluyeron un total de 2257 pacientes (857 VIH-VHC). El 76\% hombres, con una mediana de 31 años (25-37). La proporción de pacientes en TAR fue similar en ambos grupos $(>87 \%)$. Los pacientes coinfectados VIH-VHC presentan un menor recuento de CD4 respecto a los monoinfectados (520 vs $382, p<0.01$ ) y en menor proporción alcanzaron viremia indetectable (ARN-VIH $<50 \mathrm{cop} / \mathrm{mL}$ ) comparado con los monoinfectados ( $53 \%$ vs $66 \%$, p $<0$. 01). Un $49 \%$ de los monoinfectados tuvo a menos un ingreso hospitalario (media 2,9 $\pm 3,5$ ) frente al $84 \%$ de los coinfectados (media 4,7 $\pm 5,2$ ), $p<0,001$. Aunque no hubo diferencias significativas en cuanto a la estancia media en los dos grupos, la suma de estancias/paciente resultó de $43 \pm 74$ días en VIH frente a 56 \pm 60 días en HIV-HCV, p $<0.01$. Respecto a los pacientes coinfectados VIH-VHC, el 15\% (130) tuvo al menos una hospitalización por descompensación hepática (DH). La mediana de años desde diagnóstico hasta primer episodio de DH fue 10 (6-15). Del $15 \%$ de pacientes con DH un 65\% murieron por cualquier causa frente al $31 \%$ de los que nunca se descompensaron ( $\mathrm{p}<0.001)$. La mediana de tiempo desde primer episodio de $\mathrm{DH}$ a muerte fue de 12 meses (2-40). Solo un 15,6\% (134) recibió tratamiento de VHC con tasa de RVS del $65 \%$. Presentaron mayor mortalidad global los pacientes coinfectados (33,7\% vs $22,1 \%), p<0,01$. L supervivencia en los VIH-VHC no tratados o tratados sin respuesta fue similar a pacientes VIH con 20 años de seguimiento; tras 20 años, existe un detrimento significativo en los VIH-VHC.

CONCLUSIONES: La infección por VHC tiene un impacto negativo en la infección por VHH con una peor respuesta inmunovirológica al TAR y un aumento significativo de morbi-mortalidad a largo plazo. Los VIH-VHC sin control del VHC presentan un alto riesgo de DH (15\%) y una mortalidad elevada (33\%), especialmente de causa hepatica, tras 18 años de seguimiento. Considerando la baja tasa de pacientes VIH-VHC tratados en esta cohorte, este análisis apoya la necesidad de priorización de la terapia frente al VHC en estos pacientes basada en la potencia y seguridad de los nuevos antivirales.

\section{TRATAMIENTO DE LA ENFERMEDAD TROMBOEMBÓLICA VENOSA IDIOPÁTICA EN PACIENTES MAYORES DE 80 AÑOS. ¿PARAR 0 NO PARAR LAANTICOAGULACIÓN DESPUÉS DE TRES MESES?}

Velo-García $A^{\prime}$, Ríos Prego $M^{\prime}$, Alves Pereira $D^{\dagger}$, Brea Aparicio $R^{\prime}$, Encabo González $A^{\dagger}$, García $J C^{\prime}$, Anibarro L ', Núñez MJ', De Lis JM', Monreal M², y los investigadores del RIETE. SERVICIO DE MEDICINA INTERNA, COMPLEXO HOSPITALARIO UNIVERSTTARIO DE PONTEVEDRA' / HOSPITAL UNIVERSITARIO GERMAN TRIAS I PUJOL². BADALONA.

INTRODUCCIÓN: La duración óptima del tratamiento anticoagulante en los mayores de 80 años con enfermedad tromboembolica venosa (ETV) es desconocida. Las guías de práctica clínica actuales proponen tratamiento durante al menos 3 meses y posteriormente ponderar su continuación en pacientes con moderado/bajo riesgo de sangrado. Los mayores de 80 años presentan comorbilidades que pueden aumentar tanto el riesgo de recurrencia de ETV como el de sangrado, por lo que resulta complicado establecer recomendaciones en ellos.

OBEJTIVOS: Analizar el tipo y severidad de las recurrencias de ETV y la aparición de sangrado mayo durante el tratamiento anticoagulante en estos pacientes. 
MATERIAL Y MÉTODOS: Estudio prospectivo de los pacientes del registro RIETE (Registro Informatizado Enfermedad Tromboembólica) mayores de 80 años diagnosticados de ETV idiopática. Empleamos el paquete estadístico SPSS 15.0

RESULTADOS: 5494 pacientes fueron reclutados hasta mayo de 2014. Entre ellos, 3263 presentaban inicialmente tromboembolismo pulmonar (TEP) y 2231 trombosis venosa profunda (TVP). A los 3 meses del diagnóstico el $88 \%$ de los pacientes recibían anticoagulación, a los 6 el $51 \%$ y al año sólo el $19 \%$. En los tres primeros meses de tratamiento anticoagulante en pacientes con TEP había: 33 recurrencias de ETV (24 TEP, 9 TVP), 89 sangrados mayores, 15 exitus por TEP recurrente y 18 exitus por hemorragias mayores. Después del tercer mes había: 36 recurrencias de ETV (23 TEP, 13 TVP), 37 sangrados mayores, un exitus por TEP recurrente y 8 exitus por sangrados mayores. En los tres primeros meses del tratamiento anticoagulantes en pacientes con TVP había: 26 recurrencias de ETV (10 TEP, 16 TVP), 48 sangrados mayores, un fallecimiento por TEP recurrente, 6 fallecimientos por sangrados mayores. Tras el tercer mes había: 18 recurrencias de ETV, 21 sangrados mayores, no exitus por TEP y dos exitus por sangrados mayores. Los sangrados intracraneales fueron la segunda localización más frecuente en los pacientes con TEP ( 28 de 126 sangrados) y la tercera en los pacientes con TVP (13 de 69 sangrados). Además la tasa de sangrado cerebral se incrementó tras el tercer mes de tratamiento.

En el análisis multivariante la presentación como TEP y la insuficiencia cardíaca crónica fueron factores de riesgo independientes de recurrencia de TEP (p0. 009); la presentación como TVP y el sangrado reciente fueron factores de riesgo independiente de recurrencia para TVP ( $p 0.003)$. La edad >85 años (p0. 009$)$ y la anemia (p0. 001) se identificaron como factores de predicción de riesgo de sangrado.

CONCLUSIONES: En pacientes con ETV idiopática con edad $\geq 80$ años, la tasa de recurrencia fatales de ETV fue menor que la tasa de sangrados mayores, en especial después del tercer mes de anticoagulación. Nuestros datos sugieren que en la mayoría de los pacientes con ETV, la anticoagulación debería suspenderse a los 3 meses. Se han identificado factores predictores de recurrencia y sangrado.

\section{VALOR PREDICTIVO DE HAS BLED Y ATRIA PARA EL RIESGO DE} HEMORRAGIA EN PACIENTES ANTICOAGULADOS CON DABIGATRAN

Álvarez Otero J, Lamas Ferreiro JL, Pueta Louro R, González González L, Araújo Fernández S, De la Fuente Aguado J.

MEDICINA INTERNA, POVISA.

INTRODUCCIÓN: Dabigatran es un anticoagulante inhibidor directo de la trombina indicado para la prevención del ictus isquémico en pacientes con fibrilación auricular. Una de sus potenciales complicaciones son las hemorragias, que pueden en ocasiones amenazar la vida del paciente. Existen diversas escalas para valorar el riesgo hemorrágico que presentan los pacientes que necesitan ser anticoagulados, siendo 2 de las más utilizadas HAS-BLED y ATRIA, aunque ambas escalas fueron validadas utilizando datos de pacientes a tratamiento mayoritariamente con warfarina.

OBJETIVOS: El objetivo de este estudio fue determinar el valor predictivo de las escalas HAS-BLED y ATRIA para el riesgo de hemorragia en pacientes anticoagulados con dabigatran.

MATERIAL Y MÉTODOS: Se trata de un estudio descriptivo y retrospectivo en el que se incluyeron todos los pacientes que iniciaron tratamiento anticoagulante con dabigatrán entre los meses de noviembre de 2011 y septiembre de 2012. Se estimó el riesgo de hemorragia grave que presentaba cada paciente en el momento de inicio del tratamiento con dabigatran mediante las escalas HAS-BLED y ATRIA. Se establecieron 2 variables dicotómicas con el resultado de cada escala: HAS-BLED de alto riesgo (puntuación igual o mayor a 3) y ATRIA de alto riesgo (puntuación igual o mayor a 5). Asimismo, se determinó la incidencia de complicaciones hemorrágicas hasta Junio de 2013. Finalmente se estimó la sensibilidad, especificidad, valor predictivo positivo (VPP) y valor predictivo negativo (VPN) para cada una de las escalas de riesgo hemorrágico en su forma dicotómica así como el valor discriminativo para sangrado mayor de las mismas mediante curvas ROC.

RESULTADOS: Se incluyeron 316 pacientes con edad media de 76 años $( \pm 8,37)$ y predominio de varones (53\%). El 54\% de los pacientes estaban a tratamiento con Dabigatran a dosis de $150 \mathrm{mg} / 12 \mathrm{~h}$ y el $46 \%$ con 110 mg/12h. Las complicaciones por sangrado ocurrieron en 40 pacientes (10,91/100 pacientesaño): 32 presentaron hemorragia menor (8,73/100 pacientes-año) y 8 mayor (2,18/100 pacientes-año). Un $34,6 \%$ de los pacientes presentaron HAS-BLED de alto riesgo, variable que mostró una sensibilidad, especificidad, VPP y VPN del 75\%,66\%, 5\% y 99\% respectivamente, con un área bajo la curva de 0,7 (IC95\%: 0,4-0,9; P 0,1). Un 5\% de los pacientes presentaron ATRIA de alto riesgo, variable que mostró una sensibilidad, especificidad, VPP y VPN del 16\%,95\%,7\%,98\%, con un área bajo la curva de 0,55 (IC95\%: 0,3-0,8; P 0,6).

CONCLUSIONES: A pesar de que tanto el HAS-BLED como el ATRIA demostraron un VPN alto, ambas escalas presentaron un bajo valor discriminativo calculado mediante curvas ROC, a diferencia de los estudios publicados con anticoagulantes distintos del dabigatran, por lo que consideramos necesario el desarrollo de nuevas escalas que permitan una valoración más adecuada del riesgo hemorrágico en aquellos pacientes en los que se plantee el tratamiento con dicho fármaco.

\section{COMUNICACIONES POSTER}

\section{ACCIDENTE CEREBROVASCULAR CRIPTOGÉNICO Y FORAMEN OVAL PERMEABLE EN EL PACIENTE JOVEN ¿CÓMO ACTUAR?}

Dubois Silva ${ }^{1}$, García Antelo MJ?

SERV. DE MEDICINA INTERNA'. SERV. DE NEUROLOGI'A², COMPLEJO HOSPITALARIO UNIVERSITARIO A CORUÑA.

INTRODUCCIÓN Y OBJETIVOS: En los pacientes con accidente cerebrovascular criptogénico (ACVC) la prevalencia de foramen oval permeable (FOP) es mayor que en población general, siendo 5-6 veces más frecuente que en los que la causa es conocida. Esta asociación entre ACVC y FOP es más fuerte en pacientes jóvenes. Sin embargo, la actitud terapéutica a seguir en estos casos todavía no está bien definida y menudo ofrece dudas en la practica clinica.

MATERIAL Y MÉTODO: Descripción de un caso clínico y revisión de la literatura.

RESULTADOS: Varón de 37 años, fumador, que presenta de forma brusca alteraciones visuales, disartria disminución del nivel de conciencia con mejoría progresiva en 2 horas, objetivándose únicamente a la exploración física en Urgencias mínima disartria y leve paresia de recto inferior izquierdo. Se realiza TAC craneal que muestra infarto talámico anterior bilateral. Se desestimó para fibrinolisis con NHHHS $<4$ encontrándose el déficit neurológico en resolución A su llegada a planta a las 24 horas no presenta focaldad neurológica, siendo la exploración física normal (tampoco presentaba signos sugestivos de trombosis venosa profunda - TVP -). Se realizaron los siguientes estudios: analíticas normales; triaje de drogas en orina negativo; ECG en ritmo sinusal; RMN cerebral que confirmó los hallazgos sin evidenciar imágenes sugestivas de ACVs previos; angioRMN de troncos supraaórticos y polígono de Willis que no mostro anomalías y Holter ECG 24h que no registró arritmias embolígenas. El ecocardiograma transtorácico con contraste evidenció un FOP con shunt derecha-izquierda significativo, sin otras alteraciones. Se decidió antiagregar con clopidogrel en el contexto de ACV criptogénico y en su situación basal recibió el alta. CONCLUSIONES: El manejo del ACVC en pacientes con FOP es controvertido. Por una parte, no ha suficiente evidencia para establecer si la anticoagulación es equivalente o superior a la antiagregación en prevención secundaria, aunque se prefiere anticoagulación cuando se demuestre un posible origen embolígeno venoso (en caso de que esté contraindicada se puede plantear un filtro de vena cava). Por otra parte, en los principales estudios que compararon anticoagulación/antiagregación vs cierre percutáneo del FOP no se alcanzaron diferencias significativas en prevención secundaria entre los dos grupos. Los datos disponibles indican que se podría plantear el cierre percutáneo en pacientes con TVP con riesgo de recurrencia, así como en pacientes seleccionados con ACVC recurrente o que ya hayan sufrido un Ictus, con evidencia por imaen de infartos antiguos y ROPE score elevado En nuestro caso por tratarse de un paciente que no ha presentado ictus previos ni tiene lesiones isquémicas antiguas en la RMN, sin sospecha de fuente embolígena venosa, se optó por antiagregación.

\section{AMILOIDOSIS PRIMARIA Y FORMAS FAMILIARES: REVISIÓN DE} CASOS EN 10 AÑOS EN EL COMPLEXO HOSPITALARIO DE OURENSE

Latorre Diez A, Barreiro Rivas A, González Noya A, López Mato P, Fernández Regal I, Pérez Carral V. MEDICINA INTERNA, COMPLEXO HOSPITALARIO DE OURENSE.

NTRODUCCIÓN: Las amiloidosis son un grupo heterogéneo de enfermedades de etiología desconocida en las que existe un depósito extracelular de proteínas fibrilares que conforman la sustancia amiloide L manifestaciones clínicas son diversas y dependen de los órganos donde se deposite. El tratamiento fundamental son quimioterápicos, como el melfalán; y corticoides. Si es posible es de elección el trasplante de progenitores hematopoyéticos. En los casos de amiloidosis familiares subtipo TTR el tratamiento de elección es el trasplante hepático.

OBJETIVOS: Conocer las características epidemiológicas de la amiloidosis primaria (AL) y de las formas familiares, subtipo transretina en Ourense entre 2004-2014; el manejo diagnóstico y la actitud terapéutica tomada.
MATERIAL Y MÉTODOS: Estudio descriptivo retrospectivo, en el que se han seleccionado pacientes mayores de 15 años con el diagnóstico de amiloidosis AL 0 amiloidosis familiares tipo transretina. RESULTADOS: Se han diagnosticado 15 pacientes con amiloidosis; 8 mujeres y 7 hombres. De ellos el $60 \%$ fueron amiloidosis primaria o tipo $\mathrm{AL}$, el $20 \%$ fueron amiloidosis AL asociado a mieloma múltiple y el 20\% de ellos amiloidosis familiares subtipo transretina ; de estos 8 casos eran mujeres y 7 hombres. La edad media al diagnóstico fue de 73,4 años, edades comprendidas entre los 57 y 82 años. Para el diagnóstico se confirmó en diferentes tejidos el depósito amiloide que se tiñe con tinción rojo congo y birrefringencia verde manzana con luz polarizada.

Los síntomas más frecuentes fueron la astenia y la pérdida de peso en un 60\%. Hubo afectación cardíaca en el $33.3 \%$ de los casos, hepática en el $26.6 \%$ y de otros órganos en el 6,6\%. En los casos de amiloidosis familiar tipo transretina la principal manifestación clínica fue la sintomatología neurovegetativa con disautonomía progresiva; en 2 de los 3 pacientes con esta afección, presentaban además asociada cardiopatía restrictiva. En cuanto al tratamiento de nuestros 15 pacientes, tan sólo 8 recibieron terapéutica, los otros 7 pacientes no recibieron tratamiento alguno. Dos pacientes se trataron con terapia combinada de melfalán y dexametasona y 3 de ellos con pauta combinada de melfalán y prednisona. En tan sólo 1 de los 15 pacientes pudo realizarse trasplante hematopoyético, y completar con melfalán y bortezomib. Dentro de los 3 casos de amiloidosis subtipo transretina, 2 de ellos fueron sometidos a trasplante hepático. El período de supervivencia tras el diagnóstico de la enfermedad osciló entre 1 mes y 84 meses de vida. La edad media de supervivencia tras el diagnóstico fue de 16 meses,1 de los pacientes continúa actualmente en remisión parcial de la enfermedad y en tratamiento activo.

CONCLUSIONES: Los principales factores pronósticos asociados a una mayor mortalidad en el momento diagnóstico fueron: una mayor edad, la presencia de enfermedad crónica/degenerativa de base y de afectación renal y cardíaca. Por el contrario la afectación del SNP y del tracto digestivo se relacionaron con una mayor supervivencia.

\section{ANEMIA HEMOLITICA SECUNDARIA A INFECCIÓN POR CITOMEGALOVIRUS (CMV EN EL ADULTO INMUNOCOMPETENTE: DESCRIPCIÓN DE UN CASO Y REVISIÓN DE LA LITERATURA}

Gondar Barcala T, Sánchez Conde P, García Poutón N, Álvarez Otero J, De la Fuente Aguado J. MEDICINA INTERNA, POVISA S. A.

INTRODUCCIÓN: La anemia hemolítica en la infección aguda por CMV en el adulto inmunocompetente es una manifestación poco frecuente. Probablemente se trate de una entidad infradiagnosticada cuya patogenia y manejo terapéutico no están aclarados por lo que consideramos importante reportar un nuevo caso.

CASO CLíNICO: Varón de 33 años sin antecedentes médico-quirúrgicos de interés ni tratamientos habituales. Acude a nuestro centro por astenia, hiporexia, coluria e ictericia de 5 días de evolución. Toma alcohol de forma esporádica y niega consumo de otros tóxicos. Vive en medio urbano y no tiene animales domésticos. No es portador de tatuajes ni ha recibido transfusiones. Niega relaciones sexuales de riesgo. Tiene una hija de 8 meses que ha presentado un cuadro de herpangina y una gastroenteritis aguda en el último mes. El paciente está afebril y estable hemodinámicamente. Presenta icteria conjuntival y en la exploración abdominal no se palpan visceromegalias. La analítica sanguínea revela una anemia normocítica y normocrómica e hipertransaminemia con hiperbilirrubinemia a expensas de la fracción indirecta (Hb: 9,2 mg/dl; GOT: 144 U/L; GPT: 162 U/L, GGT: 51 U/L; BT 3,35 mg/dll, B indir: 2,65 mg/dl). No presenta leucopenia, trombopenia ni alteraciones de la hemostasia. Ante la sospecha de hemólisis se completa el estudio confirmándose el diagnóstico de anemia hemolítica de origen no inmune. (Coombs di e indir negativo; reticulocitos: 6,2\%; LDH: $827 \mathrm{U} / \mathrm{L}$; haptoglobina indetectable). El proteinograma y estudio del complemento son normales. No se detectan crioglobulinas séricas. El frotis de sangre perif revela anisocitosis eritrocitaria y policromatofilia y el aspirado de M. 0. hiperplasia eritroide con diseritropoyesis secundaria. El estudio citométrico descarta HPN. Ecográficamente se detecta una leve esplenomegalia que apoya el origen extravascular de la hemólisis. La serologías de VIH, lúes, VHA, VHB y VHC, Mycoplas- 
ma pneumoniae, Coxakie A9 y B, VEB y Parvovirus B19 son negativas. IgM e lgG contra CMV son positivas. Ante la posibilidad de una infección reciente o reinfección por CMV se solicita determinación de DNA CMV (AgPPG5) que resulta positiva. Al $2^{\circ}$ día de ingreso se transfunden $2 \mathrm{CH}$ por un empeoramiento brusco de la anemia. Una vez estabilizado clínicamente se inicia corticoterapia iv (1 mg/Kg/día). La evolución clínica y analítica es favorable sin precisar nuevas transfusiones y recibe el alta tras 18 días de hospitalización con el diagnóstico de anemia hemolítica posiblemente secundaria a infección aguda por CMV. Actualmente el paciente es seguido en CCEE de Medicina Interna. En la última consulta, con $50 \mathrm{mg} /$ día de prednisona oral está asintomático, con $\mathrm{Hb}$ de 12,6 g/d y los niveles de LDH, haptoglobina, bilirrubina y transaminasas se han normalizado.

CONCLUSIONES: Realizamos una revisión de la literatura y encontramos en PubMed tan sólo 13 casos reportados de adultos inmunocompetentes con anemia hemolítica en el contexto de infección aguda por CMV entre 1980 y 2013. El pronóstico fue favorable en todos ellos, incluso en los que no recibieron corticoterapia ni antivirales. De estos datos se extrae que no existe un tratamiento específico y que la mejoría espontánea forma parte de la evolución natural del proceso por lo que la actitud "wait and see" podría estar justificada si la anemia no es severa.

\section{ANTICUERPOS MONOCLONALES Y GUILLAIN BARRE}

Vares M, Arévalo A, Barbagelata C, Piñeiro P. Llinares D, Rodríguez A, Freire S.

UNIDAD DE PREINGRESO, MEDICINA INTERNA, COMPLEJO HOSPITALARIO UNIVERSITARIO A CORUÑA

INTRODUCCIÓN: Los fármacos anti factor de necrosis tumoral alpha (anti-TNF alpha) se emplean en la actualidad en el tratamiento de múltiples enfermedades reumatológicas/inflamatorias. Los efectos secundarios de los mismos incluyen entre otras el desarrollo de enfermedades desmielinizantes como el Síndrome de Guillain Barre (SGB)y su variante el Síndrome de Miller Fisher (SMF). No se ha demostrado claramente si el efecto de los antiTNF en esta enfermedad es directo, favorecido por la mayor propensión al desarrollo de infecciones o simplemente un hallazgo casual. Presentamos 1 caso de un paciente a tratamiento con antiTNF que desarrollo SGB sin evidencia de infección asociada.

OBJETIVOS: Estudiar la asociación entre los fármacos anti TNF y el SGB.

MATERIAL Y MÉTODOS: Se analizaron los casos de los pacientes en tratamiento con antiTNF diagnostcados de SGB o SMF en nuestro Hospital. Se realizó asimismo una búsqueda bibliográfica en PubMed de los casos descritos en la literatura.

RESULTADOS: En nuestro hospital se identificó 1 solo varón de 52 años a tratamiento con etanercept por psoriasis resistente que desarrolló una neuropatía desmielinizante aguda del tipo de SGB. No se demostró infección asociada. Tras revisión de la literatura se identificaron 23 pacientes (21 SGB, 2 SMF): 11 recibían tratamiento con infliximab, 5 etanercept y 7 adalimubad. De ellos $13(56 \%)$ se relacionaron con procesos infecciosos (5 con infecciones del tracto respiratorio superior, 3 fiebre, 2 síndrome gripal, 1 vacunación antigripal, 1 gastroenteritis aguda y otro infección por Campylobacter jejuni). De ellos tras retirar el fármaco y tratamiento estándar, 8 (35\%) presentaron recuperación completa, 13 (56\%) parcial, 1 no tuvo ninguna respuesta y de otro paciente no existen datos. A 4 se les readministró posteriormente el fármaco, 2 de los cuales (50\%) volvieron a desarrollar dicho cuadro. En nuestro caso la recuperación fue parcial. CONCLUSIONES: - Aunque se necesitan más estudios, los tratamientos con antiTNF podrían producir enfermedades desmielinizantes tipo SGB que en más del $50 \%$ de los casos podrían dejar secuelas permanentes.

- En la mitad de los pacientes, el SGB no se relacionó con problemas infecciosos, y de los que recibieron nuevamente el tratamiento, el $50 \%$ recayeron, lo que sugiere que dicho fármaco podría ser responsable directo.

\section{BACTERIEMIAS ASOCIADAS A CATÉTERES INTRAVASCULARES}

Val Domínguez N, Baroja Basanta A, Pérez Rodriguez M, Martínez Lamas L, Álvarez Fernández M, Sousa Domínguez A, Martínez Vidal A, Nodar Germiñas A, Portela Oriales D.

MEDICINA INTERNA (UNIDAD DE ENFERMEDADES INFECCIOSAS). SERVICIO DE MICROBIOLOGÍA, HOSPITAL XERACIÉS DEVIGO (EOXI)

INTRODUCCIÓN: El aumento del uso de catéteres intravasculares (CIV) se ha asociado con un incrementado de las infecciones relacionadas con este tipo de dispositivo. Las bacteriemias relacionadas con CIV tienen una elevada morbimortalidad asociada, lo que hace imprescindible la instauración de un tratamiento antibiótico empírico adecuado de manera precoz para mejorar el pronóstico.

OBJETIVOS: Analizar los aislamientos microbiológicos de las infecciones relacionadas con CIV en nuestro centro.

MATERIAL Y MÉTODOS: De forma prospectiva se recogieron los hemocultivos positivos de pacientes mayores de 15 años en el Hospital Xeral-Cíes de Vigo entre octubre-2014 y abril-2015. Se identificaron las bacteriemias que cumplían criterios de bacteriemia asociada a CIV y se analizaron las características de los pacientes, los aislamientos microbiológicos y el tipo catéter.

RESULTADOS: Se documentaron 56 bacteriemias relacionadas con CIV, de los que 36 eran hombres (64. $7 \%$ ) con una edad media de $60+14,6$ años. El origen más frecuente de la bacteriemia fue catéter central de larga duración (CCLD) (64. 3\%, 36 casos), seguidos de catéter central de corta duración (28. 6\%, 16 casos) y la bacteriemia secundaria a vía periférica ( $7.1 \%, 4$ casos). En las bacteriemias asociadas a CCLD el microorganismo predominante fueron los cocos gram-positivos (CGP) (26 aislamientos, 72\%), seguidos de bacilos gram-negativos (BGN) (12 casos, 33\%) y 1 Candida (3\%). En las bacteriemias asociadas a CCCD el aislamiento de CGP se realizó en 9 casos (56\%), BGN en $6(38 \%)$ y Candida en $3(20 \%)$. Todas las bacteriemias asociadas a vía periférica fueron por CGP 3 de ellas por $\mathrm{S}$. aureus. De las 39 bacteriemias por CGP 6 se produjeron por S. aureus, 50\% de ellos meticilin resistentes. De los 18 BGN aislados, 3 eran productores de BLEE y sólo se identificaron 2 bacteriemias por Pseudomonas aeruginosa. La prevalencia de bacteriemia fue más elevada en el área onco-hematológica (30 bacteriemias, 54\%), seguida de las unidades de críticos (13 bacteriemias, 23\%). En el momento del diagnóstico de la bacteriemia un $73 \%$ de los pacientes recibía una tratamiento antibiótico adecuado: 75\% de los pacientes con CCLD, 75\% CCCD y $50 \%$ vía periférica $(p=0,553)$. Fue posible desescalar el antibiótico empírico en el $33 \%$ de los casos ( $31 \%$ CCLD, $33 \%$ CCLD y $50 \%$ vía periférica, $p=0,757$ ). La mortalidad global fue el $7 \%$ ( 4 pacientes), produciéndose el fallecimiento antes del aislamiento microbiológico en un paciente. En otro el fallecimiento se produjo en la primera semana tras la bacteriemia.

CONCLUSIÓN: La bacteriemia asociada a vía periférica es más prevalente en plantas de hospitalización convencional y se asocia a infección por S. aureus. En las bacteriemias asociadas a catéteres venosos centrales se debería realizar cobertura empirica para CGP y BGN.

\section{CARACTERISITICAS EPIDEMIOLOGICAS DEL CANCER DE PULMON EN PACIENTES CON INFECCION POR VIH}

Suárez $R^{1}$, Clavero $E^{1}$, Meiijde $H^{1-2}$, Mena $A^{1}$, Rodríguez ${ }^{1}$, Pernas $B^{1}$, Castro $A^{1}$, Poveda $E^{1}$, Pedreira JD ${ }^{2}$. GRUPO DEVIROLOGÍA CLINICA. INIBIC. SERVICIO DE MEDICINA INTERNA'. CHUAC. 2- SERVICIO DE MEDICINA INTERNA², HOSPITAL QUIRONA CORUÑA, CHUAC.

INTRODUCCIÓN: Con la instauración del tratamiento antirretroviral (TAR) se ha observado un cambio en las causas de morbi-mortalidad con un notable incremento de complicaciones no definitorias de SIDA, como las neoplasias sólidas, entre ellas el cáncer de pulmón (CP). El objetivo del presente estudio es describir las características epidemiológicas de los pacientes VIH que desarrollan CP, y analizar los factores de riesgo en relación con la población general.
MATERIAL Y MÉTODOS: Estudio observacional retrospectivo de una cohorte de pacientes VIH seguida entre 1993-2013 que desarrollaron cáncer de pulmón. Se obtuvieron los casos mediante el sistema de codificación CIE_9. Se analizaron caracterísiticas demográficas, clínicas, situación inmunovirológica, TAR, tipo de tumor, estadiaie y supervivencia Las variables cuantitativas se muestran como media y desviación estandar y las cualitativas como porcentajes. Se utilizó el programa SPSS 16. 0

RESULTADOS: Se recogieron 77 neoplasias sólidas en el periodo, de las que 28 correspondieron a Ca pulmón (8 en los primeros 10 años y 20 casos en los siguientes 10 años del periodo de estudio). El $82,1 \%$ eran varones, con una edad media de $49 \pm 9$ años. Presentaron tabaquismo activo (85\%), consumo elevado de alcohol (12\%), antecedentes de neumonía previa (21\%) y coinfección VIH_VHC (43\%). El $75 \%$ tenían TAR ( $61 \%$ RNA VIH indetectable), con una duración de 84 49 meses de media, mientras que el $66,7 \%$ tenían > $200 \mathrm{cel} / \mathrm{ml}$ CD4. El 56\% eran categoría CDC-C. El tiempo medio en desarrollar la neoplasia desde el diagnóstico de VIH fue 9,8 6,6,6 años (0-24). Atendiendo al subtipo histológico, adenocarcinoma (50\%), Ca epidermoide (32,1\%), Ca microcítico (10,8\%) y Ca cél. grande $(7,1 \%)$. Respecto al estadiaje, I (16\%), II (4\%), III (32\%) y IV (48\%). Recibieron algún tipo de tratamiento el 81,5\% (50\% quimioterapia, 32\% radioterapia, 25\% cirugía). Falleció el $89 \%$ de la población estudiada, con un tiempo medio de supervivencia desde el diagnostico de 12,3 $\pm 5,8$ meses.

CONCLUSIONES: 1- El cáncer de pulmón es una de las neoplasias sólidas más frecuentes en pacientes $\mathrm{VIH}$, con un notable aumento en los últimos 10 años. 2- El tabaquismo sigue siendo el factor de riesgo más prevalente. 3- A diferencia de la población general, se presenta en edades más jóvenes y estadíos más avanzados, siendo el adenocarcinoma la estirpe más frecuente. 4- El tiempo medio de supervivencia y la mortalidad tan elevada plantean la necesidad de estrategias de cribado en esta población.

\section{CARACTERÍSTICAS DE LA HEPATITIS C CRONICA EN LOS PACIENTES} DE MÁS DE 65 AÑOS. ¿ES NECESARIO UN CAMBIO DE ACTITUD?

Otero Antón E, Bermúdez Ramos M, Martínez de Rituerto ST, Aguilera Guirao A', Gonzalez Quintela A. SERVICIOS DE MEDICINA INTERNA (UNIDAD DE HEPATOLOGIA), Y MICROBIOLOGÍA, CLINICO UNIVERSITARIO DE SANTIAGO DE COMPOSTELA'

INTRODUCCIÓN: El tratamiento clásico de la hepatitis C con interferón y ribavirina presenta contraindicaciones, efectos secundarios y eficacia reducida que limita su utilización en pacientes mayores de 65 años. El perfil de tolerancia y la eficacia de los nuevos antivirales de acción directa (AAD) permiten reconsiderar el tratamiento en este grupo de pacientes.

OBJETIVOS: Estudiar las características diferenciales de los pacientes mayores de 65 años con hepatitis $\mathrm{C}$ crónica seguidos en una unidad de Hepatología respecto a la de los pacientes de menor edad y estimar la indicación de tratamiento con AAD en ellos.

MATERIAL Y METODOS: Se realizó un estudio transversal retrospectivo, recogiendo las características de la población con hepatitis $C$ crónica activa en monoinfección, con seguimiento en los últimos 18 meses en la Unidad de hepatología del senvicio de Medicina Interna del CHUS a 31 de enero del 2015. Se analizaron las diferencias en el género, tratamientos previos, grado de fibrosis y distribución de genotipos entre los mayores y menores de 65 años

RESULTADOS: Se incluyeron 253 pacientes (67\% varones) con una media de edad de $54 \pm 13$ años (26-92 años); el 20\% (50) eran mayores de 65 años. Se dispuso del genotipo en 238 pacientes, y de una estimación del grado de fibrosis en los últimos 18 meses en 170 (67.2\%). En el grupo de $>65$ años respecto al de $<65$ años había mayor frecuencia de mujeres ( $61.8 \%$ vs $24.7 \% \cdot p<0.001$ ) de genotipos 1 y $3(89.1 \%$ vs $67.2 \%$, y $6.5 \%$ vs $1.6 \%$; $p<0$. 005), y de fibrosis grado 4 ( $42.9 \%$ vs $22.5 \%$; $p<0$. $05)$. En cambio había menos determinaciones del grado de fibrosis ( $50.9 \%$ vs $71.7 \%$; $p<0$. 005) y mas pacientes naive $(74.5 \%$ vs $60.6 \% ; p=0.057)$

CONCLUSIONES: Los pacientes con hepatitis C crónica de más de 65 años constituyen un grupo menos estudiado que los pacientes más jóvenes. Casi la mitad de ellos presentan una cirrosis hepática, en su inmensa mayoría por genotipo 1 y casi un $75 \%$ son naive, por lo que en ellos podría estar especialmente indicado el tratamiento con AAD.

\section{COMBINACIÓN INSULINA DEGLUDEC/LIRAGLUTIDA: PROGRAMA DE DESARROLLO CLÍNICO}

Soto González $A^{1}$, Bellido Guerrero D², García Gromaz D.

SERVICIO DE ENDOCRINOLOGÍA Y NUTRICIÓN', SERVICIO DE ENDOCRINOLOGÍA Y NUTRICIÓN², DEPARTAMENTO MÉDICO ${ }^{3}$, HOSPITAL DEA CORUÑN', COMPLEJO HOSPITALARIO UNIVERSITARIO DE FERROL'', NOVO NORDISK INTRODUCCIÓN: La mayoría de pacientes con diabetes tipo 2 (DM2) que reciben una insulina basal no alcanzan los objetivos de control glucémico necesarios para reducir el riesgo de complicaciones micro- y macrovasculares y la mortalidad. La intensificación del tratamiento con insulina para lograr un mejor control glucémico se ve dificultada por el riesgo de hipoglucemia, el aumento de peso y la complejidad de los regímenes de tratamiento.

OBJETIVOS: Insulina degludec/Liraglutida (IDegLira) es una combinación a razón fija de una insulina de acción prologada, insulina degludec, y un análogo de GLP-1, liraglutida, diseñado para optimizar el control glucémico. IDegLira se administra una vez al día e independiente de las comidas; la dosis máxima es de 50 unidades de dosis (50 unidades de insulina degludec y $1,8 \mathrm{mg}$ de liraglutida). MATERIAL Y MÉTODO: Se revisa el desarrollo clínico de fase 3 de IDegLira.

RESULTADOS: La fase 3 de IDegLira incluye dos ensayos clínicos de fase 3a diseñados para demostrar la superioridad de este medicamento respecto a sus componentes individuales (Tabla 1), y cuatro ensayos de fase $3 \mathrm{~b}$ para explorar la eficacia y seguridad de este producto en otras poblaciones.

CONCLUSIONES: El programa DUAL proporcionará pruebas de la eficacia y seguridad de IdegLira en diferentes poblaciones de pacientes con DM2 que requieren terapia de intensificación para conseguir el control glucémico.

\section{CORRELACIÓN ENTRE PRESENCIA DE VPH, CITOLOGÍA E HISTOLOGÍA ANAL EN VARONES HSH VIH POSITIVOS}

ocampo A, Iribarren M, Longueira R, Labajo L, Rodríguez S, Pazos MC, Rivera A.

MEDICINA INTERNA, CIRUGÍA GENERAL, HOSPITAL XERAL, COMPLEJO HOSPITALARIO UNIVERSITARIO DE VIGO (CHUVI).

INTRODUCCIÓN: Los hombres que tienen sexo con hombres (HSH) infectados por el virus de la inmunodeficiencia humana (VIH) tiene una alta incidencia, y la infección por VPH alcanza el 92.6\%. El tacto rectal, la citología anal y el cribado del VPH con detección de los serotipos de alto riesgo, pueden ayudar a identificar a aquellos pacientes en los que debería realizarse anoscopia de alta resolución para descartar esiones preneoplásicas o neoplásicas.

OBJETIVOS: Determinar la relación existente entre la presencia de VPH y de sus distintos serotipos con las alteraciones cito/histológicas a nivel anal. Identificar las características basales de los pacientes que guardan relación con estas variables.

MATERIAL Y MÉTODO: Se seleccionaron de forma aleatoria a pacientes HSH con infección por VIH con seguimiento en la consulta de VIH del Hospital Xeral que firmaron el consentimiento informado. Se recogieron distintas variables y se tomaron muestras anales para citología y determinación de VPH mediante PCR. A aquellos pacientes en los que se detectaron alteraciones citológicas y/o VPH se les realizó anoscopia, con biopsia de las lesiones acetoblancas lugol negativas. 
RESULTADOS: La presencia de VPH se relacionó con citología patológica $(p<0$. 01) y de modo específico con ASCUS ( $p$ 0. 04). En cuanto a los distintos serotipos, se encontró relación estadísticamente significativa entre: presencia de VPH 16 aislado con carcinoma infiltrante (p 0. 01), serotipos de alto riesgo (distintos de VPH 16 y 18) con AIN 2 ( 0 0 . 04) y combinación de VPH 16 y alto riesgo con citología patológica (p 0.03). La infección múltiple NPH 16, 18 y alto riesgo) se relacionó con LSIL $(\mathrm{D}<0.01)$, citología patológica $(\mathrm{D}<0.01)$ y biopsia patológica en general ( $p$ 0. 03). La presencia de citología alterada se relacionó con lesiones histológicas de modo global $(p<0.01)$, y de modo espeć́fico con AlN $1(p 0.02)$ y AIN $2(p<0.01)$. En cuanto a las distintas alteraciones citológicas se obtuvo relación entre: ASCUS y biopsia patológica de forma global (p 0.04$)$, citología LSIL y AIN $1(p<0.01)$ y biopsia patológica en general $(p<0.01)$, y citología HSIL y AIN $2(p 0.01)$. De entre las características basales de los pacientes, se encontró relación estadísticamente significativa entre las siguientes variables: presencia de VPH y ser fumador $(D<0.01)$, citología alterada con carga viral detectable ( $p 0.03)$ y también, de modo inversamente proporcional, con la edad $(p<0.01)$. En cuanto a la histología, la biopsia patológica se relacionó con el antecedente de gonorrea ( $p 0.03$ ) y con la presencia de carga viral detectable $(p<0.01)$.

CONCLUSIONES: La relación existente en los varones HSH VIH positivos entre presencia de VPH y alteraciones citológicas, y en los casos de infección múltiple también con lesiones histológicas establecidas, pone de manifiesto la necesidad de instaurar protocolos de actuación para despistaje de lesiones preneoplásicas en este grupo poblacional de alto riesgo.

\section{DERMATITIS FOTOALÉRGICA POR DEXKETOPROFENO}

García Poutón N, Novoa Lamazares L, Fernández Fernández FJ, Fernández Castro I, Rodríguez Arias M, De la Fuente Aguado J.

MEDICINA INTERNA, POVISA.

INTRODUCCIÓN: La fotosensibilidad es una reacción cutánea anormal debida a la interacción de los rayos ultravioleta en la piel tras la aplicación tópica o introducción sistémica de un fármaco en el organismo. Se estima que el $8 \%$ de las reacciones adversas a medicamentos son por fotosensibilidad y suelen ser más frecuentes en pacientes con mayor grado de pigmentación cutánea. La fototoxicidad es la forma de fotosensiblidad más frecuente (95\%). Mucho más infrecuente es la fotoalergia, mediada por una reacción de hipersensibilidad tardía, que requiere de la sensibilización previa al fotoalergeno, con aparición de la clínica a las 24-48 horas tras la exposición solar.

CASO CLÍNICO: Un varón de 56 años con DM tipo 2 y dislipemia, a tratamiento con atorvastatina y metformina, acude por clínica de una semana de evolución de tumefacción, enrojecimiento y aumento de temperatura en miembros inferiores. A la exploración se encuentra hemodinámicamente estable y afebril, con eritema en la región distal de muslo, rodilla y zona proximal de pierna izquierda, con afectación además en cara interna de muslo derecho, asociado a aumento de temperatura y edema. Refiere el inicio del cuadro 24 horas después de la exposición solar tras aplicar previamente un gel de dexketoprofeno en la rodilla izquierda por dolor articular de características mecánicas, producto que ya había aplicado en ocasiones anteriores. El análisis no muestra alteraciones significativas. Se instaura tratamiento con corticoides parenterales, con evolución óptima de las lesiones en las primeras 24 horas, y posterior pauta con prednisona en pauta descendente durante 10 días más, con práctica resolución de las lesiones tras reevaluar al paciente en las siguientes dos semanas. DISCUSIÓN: La dermatitis fotoalérgica de contacto produce lesiones cutáneas, a menudo inespecíficas, y que difieren en sus características entre los pacientes dependiendo de su tolerancia intrínseca a la radiación solar, hecho por el que resulta difícil estimar su verdadera prevalencia. Su diagnóstico se basa en una anamnesis exhaustiva, estableciendo la relación cronológica entre la aplicación del fármaco y los hallazgos clínicos que se observan en la exploración física. Una herramienta útil para el diagnóstico diferencial de ambos tipos de fotosensibilidad es el test del fotoparche. El tratamiento consiste en tres pilares fundamentales: la retirada del fármaco, incluida la presentación oral, la protección solar y los esterides tópicos, aunque en algunas ocasiones, como en nuestro paciente, pueden requerir corticoides sistémicos durante 2 ó 3 semanas. Habitualmente la evolución es satisfactoria, con resolución de la clínica, sin lesiones residuales.

\section{EFECTO DEL FILTRADO GLOMERULAR EN LA ENFERMEDAD \\ ATEROMATOSA}

Porto Pérez AB ${ }^{1}$, Arrovo $D^{2}$, Abajo $M^{2}$, Valls $J^{2}$, Betriu $A^{2}$, Valdivielso $\mathrm{JM}^{2}$, Fernández-Giráldez E², González Vigo V', Domínguez $T^{1}$, Piñeiro Parga $P$

SERVICIO DE MEDIIINA INTERNA'. SERVICIO DE NEFROLOGI'² COMPLEXO HOSPITALARIO UNIVERSITARIO DEA CORUÑN'. HOSPITAL VILANOVA DE ARNAU LLEIDA²

INTODUCCIÓN Y OBJETIVO: La enfermedad renal crónica (ERC) está asociada con una alta morbimortalidad cardiovascular y el riesgo aumenta exponencialmente con la severidad de la misma. No obstante, no está bien esclarecida la relación de la enfermedad ateromatosa (EA) con filtrados glomerulares mayores a $60 \mathrm{ml} / \mathrm{min} / 1$. $73 \mathrm{~m} 2$. El objetivo de este estudio es analizar la asociación entre EA y tasas de filtrado glomerular estimado (TFGe) mayores a $60 \mathrm{ml} / \mathrm{min} / 1.73 \mathrm{~m} 2$

MATERIAL Y MÉTODO: Estudio transversal de 1089 pacientes de atención primaria de Lleida, reclutados entre 2008 y 2011. Los criterios de inclusión son edad entre 40 y 65 años sin eventos cardiovasculares previos, con presencia como mínimo de un factor de riesgo tradicional: hipertensión arterial, dislipemia, diabetes, sobrepeso y/o tabaquismo. Definimos EA como la presencia de placa en alguno de los territorios valorados en el estudio ecográfico vascular (carótida común, bulbo y carótida interna, izquierdos y derechos). El sobrepeso fue definido como IMC $\geq 25 \mathrm{~kg} / \mathrm{m} 2$ y calculamos la TFGe según la fórmula CKD-EPI. Se determinó un punto de corte óptimo en TFGe escogiendo aquél que minimizaba el índice de Gini para discriminar EA. Se estimaron diferentes modelos de regresión logística para evaluar la asocación de TFGe con la EA ajustando por el resto de variables, utilizando el criterio de Akaike's para seleccionar el mejor modelo. Para medir el grado de asociación con EA se utilizó el odds-ratio (OR).

RESULTADOS: La media de edad fue de 54. 24 \pm 6.90 años siendo un 59. 69\% hombres, 52. 62\% hipertensos, 25 . 34\% diabéticos, 62 . 99\% dislipémicos, $83.89 \%$ con sobrepeso u obesidad, y $59.50 \%$ fumadores/exfumadores. Observamos 818 pacientes (81. 00\%) con TFGe $<101 \mathrm{ml} / \mathrm{min} / 1.73 \mathrm{~m} 2$, y en éstos la prevalencia de ateromatosis fue un $34.21 \%$ superior ( 44.53 vs $33.18 \%, 0 R=1.62, p=0.003$ ). № obstante, el efecto de TFGe perdió la significación estadística cuando se incluye en el modelo otros factores que se asocian de forma independiente, siendo éstos la edad (OR 1. 07, IC95\% 1. 04-1. 07), el tabaquismo (OR 1. 68, IC95\% 1.24-2. 3), la diabetes (OR 1. 47, IC95\% 1. 07-2. 01) y el GIMc (OR 1.05 por cada 0.01 $\mathrm{mm}$, IC95\% 1. 04-1. 07).

CONCLUSIÓN: En pacientes con TFGe $>60 \mathrm{~m} / \mathrm{min} / 1.73 \mathrm{~m} 2$, un menor filtrado glomerular se asocia a mayor prevalencia de ateromatosis. Sin embargo, dicha asociación parece estar confundida con otros factores de riesgo cardiovascular. Se precisa un análisis más detallado al respecto para poder evaluar el papel del TFGe en el desarrollo de EA en este subgrupo de pacientes.

\section{EFICACIA Y TOLERABILIDAD DE PERAMPANEL EN LA PRÁCTICA CLÍNICA HABITUAL}

García $N^{1}$. Castro $D^{2}$, Pato $A^{3}$, Bellas $P^{2}$, Cimas $I^{3}$, Rodríguez I ${ }^{3}$, Ramos $L^{3}$, Lorenzo JR ${ }^{3}$

SERVICIO MEDICINA INTERNA'. HOSPITAL POVISA. VIGO. SERVICIO NEUROLOGIA². HOSPITAL XERAL-CIES. VIGO. SERVICIO NEUROLOGÍA3. HOSPITAL POVISA. VIGO

INTRODUCCIÓN: Perampanel es un antiepiléptico con un nuevo mecanismo de acción autorizado como terapia añadida para el tratamiento de crisis focales con y sin generalización secundaria.

OBJETIVOS: evaluar eficacia y tolerabilidad de perampanel en nuestra práctica clínica habitual
PACIENTES Y MÉTODOS: Estudio descriptivo retrospectivo del uso de perampanel en la práctica clínica habitual y evaluación de eficacia y tolerabilidad.

RESULTADOS: Incluimos 40 pacientes de 43,23 años de edad media, y 25,8 años de evolución media de la enfermedad. Previamente había utilizado una media de 8,6 FAES. El número medio total de crisis epilépticas sufridas en los 3 meses previos fue de 23,10, y tras la introducción de perampanel descendió a $16,10(p<0,005) .1$ paciente se mantuvo sin crisis durante los 3 meses de seguimiento y conseguimos una reducción mayor del $75 \%$ de las crisis en el $10 \%$ de los pacientes. El $25 \%$ de los pacientes obtuvieron una reducción mayor del $50 \%$ de las crisis. En el $17,5 \%$ de pacientes hubo de retirarse perampanel durante el seguimiento, el $15 \%$ por efectos adversos de intensidad leve.

CONCLUSIONES: Perampanel es un nuevo fármaco antiepiléptico con el que se consigue reducir la frecuencia de las crisis epilépticas, con efectos adversos de intensidad leve.

\section{EL “TOP TEN” DE LAS PRESCRIPCIONES POTENCIALMENTE INADECUADAS (PPI) EN EL PACIENTE ANCIANO HOSPITALIZADO}

Suárez Fuentetaja R, Domínguez Rodríguez T, Verdeal Dacal R, Díaz Díaz JL, Martín Malmierca N, María Justo Muradas I, Saborido Froján J, Vega Riveiro P.

MEDICINA INTERNA, CHUAC.

INTRODUCCIÓN: El envejecimiento, la pluripatología y la polifarmacia son rasgos cada vez más frecuentes en la población. Todos ellos son predictores de reingreso hospitalario e incremento de gasto sanitario.

OBJETIVOS: Descripción de la población mayor de 65 años, ingresada en un S. de Medicina Interna de un Hospital Terciario.

Determinar las PPI más frecuentes según los criterios STOPP (Screening Tool of Older Persons' Potentially inappropiate Prescriptions).

MATERIAL Y MÉTODO: Estudio observacional transversal, que incluye 200 pacientes consecutivos mayores de 65 años, dados de alta entre el 1 junio 2014 y el 19 de jullo de 2014 del S. de Medicina Interna de Complejo Hospitalario Universitario A Coruña. Registrando variables epidemiológicas, clínicas y PPI. Para el análisis estadístico se empleó el programa SPSS 18.

RESULTADOS: Características de la población a estudio. Edad media $82.8 \pm 7.4$ años, $71.5 \%>80$ años, 60\% mujeres. 70\% HTA, 44\% dislipemia, 26. 5\% DM tipo 2, 31\% enfermedad renal crónica, 13. $5 \%$ cardiopatía isquémica, 20\% insuficiencia cardíaca (IC), 35\% FA permanente, 19\% enfermedad cerebrovascular, 5. 5\% arteriopatía periférica, 23\% EPOC y trastornos relacionados, 18\% neoplasia, 10. 5\% fractura de cadera, 33. 5\% demencia, 4. 5\% hepatopatía crónica. Índice de Charlson $\geq 3199$ (99. 5\%) Fármacos totales al ingreso 1452, al alta 1586. Fármacos por paciente, mediana (RIQ) al ingreso 7 (5-10), al alta 8 (6-10). Paciente Pluripatológico (PPP)124 pacientes (62\%), Paciente Polimedicado (PPM) 159 (79. 5\%), PPP y PPM 104, (52\%), PPP o PPM 179 (89. 5\%). PPI total al ingreso 179, PPI total al alta 154 Pacientes con 1 o más PPI, $n$ (\%) al ingreso $114(57 \%)$, al alta 92 (46\%) Diez principales PPI

1. Uso > 1mes de benzodiazepinas (BZD) de vida media larga o con metabolitos de larga acción al ingreso $3 \%$, al alta $12 \%$

2. BZD en pacientes con $\geq 1$ caída en los últimos 3 meses al ingreso $11.5 \%$ y al alta $12 \%$.

3. Diuréticos de asa para edemas maleolares aislados, sin signos clínicos de IC, al ingreso $7 \%$ y al alta $7.5 \%$

4. Uso $>1$ mes de neurolépticos en el parkinsonismo al ingreso $1.5 \%$, al alta $6 \%$.

5. Uso $>3$ meses de AINEs para alivio de dolor articular leve en la artrosis, al ingreso $0 \%$ y al alta $6 \%$.

6. Uso $>1$ mes de neurolépticos como hipnóticos a largo plazo $13.5 \%$ al alta $5.5 \%$

7. ISRS con antecedentes de hiponatremia clínicamente significativa al ingreso 2\%, al alta 3. 5\%

8. AAS sin antecedentes de enfermedad cardiovascular aterosclerótica, al ingreso $3.5 \%$ y al alta $2.5 \%$

9. Opiáceos a largo plazo en demencia, salvo indicación paliativa o dolor moderado/grave, al ingreso 2\% y alta $2.5 \%$

10. Anticolinérgicos para tratar efectos secundarios extrapiramidales de neurolépticos al ingreso 1.5\% y al alta $2.5 \%$

CONCLUSIÓN: Dadas las características de la población, con un envejecimiento progresivo, y aumento de comorbilidad y polifarmacia, los criterios STOPP, pueden ser adecuados para la detección de PPI entre las cuales destaca el grupo de psicofármacos.

\section{EMBOLISMO PULMONAR POR POLIMETILMETACRILATO SECUNDARIO A CIFOPLASTIA. A PROPÓSITO DE UN CASO}

Val Dominguez N, Argibay Filgueira A, Rivera Gallego A, Baroja Basanta A, Vilas Pio B, Lorenzo Castro R, Freire Dapena $M$.

UNIDAD DE TROMBOSIS Y VASCULITIS. SERVICIO DE MEDICINA INTERNA, HOSPITAL XERAL DEVIGO (EOXI). INTRODUCCIÓN: La vertebroplastia y la cifoplastia son dos técnicas cada vez más empleadas en el tratamiento las fracturas vertebrales al tratarse de técnicas poco invasivas y relativamente seguras. Coincidiendo con la generalización de la técnica, cada vez son más frecuentes la aparición de complicaciones, siendo el embolismo pulmonar (EP) por polimetilmetacrilato una de las más graves.

OBJETIVO: Descripción de un caso clínico poco habitual de EP por polimetilmetacrilato y discusión sobre las opciones terapeúticas.

MATERIAL Y MÉTODO: Revisión de la historia clínica del enfermo y búsqueda en MEDLINE sin límite de fecha las palabras clave "pulmonary embolism" and "vertebroplasty" and "polymethyl methacrylate" and "treatment".

RESULTADOS: Paciente de 71 años que ingresó en junio de 2012 por politraumatismo, con fractura y acuñamiento anterior de cuerpo vertebral dorsal 8 (D8) sin afectación raquídea, y varias fracturas costales bilaterales con hemotórax postraumático que precisó drenaje pleural. Con anestesia general y en posición de decúbito prono se procedió a cifoplastia sobre D8 mediante la inyección de polimetilmetacrilato tras dilatación con balón, sin evidenciarse alteraciones en el control fluroscópico posterior a la intervención. A los 3 días el paciente presentó cuadro de hipotensión taquicardia y sudoración profusa, evidenciándose un cuerpo extraño de características metálicas en arteria pulmonar principal y rama lobar inferior derecha en el angio-TC pulmonar, compatible con embolización de polimetilmetacrilato tras cifoplastia. Se valoró para retirada percutánea de material extraño por el servicio de Radiología Intervencionista, desestimándose finalmente por el riesgo de rotura de la pared vascular al tratarse de un material rígido. Se optó finalmente por un manejo conservador con heparina de bajo peso molecular a dosis anticoagulantes a largo plazo, con buena respuesta y sin evidencia de complicaciones hemorrágicas en el seguimiento posterior.

CONCLUSIÓN: La frecuencia de EP por polimetilmetacrilato secundario a su uso en las fracturas vertebraes se estima en torno al 3. 5\%-23\% en función de la técnica de imagen empleada para el diagnóstico. La mayoría cursan de manera asintomática y sólo un pequeño porcentaje provocan síntomas graves. La anticoagulación durante 3-6 meses o la extracción percutánea del material extraño en casos de inestabilidad hemodinámica, son el tratamiento de elección en los pacientes sintomáticos, aunque los datos publicados en la literatura a este respecto son muy escasos. No existe ninguna evidencia que justifique el rastreo sistemático mediante TAC o radiografía en los pacientes asintomáticos sometidos a este tipo de técnicas. 


\section{EMBOLISMO PULMONAR: UN TRÁGICO “FANTASMA" EN LA ÓPERA.} LOS CASOS DE CARUSO, LANZA, CALLAS Y DOMINGO

\section{Montes Santiago J.}

MEDICINA INTERNA, COMPLEJO HOSPTIALARIO UNIVERSITARIO. VIGO

El embolismo pulmonar (EP) es un proceso grave pero cuyo reconocimiento precoz permite reducir drásticamente la morbimortalidad. El objetivo de este trabajo es describir la trascendencia que el EP, sospechado o confirmado, ejerció en la vida y actividad profesional de muy conocidas estrellas de la ópera. MÉTODOS: Análisis patobiográfico de la vida de 4 conocidos cantantes de ópera, focalizado en el posible padecimiento de un EP.

RESULTADOS: 1. ENRICO CARUSO. Aunque al final de la vida del cantante más famoso de Ópera se concatenaron una serie de circunstancias aciagas, incluidos varios errores médicos, en el proceso inicia que desencadenó su postrera enfermedad -hemoptisis, dolor torácico, disnea-, se barajaron los diagnósticos de EP, tuberculosis, neoplasia o neumonia. Luego se complicó con empiema, que precisó de varios drenajes pleurales, hasta su fallecimiento a los 48 años (1921). No se realizó autopsia. 2. MARIO LANZA. Este conocido tenor americano es recordado por su caracterización del personaje anterior en la película "El Gran Caruso" (1951) y por sus legendarias interpretaciones de ópera en Italia y América. Su muerte súbita se produjo por un EP a los 38 años (1959). Se relacionó con las curas de sueño y dietas drásticas seguidas para controlar su obesidad. 3. MARÍA CALLAS. La muerte de esta diva griega siempre estuvo envuelta en el misterio. Retirada de los escenarios, durante largo tiempo su muerte rápida e inesperada a los 53 años (1977) se atribuyó a una posible cardiopatía isquémica. Sin embargo, estudios más recientes, que examinan los testimonios de sus últimos cuidadores, apuntan a la mayor probabilidad de un EP. Elo no pudo confirmarse ya que no se realizó necropsia y fue incinerada. 4. PLÁCIDO DOMINGO. Un EP le obligó a suspender su actuación en la ópera "El cartero de Neruda" en 2013. Hospitalizado varios días en un hospital madrileño, se recuperó satisfactoriamente, pudiendo reanudar su exitosa carrera. Recibió tratamiento cerca de 9 meses. Tres años antes se le había extirpado un pólipo colónico cancerígeno.

COMENTARIOS: Durante los últimos años se ha alertado a la sociedad sobre la epidemia silente de muerte súbita que ocasiona el EP. En Estados Unidos ha abanderado dicha alerta Melanie Bloom, esposa del conocido reportero de la NBC americana, David Bloom, que murió por un EP mientras cubría la guerra de Irak (2003). Otros conocidos personajes, como el actor Kevin Costner, han colaborado en estas labores divulgativas. El reconocimiento de los padecimientos por ciertos personajes socialmente reconocidos influye en la población para que adopte actitudes preventivas pertinentes.

CONCLUSIÓN: El EP constituye la $1^{\text {a }}$ causa de muerte hospitalaria evitable. Entre las medidas de divulgación para adoptar hábitos saludables y correctas actitudes preventivas se encuentra el reconocimiento de sus padecimientos por personas célebres. Los 4 artistas aquí citados constituyen claras manifestaciones de tal paradigma.

\section{ENDOCARDITE FÚNXICA NO COMPLEXO HOSPITALARI0 UNIVERSITARIO DE OURENSE. REVISIÓN EN QUINCE ANOS}

González Noya A, Barreiro Rivas A, Latorre Diez A, López Mato P, Fernández Regall, Pérez Carral V. MEDICINA INTERNA, CHUO

INTRODUCCIÓN: Os fungos son unha causa pouco común de endocardite, estimando a súa prevalencia entre $01-4 \%$ de todas as endocardites infecciosas. A etioloxía máis frecuente son as especies Cándida. Habitualmente os pacientes presentan algún factor de risco. A pesar dos tratamentos antifúnxicos dispoñibles, a súa mortalidade continúa sendo elevada, en probable relación coa alta taxa de complicacións, a tardanza no diagnóstico e a alto índice de recaídas.

OBXECTIVOS: Estudiar as características dos pacientes diagnosticados de endocardites fúnxica. MATERIAL E MÉTODOS: Estudio descritivo retrospectivo onde se analizaron as características epidemiolóxicas, clínicas e medidas terapéuticas aplicadas nos casos diagnosticados de endocardite fúnxica na poboación maior de 15 anos do CHUO de desde 0 ano 2000 ata 02015

RESULTADOS: Rexistráronse 3 casos de endocardites fúnxicas nos últimos quince anos; dos cales 2 foron de sexo feminino. A idade media foi de 68,6 anos. Destacaba en dous dos casos 0 antecedente de portador de vía central para a administración de nutrición parenteral. Un dos casos era portador de válvula protésica e outro recibira antibioterapia de amplo espectro no contexto dunha pancreatitis grave que requirira intervención cirúrxica. A clínica pola que consultaron $0100 \%$ dos casos foi febre persistente e deterioro do estado xeral. Dende 0 inicio dos síntomas ata o diagnóstico pasaron unha media de 24 días. As válvulas afectadas, que presentaban en todos os casos imaxe de verruga no ecocardiograma transesofáxico; foron a válvula aórtica, a mitral e o septo interventricular. 0 axente etiolóxico illado en ambos casos foi o fungo Cándida; a especie Parapsilose en dous casos e Albicans no outro paciente. Durante 0 curso da enfermidade, todos os pacientes presentaron como complicación un episodio de fallo cardíaco, precisando en dous casos tratamento cirúxico de recambio valvular. Os axentes antifúnxicos utilizados, a dosificación, e o tempo de tratamento están reflexadas na Táboa 1. Un dos pacientes faleceu no período postoperatorio; mentres que nos outros dous non se observaron datos de recidiva tras $1 \mathrm{e}$ 16 meses de seguimento.

CONCLUSIÓN: A El fúnxica continúa sendo unha causa moi pouco frecuente dentro das endocardites infecciosas. Os doentes adoitan asociar factores de risco, tal como valvulopatía previa ou algún grado de inmunosupresión. A presentación típica, ao igual que as endocardites bacterianas é un síndrome febril persistente; que adoita acompañarse de fallo cardíaco. 0 diagnóstico céntrase nos criterios microbiolóxicos e ecocardiográficos. 0 tratamento baséase principalmente na ciruxxía de recambio valvular e no tratamento farmacolóxico con antifúnxicos, preferentemente de forma combinada e con pautas de longa duración; a pesar do cal a mortalidade continúa sendo moi significativa; factores que nos indican que se debe manter unha actitude especialmente activa no diagnóstico, con especial índice de sospeita dos grupos de risco; para poder iniciar o tratamento de forma inmediata.

\section{ENDOFTALMITIS POR MENINGOCOCO C}

Páez-Guillán EM, Maciá-Rodríguez C, Martínez-Rey C, García-Villafranca A, Alende-Castro V. MEDIIINA INTERNA, COMPLEXO HOSPITALARIO UNIVERSTTARIO DE SANTIAGO DE COMPOSTELA. INTRODUCCIÓN: La endoftalmitis es una enfermedad infecciosa que cursa con afectación del globo ocular y que en ocasiones podemos observar en el contexto de enfermedad sistémica, como puede ser la meningitis meningocócica.

OBJETIVOS: Aportar información clínica sobre el manejo de la endoftalmitis por meningococo $\mathrm{C}$. MATERIAL Y MÉTODOS: Presentación de un caso clínico y revisión de literatura.

RESULTADOS: Mujer de 46 años que acudió a nuestro Servicio de Urgencias por fiebre de hasta $39^{\circ} \mathrm{C}$, malestar general, cefalea y vómitos. En la exploración física a su llegada a Urgencias destacaba: TA de $84 / 67 \mathrm{mmHg}$, FC de $112 \mathrm{lpm}$, bradipsiquia, rigidez de nuca y rash petequial en tronco y extremidades. En analítica de sangre destacaba leucocitosis de $19430 / \mu$ con $37 \%$ de cayados y $2 \%$ de metamielocitos, as como creatinina de $2.4 \mathrm{mg} / \mathrm{dl}$; en GSV se obtuvo un láctico de $6.9 \mathrm{mmo} / /$. Se realizó punción lumbar con resultado de 2950 leucocitos/ $\mu$ ( $95 \%$ de polimorfonucleares), proteínas totales de $3.0 \mathrm{~g} / \mathrm{l}$ y niveles indetectables de glucosa. Se ingresó a la paciente en UCl y se inició triple terapia antibiótica con Vancomicina Ceftriaxona y Ampicilina, asociada a corticoterapia sistémica. A las doce horas del ingreso la paciente comenzó con visión borrosa en ojo derecho asociada a dolor, ante el empeoramiento del cuadro se interconsultó con Oftalmología objetivándose en vítreo infiltración difusa con condensaciones blanquecinas: ante la sospecha diagnóstica de endoftalmitis endógena se inician colirios reforzados con Ceftazidima y
Vancomicina y se procede a la administración intravítrea de dichos fármacos. Ante la estabilización de la paciente se procedió a trasladar a la misma a Medicina Interna. Dada la persistencia de la infiltración vítrea hubo de realizarse vitrectomía. Tras obtención de cultivo de LCR donde creció N. meningitidis, se decidió completar la antibioterapia sistémica y local con Ceftriaxona durante 14 días. Finalmente la paciente fue dada de alta domiciliaria con Dexametasona en pauta descendente.

CONCLUSIÓN: La endoftalmitis por meningococo es una complicación rara de la meningitis. № parece encontrarse relación con estados de inmunodepresión o comorbilidad; al contrario, es relativamente común encontrar esta complicación en pacientes jóvenes y previamente sanos. Es por ello que en toda meningitis debemos realizar exploración oftalmológica para prevenirla y tratarla correctamente.

\section{ENFERMEDAD DE CREUTZFELD-JAKOB: REVISIÓN DE CASOS EN LA ÚLTIMA DÉCADA EN EL COMPLEXO HOSPITALARIO UNIVERSITARIO DE OURENSE}

Barreiro Rivas A, Latorre Díez A, González Noya A, López Mato P, Fernández Regal I, Pérez Carral V. SERVICO DE MEDICINA INTERNA, COMPLEXO HOSPITALARIO UNIVERSITARIO DE OURENSE.

INTRODUCCIÓN: Las enfermedades por priones son procesos neurodegenerativos de incubación prolongada y progresión inexorable una vez iniciada la clínica ya que no existe un tratamiento eficaz Se debe a la acumulación de una forma anormal de proteínas (priones). Es una patología muy infrecuente cuya forma más común es la enfermededad de Creutzfeldt-Jakob (ECJ) esporádica. Ésta se suele presentar como deterioro de cognitivo y ataxia, habitualmente entre los 57 y los 62 años de edad.

OBJETIVO: Conocer la incidendia de casos de Probable ECJ ${ }^{*}$ en el CHOU y sus características epidemiológicas, así como su correlación con casos confirmados mediante necropsia.

MATERIAL Y MÉTODOS: Estudio descriptivo retrospectivo en el que se recogieron datos de pacientes mayores de 15 años con diagnóstico de probable ECJ en los últimos 10 años en el CHOU. Los datos se obtuvieron a través del Servicio de Documentación, seleccionando aquellos pacientes que cumplían los criterios de Probable ECJ.

RESULTADOS: Fueron encontrados 6 casos con criterios de Probable ECJ.

La media de edad de los pacientes fue de 64,8 años, predominando el sexo femenino (80,3\%). La media de duración de la enfermedad hasta la muerte del paciente fue de 5,3 meses. La formas de presentación más habituales fueron el deterioro cognitivo y la ataxia. Dos pacientes consultaron por deterioro cognitivo y ataxia, otros dos por ataxia de forma aislada, uno por deterioro cognitivo y diplopia, y en el otro caso la clínica se inició con insomnio. En la totalidad de los casos aparecieron en algún momento de la evolución deterioro cognitivo y alteraciones de la marcha. Además, en tres casos hubo aleraciones visuales y en uno mioclonías. Hubo alteraciones típicas en la RNM en 3 pacientes. Aunque existían alteraciones en EEG en algunos pacientes, ninguno tenía alteraciones típicas. La proteína 14-3-3 estaba elevada en el LCR en todos los casos. De los 6 casos estudiados, solo se realizó necropsia en 3 de ellos. De estos, en dos se encontraron cambios histológicos típicos y se detectó proteína priónica por inmunohistoquímica, confirmándose el diagnóstico de ECJ. Uno de los casos confirmados, una mujer de 43 años, presentaba insomnio, alteraciones comportamentales, alteraciones visuales y ataxia de marcha; mostrando la RNM imágenes típicas y el EEG actividad focal theta. En el otro caso, de otra mujer de 62 años, había solo deterioro cognitivo y ataxia, y la RNM no mostró alteraciones significativas, apreciándose en EEG solo lentificación difusa. En ambos casos el paciente falleció al cabo de 6 meses de iniciada la clínica. CONCLUSIONES: La ECJ en Ourense tiene una baja prevalencia y una edad de presentación ligeramente superior a la de otros estudios. Los síntomas más frecuentes fueron deterioro cognitivo y ataxia de la marcha. Las necropsias se practicaron solo al $50 \%$ de los casos de probable ECJ, a pesar de ser la única forma de obtener el diagnóstico en estos momentos.

\section{ENFERMEDAD DE WHIPPLE: UNA ENTIDAD INFRECUENTE}

Álvarez Otero J, Sánchez Conde P, Lamas Ferreiro JL, González González L, Posada García J, García Pouton N, De la Fuente Aguado J.

MEDICINA INTERNA, POVISA.

INTRODUCCIÓN: La enfermedad de Whipple es una patología infecciosa sistémica causada por el microorganismo Tropheryma whipplei. Puede causar síntomas muy diversos, siendo la presencia de artralgias, diarrea, pérdida de peso y dolor abdominal la forma clásica de presentación. La fiebre es un sintoma infrecuente ( $30 \%$ de los pacientes). La capacidad de este proceso infeccioso de manifestarse de múltiples formas puede ser una causa de retraso en el diagnóstico y por lo tanto del tratamiento, siendo esta entidad potencialmente mortal sin una terapia adecuada.

OBEJTIVOS: Incidir en la importancia de incluir la enfermedad de Whipple en el diagnóstico diferencial del síndrome febril para realizar un diagnóstico precoz.

MATERIAL Y MÉTODOS: Presentamos un caso de enfermedad de Whipple en un paciente de 15 años diagnosticado en la consulta de Medicina Interna de nuestro hospita.

RESULTADOS: Varón de 15 años que acudió a nuestro centro por cuadro de 4 meses de evolución de astenia y febrícula diaria con fiebre ocasional. Inicialmente el enfermo no relataba ninguna otra sintomatología, refiriendo posteriormente, tras una anamnesis dirigida, la presencia de deposiciones pastosas si productos patológicos y discretas artralgias en ambas rodillas de forma esporádica. No relataba pérdida de peso ni ninguna otra sintomatología. No presentaba antecedentes médicos reseñables salvo amigdalitis de repetición que obligaron a realización de amigdalectomía 5 meses antes del inicio del cuadro clínico. La exploración física era anodina. En los análisis destacaba un calcio y vitamina $D$ bajos y en las pruebas de imagen no se observaba ninguna alteración (Rx tórax, ecografía abdominal y TAC toraco-abdominal). Se solicitó una gastroscopia con biopsia duodenal que demostró la presencia de atrofia de vellosidades, realizándose una tinción PAS que fue positiva. Se realizó una PCR de Tropheryma whipplei en LCR que fue negativa. Se envió también una muestra de la biopsia duodenal para PCR, que también fue negativa, aunque probablemente la muestra estuviese artefactada por un tiempo de fijación en formol prolongado. Se inició tratamiento con ceftriaxona durante 2 semanas, presentando al inicio del tratamiento un cuadro compatible con una reacción de Jarisch Herxheimer que se trató con ibuprofeno y se autolimitó en pocos días. Posteriormente se inició terapia con trimpetoprim-sulfametoxazol.

CONCLUSIÓN: La enfermedad de Whipple es una entidad a considerar en aquellos pacientes con síndromes febriles de larga evolución. Es importante interrogar a los pacientes con dicha clínica por la presencia de otra sintomatología sugestiva, como alteraciones del hábito intestinal o dolores articulares, aunque sean de carácter leve, ya que su presencia nos debe hacer valorar la realización de las pruebas complementarias necesarias para un diagnóstico precoz, ya que el retraso en el tratamiento tiene importantes implicaciones pronósticas.

\section{ENFERMEDAD TROMBOEMBÓLICA EXTENSA IDIOPÁTICA Y RECURRENTE A PESAR DE ANTICOAGULACIÓN}

Lorenzo Castro R, Argibay Filgueira AB, Val Domínguez N, Baroja AL, Vilas Pio B, Soto Peleteiro A, Gómez Sousa $J M$, Sousa Domínguez A, Rivera Gallego A. MEDICINA INTERNA (UNIDAD DE TROMBOSIS Y VASCULITIS), HOSPTTAL XERAL DE VIGO.

INTRODUCCIÓN: La enfermedad tromboembólica venosa (ETEV) sigue siendo una de las principales causas de muerte e implica importantes secuelas. El amplio conocimiento de los factores asociados con su aparición ayuda a los clínicos a poner en marcha medidas para evitar su aparición (profilaxis primaria) 
o su recurrencia (profilaxis secundaria). A pesar de ello continúan existiendo situaciones poco claras como la recurrencia de trombosis en pacientes ya anticoagulados.

OBJETIVOS: Exponer un caso con trombosis venosa espontánea extensa y recurrente a pesar de tratamiento anticoagulante correcto y de distintos tipos de tratamiento.

RESULTADOS: Varón de 69 años que ingresó por esputos hemoptoicos y dolor en costado derecho pleurítico de 7 días de evolución. Era ex-fumador de 2 paquetes/día, diabético tipo 2 con buen control y cardiopatía hipertensiva en fibrilación auricular tratado con acenocumarol. En la exploración física destacaba hipofonesis en tercio inferior de hemitórax derecho. Presentaba leucocitosis con neutrofilia e INR de 2,46. La radiografía de tórax objetivó opacidad basal asociada a derrame pleural derecho. Se solicitó angio-TC que confirmó tromboembolismo pulmonar y trombosis venosa a nivel de vena esplénica y cava inferior (desde venas renales hasta la aurícula derecha). El dúplex de miembros inferiores fue negativo. Se inició tratamiento con tinzaparina sódica ajustada a peso. La evolución fue buena pero a mes el enfermo reingresó por insuficiencia renal aguda (creatinina de 3. 07). La ecografia abdomina descartó causa obstructiva, con progresión de la trombosis de vena cava inferior hasta el eje ilio-femora zquierdo y venas renales. Se inició tratamiento con heparina sódica con estabilización y paso posterior a rivaroxaban. El estudio de trombofilia, la autoinmunidad y el rastreo de neoplasia fueron negativos. En el seguimiento ambulatorio la evolución fue buena, sin nuevos episodios de trombosis. El tratamiento anticoagulante en la ETEV está encaminado a evitar la progresión del trombo y la recurrencia (mayor probabilidad en los primeros meses desde el evento inicial). Nuestro paciente presentó ETEV estando anticoagulado en rango terapéutico con acenocumarol y progresó con heparina a dosis plenas. La mayoría de estos pacientes presentan síndrome antifosfolípido, cáncer o INR subóptimos, sin apenas información en trombosis idiopática.

CONCLUSIONES: Los pacientes con ETEV idiopática y extensa deben ser vigilados de forma estrecha con contoles frecuentes de los niveles de anticoagulación, sobre todo en los primeros meses. Se deben realizar estudios de extensión para descartar causas secundarias o asociadas a la trombosis. En caso de recurrencia o progresión de la ETEV en pacientes ya anticoagulados, la elección del tipo y dosis de los distintos anticoagulantes, no está clara.

\section{EPIDEMIOLOGÍA Y CARACTERÍSTICAS CLÍNICAS DE LA HEPATITIS C} EN UNA COHORTE DE PACIENTES CO-INFECTADOS POR EL VIH

Vilariño-Maneiro $L^{2}$, Valcarce-Pardeiro $N^{3}$, Álvarez-Díaz $H^{1}$, Mariño-Callejo $A^{1}$, García-Rodríguez JF', SesmaSánchez $P^{2}$

UNIDAD DE ENFERMEDADES INFECCIOSAS', SERVICIOS DE MEDICINA INTERNA2 ${ }^{2}$ FARMACIA HOSPITALARIA ${ }^{3}$ COMPIEXO HOSPITAL ARIO UNIVERSITARIO DE FERROL.

INTRODUCCIÓN: La infección por el VIH aumenta el riesgo de progresión de la infección por el VHC, y su control se asocia a una menor progresión de la enfermedad hepática.

OBJETIVO: Conocer las características epidemiológicas, clínicas y analíticas de una serie de pacientes co-infectados por VIH-VHC

MATERIAL Y MÉTODOS: Análisis retrospectivo de la información recogida de forma prospectiva en una base de datos espećífica para pacientes co-infectados en seguimiento regular durante 2014. Se describen los datos epidemiológicos, clínicos y analíticos.

RESULTADOS: Durante el 2014 acudieron, al menos a una consulta, 469 pacientes, de los que 109 (23,2\%) estaban co-infectados por el VHC. De los 109, disponemos de datos en 79 pacientes (72,5\% con seguimiento protocolizado: $61(77,2 \%)$ varones, mediana de 49 años (intercuartil $46-53)$. La vía de transmisión fue: UDVP en $63(79,7 \%)$, sexual en $8(10,1 \%)$, desconocida en 5 , transfusión sanguínea en 2 , y mixta (UDVP/sexual) en 1. Cinco pacientes (6,3\%) reconocían un consumo actual de alcohol $>30 \mathrm{~g}$ día y $24(30,4 \%)$ de otras drogas. Transcurrió una media de 19,8 66,3 años desde el diagnóstico de V/H. Según la clasificación de los CDC, 33 pacientes (41,8\%) estaban en estadio A, 15 (18,9\%) B, y 31 (39,2\%) C: 6 (7,6\%) tenían linfocitos CD4+<200 células/ul. Sólo 6 (7,6\%) pacientes tenían una CV de $\mathrm{VIH}>50 \mathrm{cp} / \mathrm{ml}$. 76 pacientes (96,2\%) recibian tratamiento antirretroviral (TAR): el $51,3 \% 2$ ITIAN y 1 IP, $23,7 \% 2$ ITIAN y 1 ITINN y otras pautas el resto; $53,9 \%$ llevaban $<5$ años con el TAR actual, $44,7 \%$ entre 5 y 10 y 1,3\% más de 10 años. De los 76 pacientes en TAR, la CV de VIH era $\leq 50 \mathrm{cp} / \mathrm{ml}$ en $72(94,7 \%)$. En los 79 pacientes co-infectados, la media de años transcurridos desde el diagnóstico del VHC fue 16,3 $\pm 6,1$. Cinco (6,3\%) se diagnosticaron en los últimos 5 años, 11 (13,9\%) entre 6 y 10 , y $63(79,7 \%)$ hacía más de 10 años. Habían sido tratados con pegIFN y RBV 39 pacientes (49,4\%). El genotipo (Gt) de VHC fue Gt 1 en 44 pacientes (55,7\%) [27 subtipo a, 16 b y 1 pendiente], Gt 3 en 15 (19\%) y Gt 4 en $20(25,3 \%$ ). La CV del VHC más reciente fue $>6.000 .000 \mathrm{Ul} / \mathrm{ml}$ en 14 casos $(17,7 \%),<6.000 .0000$ $\mathrm{Ul} / \mathrm{ml}$ en $64(81 \%)$ y desconocida en uno. El genotipo de la IL28B fue CC en 31 pacientes $(39,2 \%), \mathrm{C}$ en $36(45,6 \%)$, $\Pi$ ) en $11(13,9 \%$ y desconocido en uno. El grado de fibrosis (FibroScan $®)$ fue: F3 o F4 en 30 pacientes (38\%), F2 en 11 (13,9\%), F0-F1 en 34 (43\%) y desconocido en $4(5,1 \%)$. De los 21 pacientes con F4, 17 (80,9\%) eran Child A, 3 (14,3\%) By 1 (4,8\%) C. 6/79 (7,6\%) tenían una enfermedad extra-hepática asociada al VHC.

CONCLUSIONES: Casi la totalidad de nuestros pacientes están bien controlados, reciben TAR eficaz tenen viremia de VIH suprimida, lo que facilita el control de la infección por el VHC. La principal vía de transmisión fue el UDVP. Por el grado de fibrosis, según los criterios del SNS, está indicado el tratamiento prioritario con antivirales de acción directa frente al VHC en más de la mitad de los casos.

\section{ERITEMA AB IGNE}

Longueira R, Rivas MD, Vilas B, Baroja A, Val N, Rivera A.

MEDICINA INTERNA, HOSPITAL XERAL. COMPLEJO HOSPITALARIO UNIVERSITARIOS DE VIGO (CHUVI).

INTRODUCCIÓN: El eritema ab igne o melanosis calórica de Buschke, también denominada comúnmente "cabrillas", aparece como consecuencia de la exposición repetida de la piel a niveles de calor por debajo del umbral de quemadura. Inicialmente se presenta como mácula eritematosa con patrón reticular que evoluciona a una hiperpigmentación persistente con ese mismo patrón, cuya extensión y morfología suele dibujar la fuente de calor. Desde el punto de vista histológico se aprecia una oclusión parcial de los vasos, con fibrosis y depósito de hemosiderina. Antiguamente era más frecuente en ancianos y se relacionaba con la utilización de braseros afectando al área pretibial de las piernas. En la actualidad los casos que se diagnostican se relacionan con dispositivos eléctricos como mantas, almohadillas u ordenadores. Suele ser asintomática y no tiene tratamiento específico, aunque conviene evitar la exposición del calor tan cercana a la piel ya que se ha relacionado con la aparición a largo plazo de carcinoma epidermoide. OBJETIVOS: Comunicar un caso que se presentó como hallazgo casual en la exploración física de una paciente ingresada por infección respiratoria.

MATERIAL Y MÉTODO: Descripción de la historia clínica y revisión de la literatura.

RESULTADOS: Paciente mujer de 51 años, fumadora de 20 cigarrillos/día y consumidora ocasional de marihuana, cardiopatía isquémica en relación con consumo previo de cocaína, hipertensión arterial y enfermedad pulmonar obstructiva crónica grave. Acudió a Urgencias por disnea y expectoración purulena, sin otra clínica asociada. En las pruebas complementarias se constató insuficiencia respiratoria y se procedió a su ingreso. En la exploración física, además de taquipnea con roncus y sibilancias dispersas, se apreció una extensa lesión hiperpigmentada con patrón reticular localizada en región dorso-lumbar y en ambos flancos, no dolorosa a la palpación, no sobreelevada ni descamativa, que la paciente no había objetivado. En el interrogatorio dirigido la paciente reconoció el uso frecuente en los últimos meses de una manta eléctrica, que aplicada a ese nivel, sin haber notado ninguna sintomatología local relacionada con la utilización de la misma.
CONCLUSIONES: En la actualidad el eritema ab igne se relaciona más frecuentemente con el uso de dispositivos eléctricos utilizados como fuente de calor u ordenadores portátiles. Aunque en ocasiones se ha descrito que asocie dolor y prurito, suele ser asintomática y no tiene tratamiento específico. La sospecha clínica, identificando el antecedente de exposición al calor, es fundamental para su diagnóstico y evitar asi realización de estudios innecesarios.

\section{ESTUDIO DE PACIENTES PALIATIVOS NO ONCOLÓGICOS EN UNA UNIDAD DE HOSPITALIZACIÓN A DOMICILIO}

MA, Varez González A, Canitro

MEDICINA INTERNA. HOSPITALZACIÓN A DOMICULO, COMPIEXO HOSPTTALARIO DE PONTEVEDRA.

INTRODUCCIÓN: En las últimas décadas la Hospitalización a Domicilio (HADO) ha ganado peso en los distintos centros hospitalarios. Los pacientes paliativos no óncológicos tienen una prevalencia no desconsiderable en nuestro medio y muchas veces no tienen una Unidad de referencia clara o no se consideran comotal.

BJETIVOS: Analizar los pacientes paliativos no oncológicos hospitalizados en HADO durante el 2014 en área sanitaria del Complexo Hospitalario de Pontevedra (CHOP). Conocer las patologías más prevalens, los servicios de derivación más habituales, el motivo de reingreso en centro hospitalario y la unidad donde esto sucede y el lugar habitual de éxitus de dichos pacientes.

MATERIAL Y MÉTODOS: Estudio descriptivo retrospectivo observacional. Se analizan los pacientes hospitalizados en HADO del 1 de Enero de 2014 al 31 de Diciembre de 2014 en el área sanitaria del CHOP. Para el análisis estadístico empleamos el paquete estadístico SPSS 15.0.

RESULTADOS: 382 pacientes fueron ingresados en HADO durante el 2014, 181 eran pacientes que inplian criterios de paciente paliativo. Entre ellos, 18,2\% eran paliativos no oncológicos. Su edad media era $82 \pm 15,2$ años. El sexo predominante fue masculino $(63,6 \%)$. La media de estancia en HADO fue de 13,1+14,5 días (mediana 7,5 días). El Servicio Hospitalario que más remitió pacientes fue Medicina Interna (36. 6\%), seguido de Neumología (15,5\%), Unidad de Cuidados Paliativos (UCP) (12,1\%), Urgencias $(12,1 \%)$, Atención Primaria $(9,1 \%)$, Digestivo $(6,1 \%)$, Hematología $(6,1 \%)$ y Neurología $(3 \%)$. E motivo de derivación más habitual fue insuficiencia respiratoria crónica (36\%); siendo el principal agente etiológico el EPOC terminal y la fibrosis pulmonar ideopática (33,3\%). Otros motivos fueron: deterioro cognitivo grave (GDS 6-7) (21,2\%), hepatopatía crónica avanzada (Child-Pugh > B8) (12\%), cardiopatía terminal (NYHA 3-4) (9.1\%) y otros (24.4\%). Un 30,3\% de los pacientes precisaron ingreso hospitalario, ingresando en su unidad de origen un 50\% mientras que un 40\% fueron derivados a UCP. Los motivos de reingreso por orden de frecuencia fueron: mal control de síntomas $(30 \%)$, claudicación familiar $(20 \%)$ mal control del dolor $(10 \%)$, delirium, $(10 \%)$, disnea $(10 \%)$ y en el $10 \%$ no estaba indicado el ingreso en HADO. La patología con más reingresos es la hepatopatía crónica (75\%). El 70\% de los pacientes estudiados fallecieron durante el período de seguimiento. De ellos el 69,5\% falleció en HADO, siendo el deterioro cognitivo grave la patología con más éxitus en domicilio. Un 17,4\% de los pacientes estudiados falleció intrahospitalariamente, destacando en este grupo a los pacientes con insuficiencia respiratoria crónica (60\% de fallecimientos en hospital, 40\% en domicilio). Un 13\% de los pacientes fallecieron en bajo seguimiento de Atención Primaria.

CONCLUSIONES: El diagnóstico más frecuente de paciente paliativo no oncológico ingresado en HADO es la insuficiencia respiratoria crónica. La principal unidad de derivación es Medicina Interna. La patologia con mayor número de reingresos es la hepatopatia crónica avanzada. El exitus ocurre en domicilio en un amplio porcentaje de pacientes, sin embargo en ciertas patologías como en la insuficiencia respiratoria crónica el desenlace fatal sucede predominantemente en medio intrahospitalario. Parece importante incidir en la planificación de cuidados avanzados en patologías como EPOC terminal y hepatopatía crónica con el objetivo de reducir ingresos hospitalarios.

\section{ESTUDIO DE PACIENTES PALIATIVOS ONCOLÓGICOS EN UNA UNIDAD DE HOSPITALIZACIÓN A DOMICILIO}

Ríos Prego M, Velo-García A, Canitrol López A, Fernández González A, González Fermández D, De La Calle Otero A, Atienza Pintos A, Varela Vaamonde JA

MEDICINA INTERNA. HOSPITALIZACIÓN A DOMICILIO, COMPLEXO HOSPTTALARIO DE PONTEVEDRA.

INTRODUCCIÓN: La Hospitalización a Domicilio (HADO) es un modalidad de ingreso que ha ganado mportancia en los últimos años. Dentro de la gran cantidad de patologías que abarca un importante porcentaje de los pacientes son los que precisan cuidados paliativos. En este grupo de enfermos destacan os pacientes paliativos oncológicos que cada vez más se derivan para seguimiento domiciliario. OBJETIVOS: Con el presente trabajo pretendemos analizar a los paciente paliativos oncológicos hospitalizados en HADO en el área sanitaria del Complexo Hospitalario de Pontevedra (CHOP) durante el 2014. Conocer las patología oncológicas más prevalentes que son derivadas a dicho Servicio, el número de pacientes que reingresan y el motivo por el que esto sucede, cuantos de ellos precisan derivación a la Unidad de Cuidados Paliativos (UCP) y finalmente donde sucede el éxitus.

MATERIAL Y MÉTODOS: Estudio descriptivo retrospectivo observacional en el que se analizan los pacienes hospitalizados en HADO entre el 1 de Enero de 2014 y el 31 de Diciembre de 2014 en el CHOP. Para análisis estadistico empleamos el paquete estadistico SPSS 15.0.

RESULTADOS: 382 pacientes fueron hospitalizados en HADO ente el 1 de Enero de 2014 y el 31 de Diciembre de 2014. De entre ellos 181 eran pacientes paliativos, siendo el 81,8\% paliativos oncológicos y $18,2 \%$ paliativos no oncológicos. Entre los pacientes paliativos oncológicos la edad media era de $73,8 \pm 17,8$ días y la distribución por sexos fue de $56,8 \%$ varones y $43,2 \%$ mujeres. El tiempo medio de hospitalización fue de 27,5 32,4 días (mediana 16). El 30,4 \% de los pacientes fueron derivados directemente de Oncología mientras que el 28,7\% procedian directamente de la UCP el $4,9 \%$ de Digestivo el $4.9 \%$ de Medicina Interna. Un 31,1\% se repartió ampliamente entre otras especialidades (cirugía vascular cardiología neurología. .). El 43,3\% de los pacientes precisaron reingreso produciéndose en Su mayor parte en la UCP $(78,6 \%)$ mientras que solo el 21,4\% reingresó en su Servicio de referencia. Los motivos de reingreso más frecuentes fueron mal control de síntomas $(52,7 \%)$, seguido de: claudicación amiliar $(21,4 \%)$, delirium $(7,1 \%)$, mal control del dolor $(5,7 \%)$, disnea $(5,7 \%)$ y otros $(7,4 \%)$. El exitus durante el período de seguimiento se produjo en el $85,8 \%$ de los pacientes. Un $48 \%$ de los pacientes falleció en HADO mientras que el 41,7\% falleció en la UCP, el 4,7\% en Oncología y el 5,6\% en otros servicios. CONCLUSIONES: Los pacientes paliativos oncológicos son una parte importante de la hospitalización en a Unidad de HADO. Un porcentaje elevado de dichos pacientes son derivados directamente de Servicios distintos a la UCP (predominantemente de Oncología). El porcentaje de reingresos es considerable, siendo la mayor parte de ellos debidos a mal control sintomático o claudicación familiar. Con dichos datos parece interesante una formación adecuada de los Servicios de HADO en el manejo complejo del paciente paliavo oncológico puesto que forma parte del dia a dia de la hospitalizacion.

\section{FIBROSIS RETROPERITONEAL POR ERGOTAMINA CON EVOLUCIÓN} POSTERIOR A LINFOMA

Baroja A, Argibay A, Val N, Vilas B, Rodríguez A, Martínez A, Villaverde I, Rivera A.

MEDICINA INTERNA, HOSPITAL XERAL-CIES NIGO).

INTRODUCCIÓN: La fibrosis retroperitoneal (FR) es una entidad clínica poco frecuente (aproximadamente 0.1 por cada 100000 personas/año). Se caracteriza por la presencia de inflamación y fibrosis a nivel 
peritoneal, que frecuentemente engloba a uréteres y grandes vasos abdominales. Puede ser idiopática 0 secundaria a otras causas (fármacos, tumores, radioterapia, cirugía, infecciones). Dentro de las neoplasias, los linfomas deben estar presentes en el diagnóstico diferencial, pero también en la evolución de esta enfermedad.

OBJETIVOS: Destacar la aparición de linfoma, en la evolución de una FR secundaria a ergotamina con buena evolución clínica tras tratamiento.

MATERIAL Y MÉTODO: Presentación del caso clínico y revisión de la literatura.

RESULTADOS: Varón de 57 años que ingresó por síndrome constitucional, presentando en la tomografía computerizada una masa retroperitoneal que producía uropatía obstructiva derecha. Tras realizar estudio completo sin identificar causa, se realizó exploración laparoscópica con biopsia intraoperatoria en la que se evidenció inflamación aguda y crónica a nivel del uréter. En un segundo tiempo se ejecutó nefrectomía laparoscópica derecha sin evidenciarse malignidad en el estudio histológico. En el interrogatorio dirigido, reconoció toma de ergotamina por migrañas desde hacía 30 años. A pesar de la suspensión de dicho fármaco, la RMN de control no evidencio una gran mejoria por lo que se inicio tratamiento con prednisona y colchicina. Con dicha medida se observó una franca mejoría radiológica con práctica desaparición de las múltiples adenopatías y de las alteraciones de señal retroperitoneales visualizadas en estudio previo. Tras retirada de tratamiento y seguimiento de 2 años se objetivó en RMN de control claro empeoramiento radiológico y aparición de adenopatías retroperitoneales. Fue ingresado para estudio, reconociendo cuadro constitucional de 2 meses de evolución. En la exploración física destacaban adenopatías latero-cervicales bilaterales aisladas y supraclavicular derecha. La biopsia de una de las adenopatías dio el diagnóstico final de linfoma folicular grado 3a estadio IIIA, iniciando tratamiento quimioterápico por parte del servicio de Hematología.

CONCLUSIONES: Una vez establecido el diagnóstico de FR y a pesar de tener una etiología clara conocida, es importante una vigilancia clínica estrecha, tanto para observar la respuesta al tratamiento como para descartar una neoplasia hematológica asociada.

\section{FIEBRE TIFOIDEA EN EL HOSPITAL DEL SALNES}

García $\mathcal{C C}^{1}$, Núñez $\mathrm{MJ}^{1}$, Martínez $\mathrm{J}^{2}$, Rodrígez $M$

MEDICINA INTERNA' Y MICROBIOLOGI'A2, COMPLEJO HOSPITALARIO UNIVERSITARIO DE PONTEVEDRA.

INTRODUCCIÓN: La fiebre tifoidea era endémica en nuestra área; en 1995 Salmonella typhi era el segundo bacilo gamnegativo en frecuencia en los hemocultivos del servicio de Medicina Interna del Hospital Montecelo. En años posteriores su incidencia disminuyó

OBJETIVOS: Descripción de los casos de fiebre tifoidea en el Hospital del Salnés en 12 años.

MÉTODOS: -Estudio retrospectivo de los casos de fiebre tifoidea desde el 1 de Enero de 2002 hasta el 31 de Diciembre de 2013. Se incluyeron los casos en que S. typhi se aisló en los hemocultivos. 4- Resultados. -Se diagnosticaron 24 casos. El 58\% fueron mujeres. Edad media (DE) de 38,5 (17,2) años. La mayoría se acumularon en 3 concellos del área. Ninguno caso fue importado. Fuente de adquisición: ingestión de moluscos 33\%, consumo de agua no potabilizada $17 \%$ y $50 \%$ fuente desconocida. Formas de presentación: síndrome febril (42\%), síndrome entérico (54\%) y un caso de colecistitis aguda litiásica. Complicaciones en 17\% pacientes. Análisis: leucocitos normales o leucopenia (96\%), eosinopenia (83\%) e hipertransaminasemia (100\%). Hemocultivo positivo en el primer dia de incubación en el $75 \%$. Hemocultivos positivos 2,4 por paciente. Coprocultivo: 15 casos (63\%), positivo en 2 (8\%). Todos los aislados sensibles a Amoxicilina, TMP/SMX y Ciprofloxacino. Ingresaron el $77 \%$, en Medicina Interna $67 \%$. Estancia media(DE) $6,64(3,67)$ dias. 91\% de adultos tratados, la mayoría con quinolonas. Dos pacientes no recibieron tratamiento. El caso pediátrico tratado con TMP/SMX. Un éxitus por causa no relacionada. 2 casos evolución desconocida. El 95\% se curó y no hubo fracasos terapeúticos ni recidivas.

CONCLUSIONES: Los datos muestran alta incidencia, valores hasta 40 veces superiores a la tasa nacional. La disminución posterior indica una base endémica y se ha producido un brote epidémico que afectó a 3 ayuntamientos de la costa muy próximos geográficamente y cuyo origen parece una avería de una depuradora de aguas fecales (figura). Los casos asociados a moluscos (33\%) y la ausencia en ayuntamientos alejados del foco avalan la hipótesis. La endemicidad viene corroborada por la propia infección, la presencia de un caso de portador crónico y la ausencia de casos importados. La clínica típica, y análisis muy sugerentes condujeron a un diagnóstico y a un tratamiento adecuado. El rápido crecimiento en hemocultivo y la escasa rentabilidad del coprocultivo indican una fase precoz de la enfermedad. El gérmen fue sensible a todos los antibióticos habituales. Lo anterior explica la baja tasa de complicaciones y la ausencia de mortalidad. El manejo en fase aguda fue adecuado pero no se hizo seguimiento adecuado para detectar portadores crónicos. Éste hecho y la reaparición de casos en 2013 debe mantenernos alerta. Fallo manifiesto en los mecanismos de control epidemiológico. Debemos tener presente esta enfermedad en el diagnóstico diferencial de síndromes febriles con/sin manifestaciones digestivas.

\section{FLEGMASIA CUTÁNEA DOLENS COMO MANIFESTACIÓN DEL SÍNDROME DE MAY THURNER}

García Poutón N, Novoa Lamazares L, Arca Blanco A, Rodríguez Arias M, Puerta Louro R, González Vázquez L, De la Fuente Aguado J.

MEDICINA INTERNA, POVISA.

INTRODUCCIÓN: La trombosis venosa profunda secundaria a compresión de la vena ilíaca izquierda por la arteria ilíaca derecha sobre la columna vertebral se conoce como Síndrome de May-Thurner. Es una entidad infrecuente que debe sospecharse en mujeres jóvenes con trombosis venosa profunda proximal, predominantemente izquierda, sin factores de riesgo conocidos

OBJETIVOS: Descripción de dos casos de TVP secundario a compresión de la vena ilíaca, importancia diagnóstica y discusión de tratamiento.

MATERIAL Y MÉTODOS: Presentamos dos casos clínicos de dos mujeres de mediana edad con trombosis venosa profunda que se manifiesta como flegmasía cutánea dolens secundaria a síndrome de May-Thurner.

RESULTADOS: El primer caso es una mujer de 46 años que acude por clínica de tumefacción y dolor en miembro inferior izquierdo. Entre los antecedentes destaca la existencia de un mioma uterino. La exploración física es normal salvo frialdad, palidez y disminución de los pulsos femorales en el miembro afectado. Se realizó ecografía doppler que mostró trombosis de la vena ilíaca primitiva, iliaca externa y femoral profunda. La flebografía que se realiza posteriormente muestra trombosis venosa extensa. El segundo caso se trata de una mujer de 52 años que en 2006 había presentado una TVP por lo que recibió HBPM a dosis infraterapéuticas durante 2 meses, y acude por tumefacción aguda de miembro inferior izquierdo aunque con dolor de más de 1 mes de evolución. Asocia, a la exploración física, aumento de perímetro del miembro, palidez y disminución de los pulsos femorales. Se solicita ecografía dopple que evidencia trombosis de la vena ilíaca primitiva, líaca externa, femoral profunda y femoral superficial. En ambos casos, se inicia anticoagulación con HBPM a dosis terapéuticas previa realización de trombolisis con Alteplasa mediante abordaje con catéter con colocación de filtro de vena cava retraíble. Tras una excelente respuesta fibrinolítica en las primeras 24 hora todavía se observa la oclusión de la vena ilíaca primitiva, con abundante circulación colateral. Ante este hallazgo, se procede a angioplastia con catéterbalón y colocación de stent autoexpandible, con resolución total de la clínica sin incidencias durante la primera intervención ni en la siguiente, destinada a la retirada del filtro de vena cava

CONCLUSIÓN: La TVP secundaria a compresión de la vena ilíaca femoral es un hallazgo infradiagnosticado que puede manifestarse de manera aguda, como en nuestro caso, o crónica. El tratamiento óptimo es la trombolisis guiada por catéter, asociada a la implantación de stent y pauta de anticoagulación oral ya que demostró excelentes resultados en prevención del síndrome postrombótico y el reflujo valvular, si se compara con la anticoagulación como tratamiento único.

\section{HOSPITALIZACIONES MOTIVADAS POR BRONCOPATIA CRONICA EN PACIENTES CON INFECCION POR VIH. ESTUDIO DESCRIPITIVO EN EL PERIOD0 1993-2013}

Suárez $R^{\dagger}$, Clavero $E^{\dagger}$, Meijide $H^{1-2}$, Mena $A^{1}$, Rodríguez-Osorio ${ }^{1}$, Castro $A^{\dagger}$, Pernas $B^{1}$, Poveda $E^{\prime}$, Pedreira $J D^{1}$

GRUPO DE VIROLOGÍA CLINICA'. INIBIC. SERVICIO DE MEDICINA INTERNA. CHUAC. SERVICIO DE MEDICINA INTERNA², HOSPITAL QUIRON A CORUNNA, CHUAC.

INTRODUCCIÓN: La introducción del tratamiento antirretroviral y las características epidemiológicas del paciente VIH han modificado el perfil de las hospitalizaciones en esta población en los últimos años. El objetivo del presente estudio es analizar los ingresos motivados por broncopatía crónica de nuestra área asistencial en los últimos 20 años.

MATERIAL Y MÉTODOS: Se recogieron todos los ingresos de pacientes con infección por VIH en el Complejo Hospitalario Universitario de A Coruña (CHUAC) en el periodo 1993-2013, mediante la herramienta de codificación CIE-9. Se analizaron las características clínicas y epidemiológicas, el tipo y motivo de ingreso, el ingreso en UCl, la estancia media, el reingreso a los 30 días y la mortalidad durante el ingreso. Se analizaron los ingresos motivados por broncopatía crónica. Las variables cualitativas se expresaron como porcentajes y las cuantitativas como media $\pm S D$ o mediana (IQR). Se utilizó el paquete estadístico SPSS 16.0.

RESULTADOS: Se registraron un total de 6917 ingresos que corresponden a 1937 pacientes (75 \%varones, edad media 36+11,27\% coinfectados VIH VHC) con una media de 4 ingresos por paciente en todo el periodo; de ellos, 346 (75\% ocurrieron en el segundo periodo 2003-2013) correspondieron a hospitalizaciones motivadas por broncopatía crónica en un total de 118 pacientes, con una media de casi 3 ingresos/paciente. Respecto a las caracteristicas principales, el $73 \%$ eran varones, edad media $43 \pm 10$ años, $55 \%$ coinfectados VHH-VHC, $56 \%$ categoría CDC-C. Sólo un $8 \%$ tenían realizadas pruebas de función respiratoria. El $80 \%$ de ellos precisó ingreso no programado, con una estancia media de 8,6 $\pm 9,3$ días; el 23\% tuvo un reingreso en los 30 días siguientes al alta. El 1,7\% ingresó en UCl. Se objetivó un $2 \%$ de mortalidad intrahospitalaria.

CONCLUSIONES: 1- La mejora en el tratamiento de la infección por VIH supone un notable incremento en las hospitalizaciones motivadas por enfermedades crónicas, entre ellas, la broncopatía crónica. 2- La edad de presentación es menor que la población general, en probable relación con un elevado consumo de tabaco. 3- El predominio de las hospitalizaciones en la última década, la estancia media que suponen y los reingresos derivados hacen que esta entidad cobre más relevancia y suponga un elevado consumo de recursos en esta población. 4- Teniendo en cuenta el infradiagnostico de EPOC en población general, la elevada prevalencia de tabaquismo entre población VIH y la baja proporción de pacientes con espirometría realizada, detectamos un área de mejora tanto en el diagnostico como en el tratamiento de estos pacientes.

\section{ICTUS ISQUÉMICO EN PACIENTE JOVEN}

Álvarez Otero J, Enriquez Gómez H, Sánchez Conde P, Sanjurjo Rivo A, Paz Ferrín J, De la Fuente Aguado J. MEDICINA INTERNA, POVISA.

INTRODUCCIÓN: El ictus isquémico es una patología grave que condiciona una mortalidad y morbilidad muy elevadas. En el paciente joven las causas son más diversas, por lo que hay que realizar los estudios adecuados para establecer la etiología y el tratamiento preciso.

OBJETIVOS: El objetivo de este estudio fue determinar las características de los pacientes jóvenes con ictus isquémico, así como su manejo y tratamiento.

MATERIAL Y MÉTODOS: Estudio descriptivo y retrospectivo en el que se incluyeron pacientes menores de 55 años que presentaron un ictus isquémico durante el año 2014. Se recogieron las siguientes variables: edad; sexo; comorbilidades: hipertensión arterial, dislipemia, diabetes mellitus, insuficiencia cardíaca, fibrilación auricular y valvulopatía. Se analizó la etiología y el tratamiento prescrito.

RESULTADOS: Se incluyeron 27 pacientes con edad media de 49,78 años y predominio de varones del $66,7 \%$. Un 44,4\% presentaban HTA, 40,7\% dislipemia, 25,9\% diabetes mellitus, fibrilación auricular $7,4 \%$ y valvulopatía $3,7 \%$. El $63 \%$ era fumadores y el $51,8 \%$ consumidores de alcohol. En el $51,9 \%$ de los pacientes la localización fue en la arteria cerebral media. A todos los pacientes se le realizó TC cerebral y al $64 \%$ se le realizó también RM cerebral. El origen más frecuente fue el aterotrombótico en 17 pacientes seguido aunque en menor frecuencia de disección carotídea (4 pacientes), indeterminado ( 3 pacientes), cardioembólico (2 pacientes) y síndrome antifosfolíido (1 paciente). A dos pacientes se le realizó fibrinolisis y al alta 15 pacientes recibieron tratamiento con AAS, 7 con clopidogrel y 4 con acenocumarol. Al alta presentaban focalidad residual el $59,3 \%$ de los pacientes. No se observaron muertes ni durante el ingreso ni al mes de seguimiento.

CONCLUSIONES: La causa más frecuente de ictus en los pacientes menores de 55 años es aterotrombótica, por lo que es imprescindible un adecuado control de los factores de riesgo cardiovascular. № obstante, debemos tener en cuenta también en este grupo de pacientes otras etiologías poniendo especial atención en la disección carotídea que supone hasta un $15 \%$ de los paciente estudiados.

\section{INFECCIÓN POR CLOSTRIDIUM TETANI, LA DEBEMOS SOSPECHAR PARA DIAGNOSTICAR}

Ríos Prego M, Alves Pereira ED, Brea Aparicio R, Velo-García A, Encabo González A, Núñez Fernández JM. MEDICINA INTERNA, COMPLEXO HOSPTTALARIO DE PONTEVEDRA.

CASO CLíNICO: Mujer de 96 años que acude a Urgencias por disfagia e incapacidad para el cierre mandibular. Como antecedentes personales presenta HTA, fibrilación auricular anticoagulada con sintrom y artrosis generalizada. Intervenida de prótesis en ambas rodillas y prótesis total de cadera derecha como consecuencia de una fractura. Presenta 5 días de evolución de disfagia para líquidos y sólidos con atragantamientos constantes y afonía. Refiere cefalea holocraneal, opresión en región inframandibular, con dificultad para girar el cuello y la apertura-cierre mandibular. Refiere que 15 días antes tuvo un traumatismo craneoencefálico y se realizó una herida incisa en $1^{\circ}$ dedo de mano derecha. A la exploración física, destaca la ausencia de pulso en la arteria temporal izquierda, lengua de diámetro aumentado, limitación de la movilidad cervical, articulación témporo-mandibular con limitación de la apertura y cierre, trismus (Figura 1), ligera disartria. Reflejos osteotendinosos débiles simétricos, reflejo cutáneo plantar flexor bilateral. № alteración de coordinación. Auscultación pulmonar con crepitantes finos bibasales. Auscultación cardíaca arrítmica y soplo sistólico aórtico. En la extremidades presenta herida incisa $1^{\circ}$ dedo de mano derecha, edemas por insuficiencia venosa crónica. A su ingreso se realiza fribroscopia, en la que se observa cuerda vocal izquierda con lesión de aspecto polipoide y granulomatosa, hipersialorrea a nivel de faringe, hipertrofia lingual. Se realiza un TAC de cuello con contraste en el que no se observan adenopatías laterocervicales ni masas captantes de contraste que sugieran abscesos, y una radiografía de tórax aumento de tamaño de la silueta cardopericárdica asociada a prominencia hiliar, compatible con incipiente descompensación. Con la presentación clínica del proceso, el antecedentes de herida incisa en primer dedo de mano derecha, y los datos exploratorios previos, la principal sospecha fue una infección por C. tetani. A las 48 horas del ingreso hospitalario, la paciente presenta deterioro progresivo, con aumento del dolor generalizado y de la insuficiencia respiratoria, progresivamente hasta producirse el exitus. 
DISCUSIÓN: Enfermedad muy prevalente en países en vías de desarrollo, presentando una menor incidencia en los países industrializados. Para el diagnóstico cobran especial interés la exploración fisica anamnesis, y el diagnóstico de exclusión de otras entidades (tabla 1). El cultivo de C. tetani posee poca sensibilidad y especificidad, por lo que en la mayoría de las ocasiones el diagnóstico se realiza en base a lo inicialmente comentado. Se trata de una enfermedad que presenta una mortalidad en torno $40 \%$ (sobre todo el tétanos generalizado), la causa más frecuente de muerte es la insuficiencia respiratoria secundaria a la afectación de la musculatura laríngea y respiratoria. La gravedad de la enfermedad suele variar en función de la cantidad de toxina que alcance el sistema nervioso central y niveles preexistentes de anticuerpos contra el tétanos. El tratamiento es multidisciplinar, limpieza de la herida, neutralización de a toxina no unida mediante antitoxinas (inmunoglobulina tetánica humana) y antibioterapia (metronidazo y penicilina). La baja prevalencia de la enfermedad en los países industrializados, y el no poseer un técnica diagnóstica precisa, dificultan el diagnóstico. Siendo por tanto una patología debe sospecharse para alcanzar un diagnóstico precoz.

\section{INFECCION POR ERYSIPELOTHIX RHUSIOPATHIAE: UNA MANIFESTACIÓN POCO FRECUENTE}

Suárez Fuentetaja R, Verdeal Dacal R, Sánchez Vidal E, Castelo Corral L, Seonae González AB, Rey Fariña S, Pérez Piñeiro A.

MEDICINA INTERNA INFECIOSOS, CHUAC

INTRODUCCIÓN: Erysipelotrix rhusiopathiae es un bacilo Gram positivo patógeno en numerosos animales, tanto terrestres como acuáticos. El ser humano adquiere la infección por lesión cutánea tras manipulación de productos animales. Existen tres tipos de manifestaciones clínicas de la infección por manipulación de productos animales. Existen tres tipos de manifestaciones clínicas de la infección por con toxicidad sistémica, y bacteriemia asociada o no a endocarditis (EI) ( se asocia en un 90\%). Tras revisión de la literatura reciente especializada hemos comprobado que existe cerca de una decena de casos de El por E. rhusiopathiae publicados. La El por E. rhusiopathiae suele afectar a válvula nativa, con especial predilección por la válvula aórtica(VAo), presentando una alta capacidad de destrucción local. De hecho hasta un tercio de los casos requiere remplazo valvular. Su carácter agresivo incrementa la tas de mortalidad con respecto a El por otros microorganismos. La penicilina es el tratamiento de elección. MATERIAL Y MÉTODOS: Descripción de un caso clínico y revisión de la literatura al respecto.

RESULTADOS: Varón de 71 años, diabético, que ingresa para estudio de síndrome general de 4 meses de evolución. Presentó 2 picos febriles de $38^{\circ} \mathrm{C}$ en su domicilio, junto con tiritona. En la anamnesis por aparatos niega cuadro infeccioso asociado. La exploración física de ingreso es rigurosamente normal, a excepción de un soplo en foco mitral 2/6. Analiticamente presenta Hb de 10, PCR de 7. 28 y VSG de 120, sin otros hallazgos destacables. A las 48 horas del ingreso los hemocultivos (2/2) son positivos para E, rhusiopathiae, iniciándose tratamiento con Penicilina G Sódica a dosis de 3 MU/4h (CMI 0. 016) En el ETT a las 72 horas del ingreso se objetiva una insuficiencia trivial en vAo y mitral (VM) sin evidencia de vegetaciones. Al sexto día de ingreso se realiza ETE en el que se describe la presencia de imágenes compatibles con vegetación en vAo y vM, generando una insuficiencia 2/4 en ambas válvulas. En el día 20 de evolución se infiere progresión de la insuficiencia valvular M por la auscultación, confirmándose tras nuevo ETT donde la IM progresa de 2/4 a 3/4. Según criterios de Duke el paciente presenta una El posible (criterio mayor ecográfico, criterios menores microbiológico y fiebre). Tras realizar una nueva anamnesis dirigida el paciente recordaba que hacía cinco meses había presentado una lesión eritematosa en un dedo, con resolución espontánea. Epidemiológicamente no presentaba factores de riesgo para infección por E. rhusopathiae (exposición ocupacional)

CONCLUSIONES: Se trata de una infección infrecuente que se manifiesta en su forma más grave en un paciente sin factores predisponentes para la mism

Cabe destacar por ello la realización de estudios complementarios, en este caso, hemocultivos, que permitan el diagnóstico microbiológico ante un cuadro febril con sospecha de infección subyacente.

\section{INFECCIÓN POR VPH Y SUS LESIONES ASOCIADAS EN VARONES VIH POSITIVOS QUE TIENEN SEXO CON HOMBRES}

ocampo A, Iribarren M, Longueira $R$, Labajo L, Rodríguez S, Pazos MC, Rivera $A$

MEDICINA INTERNA, CIRUGÍA GENERAL, COMPLEJO HOSPITALARIO UNIVERSITARIOS DE VIGO.

INTRODUCCIÓN: La infección crónica por VPH se ha relacionado de forma directa con la aparición de lesiones preneoplásicas y neoplásicas a nivel anal. Los hombres que tienen sexo con hombres (HSH) tienen una alta prevalencia de infección por VPH, que asciende hasta el $92.6 \%$ en los pacientes VIH positivos. OBJETIVOS: Determinar la prevalencia de VPH, alteraciones citológicas e histológicas en nuestros pacientes con infección por VIH y HSH, así como las características basales de este grupo de riesgo.

MATERIAL Y MÉTODO: Se seleccionaron de forma aleatoria a pacientes HSH con infección por VIH con seguimiento en la consulta de VIH del Hospital Xeral, que firmaron el consentimiento informado. Se recogieron distintas variables sociodemográficas, y se tomaron muestras anales en medio líquido para citología y determinación de VPH mediante PCR. A aquellos pacientes en los que se detectaron alteraciones citológicas y/o VPH se les realizó anoscopia de alta resolución, con biopsia de las lesiones acetoblancas lugol negativas.

RESULTADOS: Se seleccionaron a 256 pacientes, con una edad media de 43 años. La edad media de icio de las relaciones sexuales fue de 18 años, con una mediana de compañeros sexuales hasta la fecha de 50 (1-5000) y en el último año 2 parejas. La media del recuento de CD4 fue de 688/ml en el momento del estudio y una cifra nadir de 370/ml. En el momento del estudio un 57\% presentaban carga viral <20. El tiempo medio de evolución del VHH fue de 5.8 años. El VPH se identificó en el $85.5 \%$ de los pacientes, en su mayoría con infección por un serotipo, con más de 2 serotipos en al menos el 60 . $7 \%$ de los pacientes. En el $40.1 \%$ de las muestras estaba presente el VPH 16, en el 18. 2\% el VPH 18 y en el $82.2 \%$ de los casos algún otro serotipo de alto riesgo. El estudio citológico mostró alteraciones en el 48. $9 \%$ de los pacientes, con la siguiente distribución: ASCUS 21. 3\%, LSIL 21.7\%, HSIL 6\%. Se realizó biopsia anal al $55 \%$ de los pacientes. De entre estos, los hallazgos más frecuentes fueron de lesión histológica de bajo grado (AIN 1 en el 41.3\%), seguido de biopsia normal (31.2\%) y lesión de alto grado 26. 6\%, con una distribución de 22. 9\% de AIN 2, 3.7\% de AIN 3). En un caso se obtuvo resultado de carcinoma infiltrante $(0.9 \%)$

CONCLUSIONES: L a prevalencia de VPH de alto riesgo a nivel anal en nuestros pacientes $\mathrm{HSH}$ y VIH positivos es elevada, a pesar de presentar buen control viral e inmunológico. En la mayoría de los casos está presentes varios serotipos simultáneamente. Las alteraciones citológicas son frecuentes, con predominio de alteraciones de bajo grado. El elevado porcentaje de alteraciones histológicas en las biopsias realizadas pone de manifiesto la necesidad de instaurar protocolos de actuación para despistaje de lesiones preneoplásicas en este grupo de pacientes.

\section{LA CARDIOPATÍA ISQUÉMICA EN PACIENTES CON INFECCIÓN POR \\ VIH: 20 AÑOS DE SEGUIMIENTO}

Clavero $E^{1}$, Osorio $\mathbb{R}^{1-2}$, Mena $A^{1-2}$, Meijide $H^{1-3}$, Castro $A^{1-2}$, Permas $B^{1-2}$, Suárez $R^{1}$, Verdeal $R^{1}$, Poveda $E^{2}$ Domingo Pedreira $J$

SERVICIO DE MEDICINA INTERNA', CHUAC. GRUPO DE VIROLOGÍA CLÍNICA², INIBIC-CHUAC. SERVICIO DE MEDIC NA INTERNA3 , HOSPITAL QUIRÓN A CORUÑA, CHUAC.
INTRODUCCIÓN: El TARGA ha modificado el pronóstico de la infección por VIH, siendo en la actualidad las enfermedades no SIDA las de mayor prevalencia. El objetivo del estudio es evaluar los ingresos por cardiopatía isquémica (Clsq) en una cohorte de pacientes VIH+.

MATERIAL-MÉTODOS: Estudio de cohortes retrospectivo realizado en un hospital de tercer nivel entre 1993-2013. Se recogen variables demográficas, clínicas y analíticas al ingreso y un año después. Se realiza un análisis descriptivo y se compararon las variables recogidas con test Chi2/t-Student según corresponda.

RESULTADOS: Se analizan 74 ingresos que corresponde a 54 pacientes. El 17\% presentan un re-evento, la media de tiempo a reingreso fue 8,30 meses. El $38 \%$ fallecen, mediana de tiempo a muerte: 2,8 años D. La incidencia fue de 3,2 casos por cada 1000 pacientes en seguimiento/año, suponiendo un $1 \%$ de os ingresos de los pacientes $\mathrm{VIH}+$. La edad media fueron $49+12$ años y un $82 \%$ eran varones. El $68 \%$ recibían TARGA, presentan carga viral indetectable un 61\% y la mediana de CD4 fue 507 (356-866) cél//LL. El 23\% eran coinfectados VHC. Las características desde el punto de vista factores de riesgo cardiovascular (FRCV) y del evento se describen en la Tabla1.

Se comparan los FRCV en el momento de ingreso y al año: objetivando diferencias estadísticamente significativas desde el punto de vista lipídico y glucémico, Tabla 1.

CONCLUSIONES: La Clsq supone un total del 1\% de los ingresos de los pacientes con infección por VIH en seguimiento. La presencia de reevento fue de hasta un $17 \%$ pese a un mejor control de FRCV y buen control inmunovirológico. En esta población, además de los FRCV, existe un efecto proinflamatorio por la propia infección por VIH. La mortalidad en estos pacientes es elevada (38\%), sería adecuado intentar establecer estrategias de prevención primaria

\section{LA MAPA: UTILIDAD EN EL DIAGNÓSTICO, AJUSTE FARMACOLÓGICO Y CONTROL EVOLUTIVO DE LA HTA}

Ríos Prego $M^{1}$, Velo-García $A^{\dagger}$, Encabo González $A^{\dagger}$, Alves Pereira ED, Brea Aparicio $R$, Martínez Muradás AJ ${ }^{12}$. SERVICIO DE MEDINA INTERNA', COMPLEXO HOSPTALARIO UNIVERSITARIO DE PONTEVEDRA (CHOP). CONSULTA DE RIESGO CARDIOVASCULAR ${ }^{2}$ COMPIEXO HOSPITALARIO UNIVERSTARIO DE PONTEVEDRA, COMPLEJO HOSPITALARIO UNIVERSITARIO DE PONTEVEDRA.

La monitorización ambulatoria de la presión arterial (MAPA), es una técnica fundamental en una consulta de riesgo cardiovascular, de gran utilidad para el reconocimiento de HTA de bata blanca, el patrón nodipper y su relación con el aumento del riesgo cardiovascular, la resistencia a fármacos; así como su importante valor en la optimización de la tensión arterial.

OBJETIVO: Estudio de las características epidemiológicas y clínicas de las MAPA realizados en la consulta de riesgo cardiovascular del $\mathrm{CHOP}$.

MATERIAL Y METODOS: Estudio descriptivo retrospectivo observacional, 61 MAPA realizadas en la consulta de riesgo cardiovascular del $\mathrm{CHOP}$ durante 3 meses. Variables: características sociodemográficas, enfermedad cardiovascular previa, diabetes mellitus, factores de riesgo cardiovascular, tipo y patrón circadiano de HTA; implicación de la realización de la MAPA en el ajuste terapéutico y número de fármacos para el control de la HTA

RESULTADOS: Se han realizado 61 MAPA, el 54,09\% (33) varones, edad media de 59,18 $\pm 13,81$ años. Factores de riesgo cardiovascular: el 18,03\% (11) fumadores, el 13,11\% (8) diabetes mellitus y el $57,38 \%$ (35) dislipemia. El 3,2\% (2) SAOS. EI IMC no fue registrado en 19 casos. 9 pacientes IMC normal, sobrepeso grado l: 6 pacientes, sobrepeso grado Il: 7, obesidad grado l: 14 y obesidad grado Il: 6 . El 29.5\% (18) presentaban enfermedad cardiovascular previa, 14 tenían enfermedad vascular cerebral 3 cardiopatía isquémica y 1 arteriopatía periférica. Además el 3,28\% (2) de los pacientes, padecian IRC y el $9,83 \%$ (6) microalbuminuria.

El motivo de solicitud de MAPA: mal control de la tensión arterial (24 pacientes), sospecha de HTA 20 pacientes, 7 síntomas relacionados ( 4 paciente por mareo y 3 por cefalea), 3 para seguimiento tras inicio de tratamiento, 2 tras diagnóstico de cardiopatía y en 4 ocasiones no aparecía reflejado el motivo de la petición. El Servicio que remite al paciente: 25 casos Neurología, 19 Médico de Atención Primaria, 3 Urgencias, 3 Medicina Interna, 2 Reumatología, 1 Cardiología, 1 Oftalmología y en 7 casos el solicitante era desconocido. Tipos de HTA: HTA buen control 32,79\% (20), HTA clínica aislada (bata blanca) 11,47\% (7), HTA enmascarada 0\% (0), HTA mal control 50,81\% (31) y 4,92\% (3) no presentaban HTA. El patrón circadiano de HTA del total de la muestra fue dipper $54,09 \%$ (33), non dipper 44,26\% (27), riser 1,64\% (1) y dipper extremo $0 \%$ (0). El número de fármacos necesarios para el control de la HTA en los dipper fue 1,67 y en los no dipper 1,88. A los 6 meses se reevaluó a los pacientes y el 87,75 \% presentaban buen control tras el ajuste farmacológico.

CONCLUSIONES: La MAPA permite comprobar la situación real de la tensión arterial y el patrón circadiano en los pacientes con HTA, siendo una herramienta eficaz tanto en el diagnóstico como seguimiento, así como de gran ayuda para el ajuste terapéutico

\section{LISTERIA MONOCYTOGENES, LA GRAN SIMULADORA}

Suárez Fuentetaja R Verdeal Dacal $R$ S Sánchez Vidal E Castelo Corral L.

MEDICINA INTERNA INFECIOSOS, CHUAC.

INTRODUCCIÓN: La Listeria monocytogenes es una bacilo Gram positivo intracelular de distribución universal L a infección en el ser humano tiene lugar tras la ingesta de alimentos contaminados por consumo de carne o pescado sometidos a un proceso de congelación o preparación inadecuados o de vegetales crudos y productos lácteos no pasteurizados. Generalmente estas infecciones son adquiridas en la comunidad, con predominio del sexo masculino y en edades extremas. Existen factores predisponentes como neoplasias sólidas y hematológicas, enfermedades crónicas, infección por VIH y tratamientos inmunosupresores. Sin embargo, hasta un 30\% no presentan factores predisponentes.

\section{MATERIAL Y METODO:Descripción de un caso clinico y revisión de la literatura a respecto.}

RESULTADOS: Se trata de un varón de 36 años, sin antecedentes destacables, que acude a Urgencias fuera de su área sanitaria por un cuadro de febrícula, vómitos y diarrea de 24 horas de evolución. Como antecedentes epidemiológicos de intererés refiere que su mujer e hija de 10 meses presentan un cuadro catarral. La punción lumbar (PL) muestra leucorraquia con 110 células/microlitro con predominio de PMN (60\%) consumo de glucosa y proteinorraquia: no se realiza toma de muestra para estudio microbiológico. Se administra Ceftriaxona 2 gramos derivándose al paciente a su hospital de referencia donde, 24 horas más tarde se realiza nueva PL (tras 2 dosis de cefalosporinas) que presenta 600 células con $77 \%$ de mononucleados sin consumo de glucosa, obteniéndose muestra para cultivo y estudio microbiológico. En el cuarto día de evolución el paciente persiste con fiebre de hasta $40^{\circ} \mathrm{C}$ y comienza con diplopia binocular, sin alteración de la musculatura extraocular en la exploración neurológica, junto con dismetría dedo-nariz. A las 92 horas se informa del resultado del Gram del LCR con la presencia de cocobacilos Gram positivos, iniciándose tratamiento con Ampicilina ( $2 \mathrm{gr} / 4 \mathrm{~h}$ ) y Cotrimoxazol ( 25/5 mg/ $\mathrm{Kg}$ cada 8h). Completamos estudio con RM cerebral con contraste objetivándose una lesión hiperintensa a nivel de la unión bulbo-protuberancial sugestiva de romboencefalitis. El paciente presenta una evolución clínica lentamente favorable alcanzando la defervescencia tras el inicio de antibioterpia dirigida, con tendencia a la normalización de los parámetros inflamatorios (PCR al alta 0. 14). Recibió 4 semanas de tratamiento endovenoso completando 6 semanas con Cotrimoxazol oral $(800 / 160 \mathrm{mg} / 8 \mathrm{~h})$ DISCUSIÓN y CONCLUSIONES: El motivo de presentar este caso es destacar la importancia de procesa las muestras de LCR para microbiología en el caso de infecciones graves del sistema nervioso centra (SNC). Debemos contar con la posibilidad de infección del SNC por L. monocytogenes también en pacientes inmunocompetentes y sin comorbilidad, máxime si el perfil del LCR no es concluyente. 


\section{LOS AMIGOS MÉDICOS DE CERVANTES}

\section{Montes Santiago J.}

MEDICINA INTERNA, COMPLEJO HOSPITALARIO UNIVERSITARIO:VIGO

INTRODUCCIÓN Y OBJETIVO: El IV Centenario de la $2^{\mathrm{a}}$ parte del Quijote (1615) y de la muerte de Cervantes (1616), han suscitado un renovado interés por su vida y obra. Incluso se rescataron parte de sus huesos de la Iglesia de las Trinitarias en Madrid, aunque sin poder individualizarlos de los de otras personas sepultadas junto a él. Se ha destacado, entre las cualidades de la obra cervantina, sus grandes conocimientos médicos. Aunque no fue médico, como sugirió algún biógrafo, Cervantes se relacionó con ciertos famosos galenos de su época, que son rememorados en este trabajo.

MÉTODOS: Análisis biográfico de la vida de Cervantes focalizado en su relación de amistad o conocimiento con conocidos médicos contemporáneos suyos.

RESULTADOS: Varios estudios han puesto de relieve que Cervantes poseía una amplia biblioteca, entre cuyos libros figuraban al menos 7 libros de tema médico; algunos de ellos procedentes del legado de su padre, el cirujano-sangrador Rodrigo Cervantes. Entre los médicos famosos que Cervantes frecuentó cabe citar 1. Dionisio Daza Chacón, reputado médico de Carlos V y Felipe II, autor del prestigioso tratado "Practica y Teórica de Cirujia" (Madrid 1588-92). Fue uno de los cirujanos de la Lepanto y ciertos biógrafos aseguran que pudo atender al mismo Cervantes, aunque no puede confirmarse. Es citado con admiración en "El Viaje al Parnaso". 2. Otros cirujanos que lo pudieron atender, en el Hospital de Mesina tras Lepanto, fueron López Madera, protomédico de la flota y médico personal de Carlos V, y Pedro Soriano. 3. Rodrigo de la Fuente, catedrático de Medicina en Toledo y el médico más prestigioso de dicha ciudad. Fue reclamado por Felipe II para la consulta sobre las dolencias de su hijo Don Carlos: Inmortalizado por el Greco (1589), Cervantes lo alaba en "La ilustre fregona" y es muy posible que lo tratara en la tertulia literaria que el médico mantenía en Toledo. 4. Francisco Díaz, autor del considerado primer tratado mundial de Urología, "Tratado de todas las enfermedades riñones, vexiga y carnosidades de la verga" (1588), que Cervantes poseía. Este escribió un soneto para su Prólogo y también lauda a médico en "El Canto de Calíope" 5. Aunque no se tiene constancia de que se conocieran, Cervantes se alojó en Sevilla cerca de la casa de Juan Monardes, médico sevillano destacado introductor en Europa de remedios medicinales procedentes de América, entre ellos el tabaco. 6. Alonso Pinziano, al que Cervantes probablemente trató en Valladolid, y que supervisó la edición de la $1^{\text {a }}$ parte del Quijote (1605). 6. También allí pudo conocer a Antonio Ponce de la Cruz, médico, clérigo, erasmista y catedrático de la Universidad, antes de trasladarse definitivamente a Madrid.

CONCLUSIÓN: Para escribir sus obras Cervantes demostró grandes conocimientos médicos, parte de los cuales le pudieron ser transmitidos por los textos de médicos a los que conoció o incluso por la amistad con dichos médicos célebres.

\section{LUPUS ERITEMATOSO SISTEMICO: NEFRITIS LÚPICA Y TIMOMA CONCURRENTES}

Vilas Pio B, Martínez Vidal A, Freire Dapena MC, Argibay Filgueiras AB, Rivera Gallego A, Rodríguez Gómez AM, Val Domínguez N. Baroja Basanta A.

MEDICINA INTERNA, HOSPITAL XERAL-CIES VIGO, COMPLEJO HOSPITALARIO UNIVERSITARIO DE VIGO

INTRODUCCIÓN Y OBJETIVOS: El lupus eritematoso sistémico (LES) es una enfermedad inflamatoria sistémicaque afecta a múltiples órganos y sistemas, entre los cuales la nefropatía lúpica (NL) es una afectación frecuente, presentándose habitualmente como elevación de las cifras de creatinina plasmática y proteinuria. La coexistencia de LES y timoma es infrecuente. Presentamos un caso de LES asociado a timoma y NL.

MÉTODOS: Descripción de caso clínico y revisión de la literatura.

RESULTADOS: Varón de 52 años con antecedentes de infarto agudo de miocardio en 2011, TTPA persistentemente alargado, anticoagulante lúpico positivo y ACLAs positivos a título alto, serología luética falsamente positiva en 2 ocasiones y epilepsia localizadacriptogénica. Tras un episodio de neumonía bilateral en 2014, durante el cual fue necesario realizar tomografía computarizada (TC) de tórax, fue diagnosticado de masa tímica, siendo seguido al alta en consulta de medicina interna (MI). En TC de control posterior se informaba de aumento de dicha masa, por lo que se decidió ingreso en MI para completar estudio. Al ingreso el paciente presentaba insuficiencia renal y proteinuria, ya presente en 2010 y que había ido en ascenso, estando en ese momento en rango nefrótico. Desde el punto de vista analítico destacaba 2480 leucocitos, 115000 plaquetas, TTPA 1.79, Creatinina plasmática $1.63 \mathrm{mg} / \mathrm{dL}$, Complemento bajo (C3 62 $\mathrm{mg} / \mathrm{dL}, \mathrm{C} 48.5 \mathrm{mg} / \mathrm{dL}$ ). Ac. Antinucleares positivos, patrón homogéneo, título 1/2560. Ac. Anticardiolpina $\lg G>120$, Ac. Anticardiolipina $\lg M>80$, Ac. Beta-2 glicoproteína l lgG e $\lg M>100$, proteinuria $4.84 \mathrm{~g} / \mathrm{L}$. Serologías VHB,VHC, CMV y lues negativas. Se realizó biopsia renal en la que se evidenció nefropatía lúpica clase V (membranosa) con índice de actividad de 5/24 y cronicidad de 3/12. En PET-TC se observó leve hipercaptación en celda tímica con predominio en lado derecho, sugestivo de timoma de bajo grado. Con estos datos se estableció el diagnóstico de: 1) Nefritis lúpica tipo V; 2) LES, cumpliendo 5 criterios de la ACR (hematológicos, neurológicos, nefrológicos, ANAs positivos y ACLAs positivos) 3) Síndrome antifostolípido secundario; 4) Masa tímica sugestiva de timoma de bajo grado. Se inició tratamiento con hidroxicloroquina y está pendiente de iniciar micofenolato mofetilo, estando actualmente en seguimiento en consultas externas de Ml con buena evolución. Desde el punto de vista de la masa tímica, está pendiente de intervención quirúrgica por parte de cirugía torácica.

CONCLUSIONES: La NL tipo V afecta a entre el 10 y el 20\% de los pacientes con LES y afectación renal. Típicamente se presenta con proteinuria en rango nefrótico, aunque no necesariamente con creatinina sérica elevada. El pronóstico es variable, aunque empeora si se asocian lesiones proliferativas. La concurrencia con un timoma es rara, no estando clara la influencia de la timectomía en el curso de la enfermedad.

\section{MALARIA GRAVE: ANEMIA HEMOLITIICA SECUNDARIA A ARTESUNATO}

Ríos Prego M, Alves Pereira ED, Velo García A, Brea Aparicio $R$, Encabo González A, Fernández González A, Anibarro García L.

MEDICINA INTERNA, COMPLEJO HOSPITALARIO UNIVERSITARIO DE PONTEVEDRA.

Paciente varón de 29 años, sin alergias medicamentosas conocidas ni antecedentes médico-quirúrgicos de interés. Nacido en la India, reside en Angola desde hace 15 años y realiza viajes frecuentes a Hong Kong por motivos laborales.

ENFERMEDAD ACTUAL: Acude a Urgencias de un centro hospitalario español, porque mientras realizaba con su esposa un crucero por Grecia y Turquía, el $8^{\circ}$ día de viaje, comenzó con fiebre, ictericia, dolor abdominal y diarrea sin productos patológicos. Acudió a un centro médico en Turquía, donde le realizan una analítica en la que se observa GOT 132 U/L; GPT 244 U/L; GGT 199 U/L, serología VHB y VHC negativos, gota gruesa y frotis negativos. 3 días después, el día $12^{\circ}$ de crucero, una vez finalizado éste, continúa con el mismo al cuadro clínico. Previamente había estado hacía 20 días en Hong Kong y durante los 7 días previos al viaje en Angola.

EXPLORACIÓN FISICA Y PRUEBAS COMPLEMENTARIAS: En urgencias, presenta fiebre(39), TA 93/54 $\mathrm{mmHg}$, FC 93lpm, y a la exploración física presenta hepatomegalia de 2 traveses, sin otras alteraciones significativas. Se le realiza una analítica, en la que destacan 18000 plaquetas, creatinina $1,74 \mathrm{mg} / \mathrm{dL}$, bilirrubina total $12.14 \mathrm{mg} / \mathrm{dl}$ (bilirubina directa $8.63 \mathrm{mg} / \mathrm{dL}$, bilirrubina indirecta $3.51 \mathrm{mg} / \mathrm{dL}$ ), GOT 141 U/l, GPT 163 U/L. ECG y radiografía de tórax sin alteraciones significativas, en la ecografía abdominal presenta discreta hepatomegalia. Se repite el test rápido diagnóstico de malaria, que resulta positivo, frotis y gota gruesa con parasitemia $17 \%$.

EVOLUCIÓN DURANTE EL INGRESO: Se diagnostica de malaria grave, presentando como criterios de mal pronóstico la hiperparasitemia, ictericia/transaminasemia y trombocitopenia. Se realiza ingreso en la UVI y se comenzó tratamiento con artesunato i. v. durante 3 días durante su estancia en la UVI, posteriormente, con la recuperación de la función renal, de la trombocitopenia, la tolerancia de la vía oral y la estabilidad hemodinámica, se decide el traslado a planta de hospitalización convencional, continuando el tratamiento con artemether-lumefantrina (Riamet), 4 comprimidos cada 12 horas durante 3 días.

Durante los días siguientes presenta estabilidad hemodinámica, disminución progresiva de la fiebre y de las transaminasas. En el día +7 de ingreso realiza de nuevo un pico febril $\left(38,7^{\circ} \mathrm{C}\right)$, y en el control analítico que se realiza se observa una hemoglobina 10,7 mg/dL (al ingreso 12,2mg/dL) y LDH de $1157 \mathrm{U} / \mathrm{L}$ (al ingreso $570 \mathrm{U} / \mathrm{L}$ ). Durante los días posteriores continuó con fiebre, disminución de la hemoglobina y elevación de la LDH, alcanzando en el día + 14 de ingreso el nadir de hemoglobina $(8,3 \mathrm{mg} / \mathrm{dL})$ y elevación de la LDH 1582 U/L. Se estudió la anemia hemolítica, realizándose estudio de hemólisis, autoinmunidad, Coombs e inmunofenotipo todos ellos negativos, descartándose también deficiencia G6PD. Sin cambios en la actitud clínica, 13 días después presentaba cifras de hemoglobina 10,2 mg/dL, LDH 647 U/L, bilirrubina total $2,91 \mathrm{mg} / \mathrm{dL}$ con normalización de las transaminasas, por lo que se decidió alta hospitalaria a domicilio con seguimiento posterior en consultas externas.

JUICIO CLÍNICO: Malaria grave. Anemia hemolítica secundaria a tratamiento con artesunato. CONCLUSIONES: La malaria es una patologías más frecuentes en el viajero enfermo. El artesunato es el tratamiento de elección para la malaria grave, uno de sus efectos secundarios es la anemia hemolítica tardía, es por ello necesario un seguimiento del paciente hasta 30 días posteriores al tratamiento.

\section{MANEJO HOSPITALARIO DE LA ENFERMEDAD TROMBOEMBÓLICA VENOSA, ¿LO ESTAMOS HACIENDO BIEN?}

Velo-García A, Alves-Pereira D, Encabo González A, Brea Aparicio R, García JC, Anibarro L, Núñez MJ. SERVICIO DE MEDICINA INTERNA, COMPLEXO HOSPITALARIO UNIVERSITARIO DE PONTEVEDRA.

INTRODUCCIÓN: La recomendaciones de manejo de la enfermedad tromboembolica venosa (ETV) tanto desde el aspecto diagnóstico como terapéutico están muy consensuadas, contando con numerosas guías de referencia internacional avaladas por los resultados de diferentes estudios. Sin embargo si analizamos la práctica clínica actual existen dudas acerca de si se cumplen dichas indicaciones.

OBJETIVOS: Con el presente trabajo se pretende conocer el manejo de la ETV en nuestro centro. Para ello analizaremos aspectos diagnósticos, terapéuticos y evolutivos de los pacientes diagnosticados de ETV en nuestro hospital.

MATERIAL Y MÉTODOS: Se realiza un estudio retrospectivo de 130 pacientes con el diagnóstico confirmado de ETV mediante técnicas radiológicas. Se pretende analizar aspectos de diagnóstico ante la sospecha clínica de ETV, manejo terapéutico y plan de seguimiento. Después del análisis de los datos obtenidos se obtendrá una visión global de la atención a los pacientes con ETV desde su ingreso en el Servicio de Urgencias, hasta el alta y control ambulatorio. Se excluyó a los pacientes fallecidos en el hospital y aquellos en el que se perdió seguimiento por traslado a otra área.

RESULTADOS: Se revisan 106 casos. Un 51\% mujeres y un 49\% hombres. La edad media era 66 años (mujeres 69,6, hombres 67,1). El tipo de ETV predominante era la trombosis venosa profunda (TVP) (47, 2\%) frente al tromboembolismo pulmonar (TEP) (39,6\%). La coexistencia se daba en el $13,2 \%$ de los casos. A su llegada a Urgencias se realizaba el cálculo de probabilidad pre-test en el $34 \%$ de los casos (no diferencias entre TEP y TVP); no procedió realizarlo en 7 casos (6. 6\%). Previo el inicio del tratamiento con HBPM, sólo en un $8.5 \%$ se registró el peso. La determinación de la función renal se realizaba en el $90 \%$ de los casos; la disminución de la dosis de HBPM en aquellos con insuficiencia renal moderada o recomendación de HFN cuando procedía, se realizó en el 52,4\% de los casos. Al alta hospitalaria de las TVP se indicó media de comprensión en el 21. 9\% de los casos. Los seguimientos ambulatorios de estos pacientes por parte de consultas hospitalarias (Medicina Interna, Hematología y Oncología, predominantemente) fueron planteados en el $71 \%$ de los pacientes (73,8\% de los pacientes con TEP, $66 \%$ TVP, $85,7 \%$ pacientes con coexistencia). El alta hospitalaria en las primeras $24 \mathrm{~h}$ ocurrió en 4 casos, todos ellos TVP. El control por HADO se realizó en 4 pacientes distintos a los de alta hospitalaria precoz, 2 de ellos TVP y los otros 2 TEP.

CONCLUSIONES: A pesar de que la ETV es una entidad frecuente y que cuenta con quías de recomendaciones con alto nivel de evidencia parece patente que en la práctica clínica habitual muchas de estas recomendaciones todavía no se ponen en práctica. Con este trabajo pretendemos analizar la situación actual de nuestro centro con el objetivo de realizar un protocolo y analizar su impacto en los próximos años.

\section{MEDIASTINITIS TARDÍA POSTCIRUGÍA CARDÍACA POR STAPHYLOCOCCUS AUREUS}

Verdeal Dacal R, Rodríguez García S, Suárez Fuentetaja R, Domínguez Rodríguez T, Clavero Fernández E, Llinares Mondéjar $P$. SERVICIO DE MEDIIINA INTERNA DEL COMPLEJO HOSPITALARIO UNIVERSITARIO DE A CORUÑA, COMPLEJO HOSPITALARIO UNIVERSITARIO DEA CORUÑA.

INTRODUCCIÓN Y OBJETIVOS: La mediastinitis es la inflamación e infección de las estructuras mediastínicas. Su causa más frecuente es la postesternotomía tras cirugía cardíaca. Presentamos un caso raro de mediastinitis tras una cirugía cardíaca y pericardiocentesis 3 años antes.

MATERIAL Y METODO: Descripción de un caso clínico y revisión de la literatura.

RESULTADOS: Varón de 43 años que acude por fiebre. Como antecedentes presenta válvula aórtica bicúspide, dilatación aneurismática de aorta y disección aórtica tipo $A 3$ años antes realizándose sustitución de válvula aórtica y aorta ascendente con tubo valvulado metálico. Reingresó en el mes siguiente por taponamiento cardíaco realizándose pericardiocentesis evacuadora urgente. El ETT al año siguiente a la cirugía no presenta alteraciones. Acude por fiebre de hasta $39^{\circ} \mathrm{C}$ de 5 días de evolución. Había recibido tratamiento antibiótico 4 días antes por sospecha de faringitis sin disfagia ni otra clínica a nivel cervical u otro nivel. En la exploración física sólo destaca fiebre de hasta $38,4^{\circ} \mathrm{C}$ y soplo sistólico en foco aórtico recogiéndose hemocultivos donde se aisla Staphylococcus aureus meticilin sensible (SAMS) con CMl a la vancomicina de $1,5 \mathrm{mcg} / \mathrm{ml}$ por E-test. Se inicia tratamiento con cloxacilina, gentamicina y daptomicina por sospecha de endocarditis. El paciente persiste con fiebre, dolor pleurítico al $4^{\circ}$ día de antibioterapia añadiéndose rifampicina. Se realiza ETT y ETE que no muestra lesiones a nivel valvular ni otras alteraciones, hemocultivos de control con persistencia de la bacteriemia 3 días y TC toracoabdominal que muestra múltiples colecciones encapsuladas en el mediastino anterior que se extienden a la región pretraqueal y rodean la aorta ascendente. El $8^{\circ}$ día de ingreso se realiza cirugía de drenaje visualizándose en el acto quirúrgico, colecciones mediastínicas cercanas a la aorta ascendente sin estar en contacto con la misma y que describen en el trayecto de la pericardiocentesis realizada 3 años antes con crecimiento de SAMS en el cultivo de los abscesos. El paciente presenta desde entonces buena evolución, con defervescencia, hemocultivos negativos y normalización de la PCR. Se mantienen cloxacilina, daptomicina y rifampicina 5 semanas más y posteriormente levofloxacino y rifampicina hasta completar 8 semanas. En las TC de seguimiento se observaron progresiva disminución de las colecciones mediastínicas hasta su desaparición CONCLUSIONES: La mediastinitis postesternotomía es una complicación rara con incidencia del 1-3\% y alta mortalidad. Suele manifestarse en las primeras 4-6 semanas tras la cirugía siendo tras este periodo anecdótica. Albert K. Oh et al y Domaradzki et al describieron dos casos de mediastinitis, uno por SARM, 15 y 5 años después a una cirugía de revascularización coronaria, Kaul P. et al un caso de absceso me- 
diastinico a los 12 años de una cirugia valvular aórtica y Urbanowicz et al otro caso de absceso periaórtico 9 años tras una cirugía de aorta ascendente.

\section{MIOCARDIOPATÍA DILATADA SECUNDARIA A HEMOCROMATOSIS SECUNDARIA}

Gondar Barcala T, García Poutón N, Arias Castaño JC, De la Fuente Agudado J.

MEDICINA INTERNA Y CARDIOLOGÍA, POVISA S. A.

INTRODUCCIÓN: La hemocromatosis es una enfermedad que se caracteriza por el depósito excesivo de hierro en distintos órganos. Se reconocen dos tipos: primaria y secundaria. La forma secundaria se presenta habitualmente en pacientes con anemia crónica politransfundidos. El diagnóstico precoz de la enfermedad es fundamental ya que el inicio temprano de tratamiento puede prevenir, retrasar o incluso revertir las complicaciones. Si no se trata, la hemocromatosis puede producir disfunciones orgánicas graves e incluso la muerte.

CASO CLÍNICO: Mujer 37 años que acude a nuestro centro por astenia de 2 semanas de evolución, con aparición de disnea y aumento del perímetro de miembros inferiores en los últimos 5 días. La paciente padece una anemia hemolítica en relación con eritropatología congénita no filiada. Ha recibido múltiples transfusiones y en el año 2005 es esplenectomizada a pesar de lo cual continúa precisando transfusiones. Desarrolla hemocromatosis secundaria con afectación hepática, hipofisaria y pancreática. Sigue tratamiento con insulina, anticonceptivos orales y pese a tener prescrito desferasirox reconoce no tomarlo regularmente. La radiografía de tórax solicitada en Urgencias muestra cardiomegalia y un derrame pleural bilateral. Con la sospecha de insuficiencia cardíaca (IC) por miocardiopatía dilatada secundaria a hemocromatosis, la paciente ingresa en el servicio de Cardiología. El ETT pone de manifiesto un VI dilatado, disfunción sistólica severa (FE: 33\%) y disfunción diastólica tipo 3 y la RNM cardíaca una enfermedad por depósito de hierro miocárdico. Durante el ingreso también se realiza una RNM hepática que informa de una severa enfermedad por depósito de hierro (277 micromoles Fe/g de tejido hepático). Se instaura tratamiento diurético logrando balances negativos y resolución de la semiología de IC. Precisa ser transfundida ante un empeoramiento brusco de su anemia de base Tras 14 dís de ingreso recibe el alta iniciando tratamiento con ivabradina y aumentando dosis de desferasirox. A los 7 dias reingresa por descompensación de la IC con insuficiencia hepática mixta por hígado de estasis y hemólisis. Se intensifica el tratamiento diurético e inicia corticoterapia con estabilización clínica la primera semana. Posteriormente presenta deterioro progresivo con aumento de la disnea y de los edemas sin respuesta a las medidas instauradas falleciendo por parada cardiorrespiratoria.

CONCLUSIONES: La afectación cardíaca aparece en el 15\% de los pacientes y se manifiesta con arritmias e ICC. Existen publicaciones que demuestran regresión de la afectación con el empleo de quelantes del hierro en pacientes con hemocromatosis secundaria. Aun así, el tratamiento no siempre logra detener el proceso de deterioro, incluso pese a demostrar depleción de los depósitos de hierro, la cardiopatía puede progresar, probablemente por la existencia de lesión celular irreversible por peroxidación lipídica inducida por el hierro.

\section{MONONEURISTIS MÚLTIPLE POR CITOMEGALOVIRUS EN PACIENTE} CON INFECCIÓN POR VIH

\section{ongueira R, Mouronte C, Gómez S, Ocampo A, Miralles C, Rivera A.}

SERVICIO DE MEDICINA INTERNA, COMPLEJO HOSPITALARIO UNIVERSTTARIO DE VIGO (CHUVI).

INTRODUCCIÓN: Dentro de las neuropatías asociadas a la infección por el virus de la inmunodeficiencia humana (VIH), la mononeuritis múltiple (MM) es infrecuente. Existe una forma de presentación temprana, asociada a niveles de linfocitos CD4 mayores de 200/mm3 y con buen pronóstico, y otra forma de presentación tardía, asociada a inmunosupresión severa y peor pronóstico. En esta última hay que descartar causas como linfoma, crioglobulinemia, meningitis criptocócica, toxoplasmosis, herpes zóster $y$ citomegalovirus (CMV).

OBJETIVOS: Comunicar el caso de un varón sin infección por VIH conocida que debutó con MM como forma de presentación de infección por CMV.

MATERIAL Y MÉTODOS: Descripción de un caso clínico y revisión de la literatura.

RESULTADOS: Varón de 33 años con antecedentes personales de tabaquismo y consumo ocasiona de cocaína inhalada, que consultó por cuadro progresivo de un mes de evolución de paresia en las extremidades, de predominio proximal y asimétrica, asociada a hipoestesia en hemicuerpo derecho y en miembro inferior izquierdo, así como disfonía y disfagia. En la exploración física presentaba leucoplasia oral vellosa, parálisis de cuerda vocal izquierda en abducción, marcada amiotrofia en cintura escapular bilateral de predominio derecho y reflejos osteotendinosos abolidos en miembros inferiores, con leve ataxia y aumento de base de sustentación. El paciente fue valorado por Neurología, donde se diagnostico de infección por VIH estadío B3 (infocitos CD4: 119/mm3) y MM probablemente secundaria a dicha infección, por lo que inició tratamiento antirretroviral de gran actividad (TARGA) y rehabilitación. La evolución del paciente fue desfavorable, con empeoramiento neurológico a nivel motor y dependencia para las actividades básicas de la vida diaria, y con desarrollo de fiebre, por lo que ingresó en Medicina Interna. Ante sospecha de enfermedad neurológica por CMV se realizó punción lumbar con identificación del ácido desoxirribonucleico (ADN) del virus en líquido cefalorraquídeo (LCR), con valores de 1.200 copias/m. Se instauró tratamiento con ganciclovir ( $5 \mathrm{mg} / \mathrm{kg} / 12$ horas) durante 3 semanas, constatando respuesta virológica y estabilización clínica. Se mantuvo valganciclovir (900 mg/24 horas) como terapia de mantenimiento, mostrando durante el seguimiento progresiva recuperación funcional y datos de reinervación en los estudios neurofisiológicos.

CONCLUSIONES: Aunque la MM es una forma infrecuente de presentación de la infección por CMV constituye la primera causa de esta entidad en individuos infectados por VIH con inmunosupresión severa. Suele manifestarse con déficits sensoriales y motores asimétricos, y la afectación del nervio laríngeo es frecuente. La biopsia del nervio afectado puede confirmar el diagnóstico, pero ante un caso de MM en un paciente con infección por VH avanzada, aun sin evidencia de infección por CMV, se recomienda tratamiento empírico con ganciclovir y terapia posterior de mantenimiento.

\section{MORBIMORTALIDAD EN PACIENTES A SEGUIMIENTO EN UNA CONSULTA ESPECÍFICA DE INSUFICIENCIA CARDIACA}

García-Villafranca A, Páez-Guillán E, Alende-Castro V, Macía-Rodríguez C, Mateo-Mosquera L, Bermúdez Ramos M. Martínez-Braña L, Lado Lado

MEDICINA INTERNA, COMPLEXO HOSPITALARIO UNIVERSTTARIO DE SANTIAGO DE COMPOSTELA.

INTRODUCCIÓN: La insuficiencia cardíaca es un problema frecuente en la práctica clínica habitual, de ahi a creación de unidades específicas para el manejo y seguimiento de dichos pacientes.

OBJETIVO: Analizar las características clínicas y los factores asociados a mortalidad en el seguimiento reingreso de los pacientes con insuficiencia cardíaca manejados en una consulta específica de Insuficiencia Cardíaca en el servicio de Medicina Interna.

MATERIAL Y MÉTODOS: Estudio retrospectivo en el que se incluyeron los pacientes de la consulta de Insuficiencia Cardíaca entre enero de 2007 y diciembre de 2011. Se recogieron variables epidemiológicas, clínicas y analíticas. Se realizó un estudio descriptivo y univariante para determinar los factores asociados a mortalidad durante el seguimiento y reingreso.

RESULTADOS: Se incluyeron 337 pacientes (59. 8\% mujeres) con una edad media de 79.57 .7 años. E 43. $3 \%$ de los pacientes se encontraban en clase funcional II de la NYHA. La etiología de la insuficiencia cardiaca se distribuyó de la siguiente forma: hipertensiva en el $58.6 \%$, isquémica en el $14.8 \%$, valvular en el 9. 2\%. En cuanto a la FEVI el 63\% correspondía a insuficiencia cardíaca con función sistólica conservada. La mortalidad en el seguimiento fue del $42.3 \%$, siendo la causa de éxitus más frecuente con casión el $10.8 \%$ en dos ocasiones y el $15.6 \%$ en más de dos ocasiones. L a principal causa de fin de seguimiento en la unidad fue la derivación a Atención Primaria. Respecto a la comorbilidad, las patologías más frecuentes fueron: la hipertensión arterial (81. 4\%), la fibrilación auricular (57. 1\%), la insuficiencia renal grado $3(50.5 \%$ y y la diabetes mellitus (33. 4\%). En cuanto a los factores asociados a mortalidad en el seguimiento figuran: ahorradores de potasio ( $p 0.016)$, nitratos ( $p 0.004)$, digoxina ( $p 0.007)$ y amiodarona ( $p$ 0. 011). Se asociaron a disminución de mortalidad: los diuréticos de asa ( $\mathrm{p} 0.003)$, los betabloqueantes ( $p 0.003$ ), las estatinas $(p<0,005)$, los calcioantagonistas ( 0.019$)$, los antiagregantes (p 0.033) y la anticoagulación oral (p 0.013$)$

CONCLUSIONES: Los pacientes a seguimiento en una consulta específica de Insuficiencia Cardíaca son pacientes de edad avanzada con una elevada mortalidad en el seguimiento. Los pacientes a seguimiento en una unidad específica tienen una baja tasa de reingresos en el seguimiento. Entre los factores asociados a mayor mortalidad en el seguimiento se encuentran ahorradores de potasio, nitratos, digoxina y amiodarona. Entre los factores asociados a menor mortalidad en el seguimiento son los diuréticos de asa los betabloqueantes, las estatinas, los calcioantagonistas, los antiagregantes y la anticoagulación oral.

\section{NECROSIS RETINIANA COMO MANIFESTACIÓN DE NEUROSÍFILIS EN PACIENTE VIH}

Verdeal Dacal R, De la Fuente Iglesias M, Suárez Fuentetaja R, Piñeiro Parga P Martínez Rodríguez G, Vázquez

Rodríguez P, López Calvo S.

SERVICIOS DE MEDICINA INTERNA Y OFTALMOLOGÍA DEL COMPLEJO HOSPITALARIO UNIVERSITARIO DEA CORUÑA, COMPLEJO HOSPITALARIO UNIVERSITARIO DEA CORUÑA.

INTRODUCCIÓN Y OBJETIVOS: La neurosifilis es la infección del sistema nervioso central (SNC) por Treponema pallidum. En las formas precoces las manifestaciones suelen ser meningitis y enfermedad meningovascular y en las tardías demencia progresiva, parálisis general progresiva y tabes dorsal. Presentamos un caso de coriorretinitis por sífilis en un diagnóstico nuevo de VIH

MATERIAL Y MÉTODO: Descripción de un caso clínico y revisión de la literatura

RESULTADOS: Varón de 44 años, fumador, nunca uso de drogas por vía parenteral, sin historia de enermedades oculares ni otros antecedentes de interés. Acude por clínica de disminución de visión en ojo zquierdo sin otra clínica neurológica referida. Niega rash cutáneo, lesiones genitales o secreción uretra recientes. Refiere relaciones sexuales de riesgo desde hace unos meses. Remitido 2 semanas antes a Oftalmología objetivándose en la exploración del ojo izquierdo una agudeza visual de 2/10 con presión intraocular normal. En la biomicroscopía presenta precipitados retroqueráticos finos en 1/3 inferior corneal, Tyndall ++/+++ y en el fondo de ojo áreas de necrosis retiniana temporal superior con envainamiento perivascular asociado a hemorragias intrarretinianas. En hemirretina inferior lesiones blancoamarillentas agrupadas sugestivas de coriorretinitis por sífilis (retinitis puntacta interna) y vitritis moderada. Se solicitan serologías, siendo positivas la serología de VIH y sífilis y negativas las de citomegalovirus (CMV), herpes y toxoplasma. En la exploración general destacaban adenopatías inguinales no dolorosas, sin lesiones genitales. El análisis del LCR mostró un cultivo negativo y PCR para Treponema pallidum y herpes negativas. Se pautó tratamiento con penicilina $\mathrm{G}$ intravenosa durante 14 días asociándose corticoides sistémicos para acelerar la recuperación, y se completó el estudio con RNA de VIH (39271copias/ml) y poblaciones infocitarias (CD4 447, 26\%). La evolución fue buena, con disminución importante del área de necrosis etiniana, mejoría de la vitritis y de la agudeza visual hasta 8/10

CONCLUSIONES: CMV, herpes y toxoplasmosis han sido habitualmente las causas infecciosas más frecuentes de afectación retiniana. Otros gérmenes que pueden ocasionar panuveitis son sífilis, tuberculosis, hongos... La sifilis ocular puede envolver a la mayoría de las estructuras oculares y supone el 1-2\% de las uveítis aunque su incidencia está aumentando en algunos países desarrollados. La uveítis posterio puede manifestarse de diversas formas: vitritis, vasculitis retiniana, neuritis óptica, coriorretinitis, papilitis... Los pacientes VIH con uvétís sifilitica presentan afectación del polo posterior en más del $90 \%$ de os casos, siendo bilateral en más del 50\%. Su curso suele ser más agresivo y rápidamente progresivo, con afectación más extensa y es independiente del recuento de linfocitos CD4. La retinitis necrotizante es la manifestación retiniana en algún estudio en hasta el $35 \%$ de los casos

\section{NEUMOTÓRAX ESPONTÁNEO BILATERAL ASOCIADO A TUBERCULOSIS MILIARF}

García-Viliafranca A, Alende-Castro V, Martinez-Rey C, Páez-Guillán E, Macía-Rodríquez C. MEDICINA INTERNA, COMPLEXO HOSPITALARIO UNIVERSITARIO DE SANTIAGO DE COMPOSTELA.

INTRODUCCIÓN: El neumotórax es un mecanismo de colapso pulmonar que puede llegar a supone una emergencia médica. La mayoría de ellos son espontáneos y presentan una base lesional pulmona previamente conocida.

OBJETIVOS: Aportar información clínica sobre la presentación de neumotórax bilateral recurrente en la tuberculosis miliar.

MATERIAL Y MÉTODOS: Presentación de un caso clínico y revisión de literatura.

RESULTADOS: Varón de 43 años con antecedentes personales de: eXADVP desde 2002, en programa de deshabituación con metadona; fumador de 15 cigarrillos/día y de cannabis; hepatopatía crónica por VHC tratada con Interferon hace más de 20 años; esplenectomizado por traumatismo abdominal a los 18 años y colecistectomizado por litiasis biliar en 2002. Ingresa en Medicina Interna el 21/05/14 por síndrome general. En las pruebas complementarias, al ingreso, destaca en la analítica de sangre 11. 110 Leucocitos $(89,9 \% \mathrm{~N})$, Hemoglobina $12.9 \mathrm{~g} / \mathrm{dL}$, Hematocrito $40.3 \%$, VCM 80. $6 \mathrm{fl}, \mathrm{MCH} 25.8 \mathrm{pg}$, Plaquetas 397 . 000, INR 1.39, Sodio 131.0 mmol/, GOT 64. 0 UI/L, GPT 43. 0 UI/L, GGT 114. 0 UI/L, FA 209. 0 U//L y una radiografía de tórax en la que se identifica un patrón compatible con enfermedad pulmonar micronodula difusa, siendo la primera posibilidad diagnóstica una tuberculosis miliar. Posteriormente, se confirma en esputo la positividad de BAAR y se aísla Mycobacterium tuberculosis, por lo que se inicia tratamiento tuberculostático con Isoniazida Rifamipicina Pirazinamida Etambutol. Durante el ingreso presenta episodio brusco de dificultad respiratoria, objetivándose neumotórax espontáneo derecho que tras colocación de drenaje, recurre a los dos días. Doce días después, nuevamente y de forma espontánea y brusca, presenta dolor torácico izquierdo con insuficiencia respiratoria asociada, objetivándose neumotórax izquierdo que precisa igualmente de drenaje. Como complicación añadida, tras suspender durante 48 horas la aspiración por ambos drenajes torácicos, se objetiva colapso pulmonar derecho, por lo que se procede de nuevo a conectar la aspiración. Una vez confirmada la negatividad del BAAR en esputo y, después de un mes de tratamiento tuberculostático adecuado, se retira el aislamiento. Es valorado por Cirugía Torácica quien descarta la opción quirúrgica y decide tratamiento conservador. Finalmente, el día 07/07/14, se procede a la retirada del drenaje izquierdo y se cambia el derecho, que se pinza el 08/07/14, pudiéndose retirar definitivamente dos días después, al mantenerse ambos pulmones reexpandidos en radiografías de control. Durante el seguimiento en consultas externas de la Unidad de Enfermedades Infecciosas-Medicina Interna, presenta evolución favorable, sin complicaciones posteriores al alta

CONCLUSIÓN: El neumotórax espontáneo es una complicación frecuente de la tuberculosis pulmona cavitada, no obstante, son muy pocos los casos descritos en la tuberculosis miliar y menor aún la presentación bilateral. 


\section{PANCREATITIS AGUDA SECUNDARIA A INFECCIÓN POR VARICELA ZOSTER EN UN ADULTO INMUNOCOMPETENTE}

Clavero E, Vares González M, Sánchez Vidal E, Verdeal Dacal R, Suárez Fuentetaja $R$.

MEDICINA INTERNA, COMPLEXO HOSPITALARIO UNIVERSITARIO DE A CORUÑA.

INTRODUCCIÓN: La pancreatitis aguda (PA) se ha descrito como una complicación rara asociada a la infección aguda por el Virus Varicela Zoster (WZ), más frecuente en inmunodeprimidos y en la edad pediátrica. Presentamos el caso de un varón adulto e inmunocompetente, que desarrolló una PA en e seno de una infección por el WZ. El interés radica tanto en lo infrecuente del caso, como en el pronóstico vital de la PA, pero sobre todo, en el desconocimiento de la patogenia, poniendo de manifiesto la necesidad de ilustrar nuevos casos que permitan una actitud terapéutica definida, que iría sin duda ligada a un mejor pronóstico.

CASO CLÍNICO: Varón de 29 años. Intervenido de estenosis pilórica (neonatal), apendicitis y obstrucción intestinal por bridas. Fumador activo. Consulta en el sevvicio de urgencias por rash vesiculo-pustular pruriginoso de horas de evolución, fiebre de hasta $39^{\circ} \mathrm{C}$, mioartralgias generalizadas y cefalea frontal. Se realizó punción lumbar obteniendo un LCR normal y fue dado de alta con el diagnóstico de varicela cutánea no complicada sin tratamiento específico. № había tenido la varicela previamente y no estaba vacunado. Un día después, consulta por persistencia de la fiebre y dolor epigástrico agudo y continuo, irradiado a hipocondrio derecho, asociando vómitos biliosos, anorexia y deposiciones diarreicas (sin productos patológicos). En la exploración física destacaban lesiones pápulovesiculosas y costrosas en cara, tórax y miembros superiores; el peristaltismo intestinal estaba reducido; presentaba dolor a la palpación en epigastrio e hipocondrio derecho con esplenomegalia leve no dolorosa. Analíticamente, trombopenia (91. 000), presencia de cayados y linfocitos activados, amilasa 363 UI/L, GOT 82U/L, GPT 106 UI/L, GGT 44 UI/L, FA 141/L, BT $0.41 \mathrm{mg} / \mathrm{dL}$. Los niveles de calcio, triglicéridos y resto de parámetros analíticos fueron normales. La ecografía abdominal mostró únicamente discreta esplenomegalia homogénea. Con sospecha de PA probablemente secundaria a infección por el WZ se adoptó reposo digestivo y se inició tratamiento con aciclovir intravenoso, que se mantuvo durante una semana. Al $4^{\circ}$ día se reintrodujo la dieta con buena tolerancia y al $8^{\circ}$ día fue dado de alta, con normalización de las alteraciones analíticas. En el caso de nuestro paciente, el diagnóstico se basó en la simultaneidad del dolor abdominal y la hiperamilasemia, asociado temporalmente con las lesiones cutáneas secundarias a la infección por WZ, además de excluirse por historia clínica, estudio analítico y ecográfico, otras causas de PA. Tras el inicio del aciclovir, la fue francamente favorable.

CONCLUSIONES: Este caso pone de manifiesto la necesidad de considerar la PA en el diagnóstico diferencial del dolor abdominal durante el curso de la infección aguda por el WZ. Además, creemos que el aciclovir, iniciado precozmente, juega un papel fundamental en la evolución favorable, sin bien, es necesario el conocimiento de nuevos.

\section{PERICARDITIS RECURRENTE COMO ÚNICA MANIFESTACIÓN CLINICA DE FIEBRE MEDITERRÁNEA FAMILIAR}

Lorenzo Castro R, Argibay Filgueira AB, Val Domínquez N, Baroja Basanta AL, Vilas Pio B, Gómez Sousa JM, Soto Peleteiro A, Sousa Domínguez A, Rodríguez Gómez AM, Martínez Vidal Al, Rivera Gallego A. MEDICINA INTERNA, HOSPITAL XERAL DE VIGO

INTRODUCCIÓN: La pericarditis recurrente probablemente sea la complicación más frecuente y problemática de la pericarditis, y afecta a alrededor de un $20-30 \%$ de los pacientes después de un primer episodio de pericarditis aguda. Aunque se ha considerado la mediación inmunitaria o la vírica, la etiopatogenia de las recaídas no se conoce bien y la mayoría de los casos continúan siendo idiopáticos. La fiebre mediterránea familiar (FMF) es una enfermedad autoinflamatotia caracterizada por fiebre recurrente y poliserositis. Si la única manifestación es a nivel del pericardio, normalmente no se piensa en esta entidad.

OBJETIVOS: Presentamos 2 casos de pericarditis recurrente diagnosticados finalmente por estudio genético de FMF.

MATERIAL Y MÉTODO: Descripción de los dos casos clínicos y revisión de la literatura.

RESULTADOS: Paciente de 26 años sin antecedentes de interés, que presentó episodios de pericarditis recidivante que requirieron hospitalización a pesar de tratamiento con antiinflamatorios y corticoides. En uno de los ingresos fue necesario incluso pericardiectomía por taponamiento cardíaco. Se decidió inicio de colchicina con buena respuesta. El segundo caso era un varón de 55 años con déficit selectivo de IgA y episodios de pericarditis recidivante desde los 48 años. Recibió tratamiento con corticoides y varios inmunosupresores sin respuesta, hasta que se inició colchicina. En ambos casos se realizaron estudios serológicos, de autoinmunidad y de imagen sin encontrar la etiología, salvo elevación de reactantes de fase que se normalizaban tras el proceso agudo. Por este motivo fueron etiquetados de pericarditis recidivante idiopática. En el seguimiento en consultas externas se decidió realizar despistaje genético de FMF hallándose en el primer caso heterozigosis para la mutación Prol-175-Hys y en el segundo heterozigosis para la mutación lle-591-Thr. La FMF es una enfermedad autosómica recesiva cuyo diagnóstico se basa en criterios clínicos y en algunos casos atípicos es necesaria la confirmación genética. Aunque las manifestaciones clínicas más frecuentes son la peritonitis (90\%), artritis (75\%) y pleuritis $(20-45 \%)$, la pericarditis es mucho menos frecuente (0.7-1.4\%), aunque en algunas series puede encontrarse alteración del pericardio hasta en un 27\% de los pacientes si se realizase ecocardiograma de forma sistemática. CONCLUSIÓN: La pericarditis recidivante idiopática aislada puede ser una forma de presentación atípica de la FMF, por lo que se debería incluir en el diagnóstico diferencial. El realizar un diagnóstico precoz es importante para un correcto tratamiento y sobre todo para evitar recidivas o la progresión de la enfermedad a amiloidosis.

\section{PERITONITIS BACTERIANA ESPONTÁNEA. ¿SEGUIMOS IGUAL?}

Fernández Fernández FJ, Enríquez Gómez H, Araújo Fernández S, Álvarez Otero J, Gondar Barcala T, De la Fuente Aguado J.

MEDICINA INTERNA, POVISA.

INTRODUCCIÓN: La peritonitis bacteriana espontánea (PBE) es una infección característica de pacientes con cirrosis avanzada. La mayoría están causadas por Enterobacteriaceae y Streptococcus. Recientes publicaciones han descrito un aumento en la incidencia de PBE causadas por microorganismos resistentes a cefalosporinas, así como una mayor mortalidad en pacientes con PBE asociada a los cuidados de la salud o nosocomial.

OBJETIVOS: Describir las características clínicas y microbiológicas de los pacientes con PBE ingresados en nuestro hospital.

MATERIAL Y MÉTODO: Estudio descriptivo retrospectivo mediante revisión de historias clínicas de todos los pacientes con PBE ingresados en el Hospital Povisa entre 2005 y 2014. Se recogieron variables clínicas, microbiológicas y terapéuticas, y se analizó posteriormente la evolución.

RESULTADOS: Se diagnosticaron 36 pacientes, 81\% varones, edad media 65 años. El 86\% de los pacientes tenía al menos una enfermedad concomitante, las más frecuentes hepatocarcinoma (36\%), insuficiencia renal (22\%), VIH (11\%), DM (11\%) y ascitis refractaria (11\%). El 53\% de las cirrosis eran de origen alcohólico y el $36 \%$ por VHC. La PBE fue adquirida en la comunidad en el $28 \%$, relacionada con los cuidados de la salud en el $36 \%$ y nosocomial en el $36 \%$. Los síntomas más frecuentes fueron aumento del perímetro abdominal $(78 \%)$, dolor abdominal (30\%) y fiebre (22\%). El tiempo medio de evolución de los síntomas fue de 5 días. En la clasificación de Child-Pugh el estadio más frecuente fue B (53\%), y un $47 \%$ estadio C. El valor medio en la escala de Meld-Na fue de 21. Seis pacientes habían recibido antimicrobianos en los 3 meses previos, cefalosporinas los más empleados.

El cultivo de líquido ascítico fue positivo en el $41 \%$ de los casos realizados, y los hemocultivos en el $33 \%$. El microorganismo aislado con mayor frecuencia fue E. coli (53\%); otros fueron $\mathrm{K}$. pneumoniae, $\mathrm{K}$ oxytoca, P. mirabilis, S. mitis, E. faecalis y E. faecium. Todos fueron sensibles a amoxicilina, cefotaxima y ciprofloxacino, salvo S. hominis y los enterococos. Los 3 pacientes con microorganismos resistentes habían tomado antibióticos previamente como única diferencia estadísticamente significativa respecto a los pacientes con microorganismos sensibles. La antibioterapia más empleada fueron las cefalosporinas de tercera generación. El 48\% desarrollaron insuficiencia renal. El 35\% presentaron una nueva PBE. El 31\% falleció, $45 \%$ de las muertes atribuibles a la PBE. El único factor predictor independiente de mortalidad hospitalaria fue la insuficiencia renal. El tiempo medio hasta el fallecimiento fue de 7 meses. CONCLUSIONES: En nuestro medio existe crecimiento de microorganismos menos habituales en pacientes que han recibido tratamiento antimicrobiano previo. Se debería plantear una modificación de tratamiento antibiótico empírico en este grupo de pacientes. En nuestro estudio la insuficiencia renal es el único factor que se relaciona con una mayor mortalidad.

\section{PRESENTACIÓN ATÍPICA DE GIST GÁSTRICO \\ EN MUJER DE 41 AÑOS}

Puente Hernandez $M^{1}$, Martínez-Rey $C^{2}$, Baamonde ${ }^{3}$, Pose $A^{2}$, Gonzalez Quintela $A^{2}$

SERVICIO DE NEUROLOGIA ${ }^{1}$ MEDICINA INTERNA ${ }^{2} Y$ CIRUGIA GENERAL ${ }^{3}$, CHUS. SANTIAGO DE COMPOSTELA.

INTRODUCCIÓN: Los tumores del estroma gastrointestinal (GIST) son tumores mesenquimales del tubo digestivo poco frecuentes. Los síntomas iniciales más frecuentes son el dolor abdominal y el sangrado gastrointestinal. A continuación presentamos un caso en que la presentación fue como ascitis masiva. CASO CLíNICO: Se trata de una mujer de 41 años de edad sin antecedentes de interés que presenta distensión abdominal progresiva de 4 meses de evolución, que se acompaña de astenia, anorexia, disnea y edema de miembros inferiores. A su ingreso la paciente presentaba signos de ascitis a tensión, edema de pared abdominal y de de extremidades inferiores. En la imagen de TC de tórax-abdomen-pelvis se confirma la presencia de una masa abdominal heterogénea de aproximadamente 167 × 163 × 159 mm. Se realizó drenaje de unos 23 litros de fluido ascitico aproximadamente. La microbiología, el cultivo y la citología del líquido resultaron negativos. El analisis bioquimico del liquido muestra un gradiente de albumina de 0,2 Mediante laparotomía media extensa se llevó a cabo la resección de una masa tumora ovoidea de 18 × 18 × 8,7 cm y 1694 gramos de peso, dependiente de la curvatura mayor del estómago. No se objetivaron implantes peritoneales, mesentéricos ni epiploicos. El estudio microscópico de la masa confirmó la presencia de un GIST con índice mitótico inferior a $5 \times 50$ campos de gran aumento. La inmunohistoquímica resultó positiva para vimentina, dog1, c-Kit, CD34 y desmina. El índice de proliferación medido con Ki-67 fue bajo. El postoperatorio cursó sin incidencias. Tras el alta, la paciente recibio tratamiento con imatinib mesilato, con buena tolerancia.

DISCUSIÓN: El tumor del estroma gastrointestinal tiene una incidencia de 10-20 por cada millón de habitantes/año. La inmensa mayoría de los tumores gástricos tienen un tamaño inferior a $10 \mathrm{~cm}$. La presentación como ascitis es también sumamente rara, en menos del $1 \%$ de los casos, y prácticamente siempre asociada a la presencia de metástasis peritoneales 0 al tratamiento con imatinib mesilato.

\section{PROBABLE MIOPATÍA POR RALTEGRAVIR Y REVISIÓN DE LA LITERATURA}

Verdeal Dacal $R$, Suárez Fuentetaja R, Porto Pérez AB, Vázquez Rodríguez P, López Calvo $S$.

MEDICINA INTERNA, COMPLEJO HOSPITALARIO UNIVERSITARIO DEA CORUÑA.

INTRODUCCIÓN Y OBJETIVOS: Las principales causas de miopatías incluyen trastornos electrolíticos, endocrinos y metabólicos, enfermedades inflamatorias, infecciosas, rabdomiolisis, tóxicos y fármacos. Presentamos un caso de miopatía atribuida al tratamiento antirretroviral (TAR) en una paciente con virus de la inmunodeficiencia humana $(\mathrm{VIH})$.

MATERIAL Y MÉTODO: Descripción de un caso clínico y revisión de la literatura.

RESULTADOS: Mujer de 52 años con infección por virus de hepatitis C (VHC) con fibrosis hepática avanzada, e infección VIH categoría C3 con resistencia y toxicidad a diversos TAR. Desde hace aproximadamente 2 años se encontraba a tratamiento con tenofovir, emtricitabina y raltegravir, que hace 8 meses se sustituyó por abacavir, lamivudina y raltegravir por cuadros de necrosis avascular ósea en caderas y un hombro, reanudándose un mes antes del ingreso tenofovir, emtricitabina y raltegravir para plantea tratamiento frente a VHC. Había presentado 2 ingresos por parestesias en miembros inferiores hace 10 y 2 años con analíticas con aldolasa, creatincinasa (CPK), electromiografía (EMG) y estudios de imagen normales salvo pequeña hernia discal posterior L5-S1. Tomaba corticoides y beta2agonistas inhalados. Ingresa por cuadro de meses de evolución de pérdida de fuerza progresiva en miembros inferiores, descendente, de predominio proximal, acompañado de intenso dolor muscular en muslos y calambres, sin otra clínica neurológica. La paciente relaciona el cuadro con el inicio de tratamiento con raltegravir con mejoría tras abandono de este TAR 2 semanas antes, con reanudación de la clínica tras reinicio del mismo En la exploración física destacaba dolor a la palpación en muslos y en la exploración neurológica fuerza de $5 / 5$ en miembros superiores, con 4-/5 en flexoextensión de las caderas y flexión de las rodillas y $4+/ 5$ en extensión de rodillas y flexoextensión de pies, conservando reflejos y sensibilidad, y una atrofia muscular generalizada de predominio en miembros inferiores. La CPK y aldolasa fueron normales, la RMN dorsolumbar no mostró complicaciones medulares ni en la cola de caballo y la EMG mostró cambios inespecíficos en la musculatura de miembros inferiores y miembro superior derecho sin signos de polineuropatía. Se retiró tratamiento con raltegravir con progresiva desaparición de la clínica referida. CONCLUSIONES: Las infecciones y neoplasias son las causas más frecuentes de debilidad muscular en pacientes VIH. Dentro del TAR, los análogos de nucleósidos han sido los más implicados, pero se han descrito diversas formas de toxicidad musculoesquelética por raltegravir en más de 750 pacientes, como elevaciones asintomáticas de CPK (11,2-21,3\% dependiendo del estudio), síntomas de mialgias, debilidad muscular y calambres $(1,5-5,2 \%$ y yl menos 5 casos de rabdomiolisis, precisando suspensión del fármaco en pocos pacientes $(0-1,4 \%)$. Existe ausencia de correlación entre el aumento de CPK y la clínica muscular en la mayoría de estudios.

\section{PROGRAMA DE VIGILANCIA INFECCION DE HERIDA QUIRURGICA EN EL HOSPITAL QUIRON A CORUÑA EN EL AÑO 2014}

Meijide H, Serrano J, Porteiro J, Moreno JA, Asensio P, Rico P.

MEDICINA INTERNA, HOSPITAL QUIRON A CORUÑA.

INTRODUCCIÓN: La vigilancia tradicional de la infección del sitio quirúrgico (ISQ) que se realiza durante e ingreso hospitalario puede infraestimar su incidencia al ser cada vez más corta la estancia hospitalaria. El objetivo del presente trabajo es conocer las tasas reales de ISQ prolongando la vigilancia después del alta. MATERIAL Y MÉTODOS: Se incluyeron en el proyecto 4 procedimientos quirúrgicos programados (artroplastia de rodilla y cadera, cesárea, mastectomía y colecistectomía). Fueron analizados durante un periodo de 3 meses/ procedimiento en el año 2014. Los datos de ISQ se recogieron de manera prospectiva según el sistema de vigilancia de infección nosocomial en planta de hospitalización. La vigilancia post-alta (VPA) se realizó mediante encuesta telefónica pasados 30 días después del alta. Se analizaron el \% ISQ, la adecuación de la profilaxis infecciosa recibida y la evolución clínica. 
RESULTADOS: Se incluyeron un total de 164 pacientes (44 artroplastias, 52 cesáreas, 20 mastectomías y 50 colecistectomías). Se objetivó ISQ en planta de hospitalización en 2 pacientes $(1,2 \%$, incrementandose a 7 pacientes $(4,2 \%$ ) tras la VPA. Por procedimiento, en artroplastias 2 ISQ organoespacio (4,5\%); en cesárea, 1 ISQ profunda (1,9\%); en mastectomía, 1 ISQ superficial (5\%);en coecistectomía, 1 ISQ superficial y 2 ISQ profunda (6\%). Se detectó un 10,3\% de inadecuación en la profilaxis antibiótica; por procedimiento, se registró inadecuación en artroplastia $(0 \%)$, cesárea $(0 \%)$, mastectomía (65\%) y colecistectomía (8\%), todas ellas por exceso. La evolución de ISQ fue favorable en todos los casos.

CONCLUSIONES: La VPA incrementó la incidencia de ISQ en los procedimientos quirúrgicos analizados. La VPA es útil para analizar la tendencia real de ISQ y evaluar posibles áreas de mejora. ES necesario estandarizar los protocolos de vigilancia y hacerlo extendido a la mayor parte de los procedimientos quirúrgicos. Son necesarias estrategias de prevención para disminuír morbi-mortalidad ahorrar costes derivados de ISQ, entre ellas la optimización de la adecuación de la profilaxis antibiótica.

\section{RECIDIVA EN ENFERMEDAD TROMBOEMBÓLICA VENOSA}

Fernández Bouza E, Gómez Buela I, Lijó Carballeda C, García Alén D, Bravo Blázquez I, Dalama López T, Sesma Sánchez $P$.

MEDICINA INTERNA COMPIEXO HOSPITALARIO UNIVERSTARIO DE FERROL.

NTRODUCCIÓN: la enfermedad tromboembólica venosa (ETV) en una patología que frecuentemente recurre, especialmente en pacientes varones, con trombosis proximal y sin factor provocador.

OBJETIVOS: conocer las características epidemiológicas y clínicas de nuestros pacientes que han sufrido ETV recurrente Métodos: revisión retrospectiva del historial clínico de pacientes seguidos en una consulta monográfica de ETV. Resultados:Entre julio-2012 y abril 2015 se siguieron 332 pacientes. De ellos $46(13 \%)$ sufrieron recidiva. Se trata de 26 mujeres (56. 5\%) y 20 hombres (43. 5\%) con edad media de 68 años (43-93, DS 14) e IMC medio de 29 (22-40, DS 4). El primer evento fue (trombosis venosa)TVP en 28 casos (60\%), EP (embolia pulmonar) en 13 (28\%) y ambos en 5 (10. 9\%). La TVP fue femoral en 17 casos $(60 \%)$, poplítea en $7(25 \%)$ y $4(14 \%)$ en otras localizaciones. De ellos $12(43 \%)$ desarrollaron trombosis residual, $8(28 \%)$ no, y en $10(35 \%)$ se desconoce. El factor de riesgo más frecuente fue el inmovilismo en 21 enfermos (45\%), seguido de cáncer (10 casos, 21\%) y cirugía 7 (15\%); en 9 pacientes (20\%) no hubo ninguno y 10 pacientes (21\%) tenían más de un factor. La cirugía fue ortopédica en $3(43 \%)$, abdominal en $3(43 \%)$ y otras en $1(14 \%)$. El cáncer fue colorrectal en 5 $50 \%$ ) y otros $5(50 \%)$. El $50 \%$ estaban en estadios I y II, el $30 \%$ en estadios III y IV y el $20 \%$ se desconoce. El 80\% fueron adenocarcinomas. Tras el primer evento los pacientes estuvieron anticoagulados una media de 14. 5 meses (0-48, DS 11. 8). La recidiva fue TVP en 28 (60. 9\%), TEP en 17 (37\%) mbos en 1 (2.2\%). En 21 pacientes (75\%) se recogió la extremidad de laTVP. en 15 pacientes $771 \%$ la recidiva fue ipsilateral. La recidiva se produjo durante el tratamiento anticoagulante en 7 casos (15\%) y tras haberlo finalizado en $39(85 \%)$. La recidiva surgió a los 50 meses de media tras haber finalizado el tratamiento (2-582, DS 105). Sólo en 6 pacientes (13\%) se determinó el dimero D tras finalizar el tratamiento del primer episodio, obteniéndose una puntuación media en el DASH score de 1. 1 (0-3, DS 0. 9). La media de meses transcurridos entre ambos eventos fue de $89(3-588$, DS 125$)$ Los factores de riesgo de la recidiva fueron inmovilismo en $23(50 \%)$, cáncer en $10(21 \%)$, ninguno en 11 (23\%) y otros en 2. Fallecieron 4 pacientes (8. 7) y solo 1 como consecuencia de la recidiva. CONCLUSIONES: la ETV se manifiesta más frecuentemente en forma de TVP tanto en su primer evento como en la recurrencia, generalmente ipsilateral y asociada a trombosis residual. A diferencia de lo publicado, nuestras recurrencias son más frecuentes en mujeres. Se observó con alta frecuencia un factor precipitante tanto en el debut como en la recidiva. En concordancia con lo publicado, las recidias suelen producirse mayoritariamente tras la suspension del anticoagulante.

\section{RESULTADOS DE LA FASE 3 DE INSULINA DEGLUDEC/ LIRAGLUTIDA EN EL TRATAMIENTO DE LA DIABETES MELLITUS TIPO 2A}

Bellido Guerrero D', Soto González $A^{2}$, García Gromaz D .

SERVICIO DE ENDOCBINOLOGIAA Y NUTRICIÓN 1 'SERVICIO DE ENDOCRINOL OGIA Y NUTRICIÓN ${ }^{2}$ NOVO NORDISK ${ }^{3}$, COMPLEJO HOSPITALARIO UNIVERSITARIO DE FERROL ${ }^{1}$, HOSPITAL DE A CORUÑNA ${ }^{2}$, NOVO NORDISK INTRODUCCIÓN: Insulina degludec/Liraglutida (IDegL Lira) es una combinación a razón fija de una insulina de acción prologada, insulina degludec, y un análogo de GLP-1, liraglutida, diseñado para optimizar el control glucémico. IDegLira se administra una vez al día e independiente de las comidas; la dosis máxima es de 50 unidades de dosis (50 unidades de insulina degludec y 1,8 mg de liraglutida). OBJETIVOS: Describir los resultados de los ensayos clínicos de fase 3 a con IDegLira

MATERIAL Y MÉTODO: El programa DUAL de fase 3a con IDegLira incluyó dos ensayos clínicos multinacionales, aleatorizados, de tratamiento hasta el objetivo. EI DUAL I fue un estudio no enmascarado para confirmar la superioridad de IDegLira vs Lira y la no inferioridad vs IDeg, en pacientes que no habían recibido previamente insulina y que no estaban controlados con metformina \pm pioglitazona. El DUAL II fue un estudio doble-ciego diseñado para confirmar la superioridad de IdegLira vs IDeg. En ambos estudios la variable principal fue el cambio a las 26 semanas con respecto a basal en la HbA1c. Las variables secundarias incluyeron, entre otras, cambio en el peso, número de episodios de hipoglucemia confirmados y dosis final de insulina.

RESULTADOS: Los principales resultados de los estudios DUAL I y II se presentan en la Tabla 1. CONCLUSIONES: LOS estudios DUAL I y || muestran que cada componente de IDegLira contribuye a control glucémico, al tiempo que reduce efectos secundarios importantes asociados al tratamiento con insulina como el aumento de peso y las hipoglucemias, en pacientes no controlados con una insulina basal (DUAL II) y en pacientes que no habían recibido insulina previamente y no estaban controlados con metformina+pioglitazona (DUALI).

\section{SIADH EN PACIENTES CON ESTESIONEUROBLASTOMA}

\section{Sarbageta $C$,}

UNIDAD DE PREINGRESO, MEDICINA INTERNA, COMPLEJO HOSPITALARIO UNIVERSITARIO A CORUÑA. INTRODUCCIÓN: El neuroblastoma olfatorio o estesioneuroblastoma (ENB), es una rara neoplasia maligna de la cavidad nasal que procede del epitelio olfatorio. Supone el $2 \%$ de los tumores nasosinusales. Su diagnóstico se ve retrasado por sus síntomas poco específicos, los más frecuentes obstrucción nasal y epistaxis. En los tumores de cabeza y cuello esta descrita una incidencia global de SIADH de $3 \%$, en el caso del estesioneuroblastoma en torno al $2 \%$. Dentro de los estudios que se realizan a los pacientes con SIADH se encuentran el Tac toráco-abdominal y cerebral, pero no se incluye la búsqueda de tumores nasosinusales por su rareza, lo que puede conllevar un retraso en su diagnostico. OBJETIVOS: Evaluar la incidencia de SIADH y la duración del mismo previo al diagnostico de ENB. MATERIAL Y MÉTODOS: Estudio retrospectivo descriptivo de todos los casos diagnosticados de Estesioneuroblastoma en CHUAC entre enero 2005 y diciembre 2014.

RESULTADOS: Se diagnosticarón 8 casos de ENB, 4 hombres y 4 mujeres con una edad media de 61 años. Respecto al estadio modificado de Kadish: 12\% estaban limitados a cavidad nasal (estadio A) $37,5 \%$ se extendian a senos paranasales (estadio B), 37,5\% afectaban a la base del craneo (estadio C) y $12 \%$ presentaba metastasis (estadio D). Se realizó tratamiento quirurgico en el $75 \%$ de los casos, asociandose el $40 \%$ a quimioterapia o radioterapia. En el $40 \%$ de los casos hubo recurrencia del tumor. Al diagnostico de ENB dos pacientes presentaban hiponatremia con criterios de SIADH, lo que representa una incidencia del $25 \%$, con unas cifras de Na de 126 y 115 respectivamente con sintomas eves de hiponatremia y en estadio Kadish A-B. Las cifras de sodio bajo eran conocidas desde 5 y 8 años antes. El primer caso diagnosticado en 2005 recibio tratamiento con restricción de liquidos, manteniendo cifras de na bajas (126/128), el segundo caso diagnosticado en 2014 recibio tratamiento con Tolvaptan con cifras na entre 128-134. En ambos casos la hiponatremia se resolvio rápidamente ras la extirpación del tumor.

CONCLUSIONES: 1. En aquellos casos sin causa aparente de SIADH esta indicado realizar técnicas de imagen para descartar patologia pulmonar o intracraneal; pese a que el estesioneuroblastoma es un neoplasia maligna poco frecuente deberiamos considerar vigilar la posibilidad de tumores nasosinusales en aquellos casos de SIADH idiopatico, sobre todo en aquellos que se evidencia algún tipo de anomalia u ocupación de senos en la imagen de TAC craneal, realizando tac o rnm y exploración de senos paranasales. 2. Aunque en la literatura se refiere una incidencia del 2\% de SIADH en el ENB, se reflexiona que probablemente se encuentre infraestimada, en esta corta serie encontramos una incidencia del 25\% apoyando esta conclusión. 3. El diagnostico de SIADH precedia al diagnostico de ENB una media de 6,5 años, resolviendose rápidamente tras la extirpación del tumor.

\section{SÍNDROME ANTISINTETASA CON ANTI-JO NEGATIVO. A PROPÓSITO DE 2 CASOS}

Val Domínguez N, Argibay Filgueira A, Freire Dapena M, Sousa Domínguez A, Martínez Vidal A, Rodríguez

Gómez A, Gómez Sousa J, Rivera Gallego A.

UNIDAD DE TROMBOSIS Y VASCULITIS. SERVICIO DE MEDICINA INTERNA, HOSPITAL XERAL DEVIGO (EOXI).

INTRODUCCIÓN: El Síndrome Antisintetasa (SAS) es una entidad poco frecuente que se engloba dentro de las miopatías inflamatorias del adulto. La tríada clínica típica consiste en la presencia de miositis simétrica de predominio proximal, afectación pulmonar intersticial y poliartritis inflamatoria de pequeñas articulaciones. La presencia de anticuerpos (Ac) antisintetasa apoya el diagnóstico, siendo los más frecuentes los Ac anti-Jo-1 (hasta en el 50\% de los casos). Sin embargo existen al menos otros siete Ac descritos asociados a esta entidad, que son positivos en un porcentaje mucho menor de pacientes, siendo los más representativos de este grupo los anti-PL7 y anti-PL12.

OBJETIVO: Presentar 2 casos clínicos diagnosticados de SAS en nuestro centro con Ac anti-Jonegativos.

TATERIAL Y MÉTODOS: Descripción de los dos casos clínicos y revisión de la literatura.

RESULTADOS: Caso 1: Varón de 55 años que presentó cuadro de debilidad muscular progresiva con disnea de mínimos esfuerzos y poliartritis en articulaciones interfalángicas de características inlamatorias. Además presentaba lesiones cutáneas compatibles con pápulas de Gottron y manos de mecánico. Los niveles de CPK (18130) y aldolasa (190) fueron elevados, el estudio neurofisiológico compatible con patrón miopático severo y la biopsia de músculo deltoides fue compatible con una miopatía inflamatoria. EI TAC pulmonar y la espirometría demostraron un patrón intersticial bilatera centrolobulillar con alteración de la difusión moderada. Los Ac antinucleares (ANA) fueron positivos a título 1/5120 con anti-Jo-1 negativo. Ante la alta sospecha de SAS se amplió el estudio de autoinmunidad con anti-PL7/PL12 que fueron positivos a título elevado (1/320). Se inició tratamiento con pulsos de metilprednisolona y posteriormente prednisona y azatioprina con muy buena respuesta.

Caso 2: Mujer de 72 años que presentó un cuadro de debilidad progresiva de musculatura deglutoria, con dificultad para el habla, llegando a precisar intubación oro-traqueal e ingreso en intensivos. En aquel momento presentaba una CPK de 3000 aldolasa elevada, ANA positivos (título 1/640), anti-Jo-1 negativo y Ac antireceptor de la acetilcolina levemente positivos (0. 95). Inicialmente se diagnostico de un síndrome overlap (miastenia gravis-polimiositis) con buena respuesta inicial al tratamiento con corticoides y metrotrexato. En el seguimiento posterior la paciente desarrolló una enfermedad intersticial pulmonar bilateral con alteración moderada de la difusión. Se decidió completar el estudio con anti-PL7 y anti-PL12 que fueron positivos, siendo finalmente diagnosticada de un SAS.

CONCLUSIONES: Los anticuerpos anti-Jo1 sólo están presentes en aproximadamente el 50\% de los casos de los pacientes diagnosticados de SAS. Por lo tanto, presentar unos anticuerpos anti-Jo-1 negativos no excluye el diagnóstico y debemos valorar el completar el estudio de autoinmunidad en aquellos pacientes con una alta sospecha diagnóstica.

\section{SÍNDROME DE HIPERPERMEABILIDAD CAPILAR: LA IMPORTANCIA \\ DE UN ALTO ÍNDICE DE SOSPECHA}

Val Domínguez N, Freire Dapena M, Gómez Sousa JM, Vilas Pío B, Argibay Filgueira A, Rivera Gallego A. UNIDAD DE TROMBOSIS Y VASCULITIS. SERVICIO DE MEDICINA INTERNA, HOSPITAL XERAL DE VIGO (EOXI) INTRODUCCIÓN: El síndrome de hiperpermeabilidad capilar (SHP) es una entidad extremadamente ra de etiología desconocida que se caracteriza por una disfunción endotelial aguda con extravasación de plasma y proteínas al espacio extracelular que puede llegar a condicionar un shock refractario. a mortalidad durante los brotes agudos de la enfermedad es muy elevada influída por el retraso diagnóstico derivado del desconocimiento de la entidad y los síntomas poco específicos, que hacen que el diagnóstico suela hacerse por exclusión.

OBJETIV0: Realizar un análisis descriptivo de la forma de presentación de los pacientes diagnosticados de SHP en nuestro centro hospitalario, resaltando los signos que pueden ayudar a realizar un diagnóstico precoz.

MATERIAL Y MÉTODOS: Se seleccionaron los tres pacientes diagnosticados de SHP en el Complexo Hospitalario de Vigo. Se recogieron las características epidemiológicas, síntomas y signos en el momento del debut, episodios previos no diagnosticados, tiempo transcurrido hasta el diagnóstico, tratamiento recibido y evolución.

RESULTADOS: Se identificaron 3 pacientes, 2 mujeres y un hombre, con una edad media al diagnóstico de 47 años (rango 33-57). En 2 pacientes se detectaron episodios previos sugestivos de SHP que habían recibido otros diagnósticos alternativos (posible policitemia vera, sepsis de origen urinario).

En ninguno de ellos se detectó ganmapatía monoclonal en el momento del diagnóstico y sólo uno la desarrolló una a lo largo del seguimiento. 2 pacientes referían síntomas prodrómicos en los días previos (fiebre, mialgias y astenia). Los 3 pacientes presentaban hipotension y edemas generalizados a ingreso Los 3 desarrollaron síndrome compartimental en algún momento de la evolución, precisando 2 de ellos fasciotomías y otro amputación de miembro inferior. Todos lo casos presentaban datos de hemoconcentración en el momento del diagnóstico con niveles de leucocitos $>11.000$ (media 27159 rango 12360-39490) y de $\mathrm{Hb}>14 \mathrm{mg} / \mathrm{dL}$ (media 22, rango 19-25. 5). Sólo un paciente presentaba albúmina <3. 5 (1.58). El retraso medio en el diagnóstico durante el episodio fue de 16.3 días y desde el primer brote 2 años (?).

En la fase aguda los 3 pacientes recibieron tratamiento con teofilina/terbutalina y dos de ellos además con inmunoglobulinas iv. Se mantuvo teofilina/terbutalina para mantenimiento. Uno de los pacientes presentó hasta 4 recaídas, falleciendo 3 años después del diagnóstico. Otro presentó una recaída a raiz de la cual se inició tratamiento mensual con inmunoglobulinas (2gr $/ \mathrm{kg})$ sin nuevos episodios posteriores (seguimiento dos años).

CONCLUSIÓN: La presencia de hipotension refractaria de instauración brusca en un paciente joven con hemoconcentración e hipoalbuminemia y presencia de edemas generalizados con o sin síndrome compartimental, debe hacernos sospechar el diagnóstico de SHP. Iniciar precozmente las medidas terapéuticas adecuadas ayuda a reducir la altísima morbimortalidad de este síndrome. 


\section{SÍNDROME DE SAPHO ¿PENSAMOS EN ÉL?}

Longueira R, Vargas J, Portela D, Rivera A.

MEDIIINA INTERNA, NEUMOLOGIAA, COMPLEJO HOSPITALARIO UNIVERSITARIO DE VIGO (CHUVI).

INTRODUCCIÓN: El acrónimo síndrome de SAPHO se describió por primera vez en 1987 por Chamo y colaboradores para englobar una serie de hallazgos clínicos que incluían sinovitis, acné, pustulosis, hiperostosis y osteomielitis. Se incluye dentro de las dermatosis neutrofilicas y afecta generalmente a niños y a adultos jóvenes, con predominio en el sexo femenino. La pared anterior del tórax en el área más frecuentemente afectada, con osteítis e hiperostosis, y la histología de estas lesiones muestra una osteomielitis aséptica. Su diagnóstico es fundamentalmente clínico y requiere un alto nivel de sospecha. Su tratamiento, aunque no está bien establecido, incluye AINES, colchicina, corticoides, sulfasalazina, metotrexate, retinoides, bifosfonatos y fármacos anti-TNF.

OBJETIVOS: Comunicar el caso de una paciente diagnosticada de síndrome de SAPHO

MATERIAL Y MÉTODOS: Descripción de un caso clínico y revisión de la literatura.

RESULTADOS: Mujer de 33 años que consultó por cuadro de 2 años de evolución de dolor en región cervical, escapular derecha y cara anterior del tórax. Fue diagnosticada de protusión discal C5-C6 y se trató con relajantes musculares, corticoides intramusculares, rehabilitación, acupuntura y toxina botulínica, con escasa respuesta analgésica. En la evolución asoció cuadro de sinovitis articular en rodilla derecha (objetivada en una resonancia magnética) y poliartralgias generalizadas sin artritis, así como episodios recurrentes de lesiones cutáneas acneiformes en tronco y extremidades e hidroxiadenitis supurativa en axilas, por lo que estaba a tratamiento con doxiciclina. Ante empeoramiento del dolor a nivel esternal, se realizó gammagrafía ósea que mostró una lesión focal en el arco posterior de la $3^{\text {a }}$ costilla derecha, además de captación a nivel esternal. Una tomografía axial computarizada torácica evidenció fractura a nivel costal, sin identificar la paciente traumatismo a dicho nivel. Los hallazgos clínicos y de las pruebas de imagen fueron compatibles con un síndrome de SAPHO. A pesar de ello y ante la presencia de una fractura patológica, con imágenes radiológicas que no permitían descartar malignidad, de acuerdo con la paciente se optó por realización de biopsia ósea, cuya histología descartó esta posibilidad y permitió confirmar el diagnóstico de síndrome de SAPHO. En la actualidad la paciente está a tratamiento con metotrexate, sin nuevos episodios de foliculitis y con franca mejoría de la sintomatología dolorosa.

CONCLUSIONES: El síndrome de SAPHO síntomas (sinovitis, acné, pustulosis, hiperostosis y osteomielitis) es una entidad infrecuente y de etiología desconocida. Se requiere un alto grado de sospecha clínica, y la imagen gammagráfica en "asta de toro" a nivel de la articulación esternoclavicular es bastante específica de este síndrome. Aunque habitualmente el diagnóstico se realiza en base a la correlación clínica y radiológica, en ocasiones es necesaria la realización de biopsia ósea para excluir otras causas

\section{SÍNDROME OVERLAP POLIMIOSITIS-ESCLERODERMIA (ESCLEROMIOSITIS)}

Álvarez Otero J, Enríquez Gómez H, Sánchez Conde P. González Vázquez L, Gondar Barcala T, De la Fuente Aguado $\mathrm{J}$

MEDICINA INTERNA, POVISA.

INTRODUCCIÓN: El síndrome overlap polimiositis - esclerodermia es un síndrome de superposición que abarca características clínicas e inmunológicas de esclerosis sistémica y polimiositis. OBJETIVOS: Comunicar un caso de síndrome overlap polimiositis-esclerodermia y su manejo. MATERIAL Y MÉTODOS: Presentamos un caso de síndrome overlap polimiositis-esclerodermia en una paciente de 62 años.

RESULTADOS: Mujer de 62 años que acude a la consulta de Medicina Interna por cuadro de 6 meses de evolución de dactilitis con engrosamiento cutáneo y grietas en pulpejos sin otros síntomas de conectivopatía. Se realiza estudio autoinmunitario básico con positividad de ANAs a título alto con patrón moteado y nucleolar. Ante la sospecha de esclerosis sistémica limitada se solicitan Ac anticentrómero, anti SCL70, anti-ENAs que resultan negativos. Solicitamos TAC torácica con datos compatibles con neumonía intersticial no específica. Precisa posteriormente ingreso por cuadro progresivo de un mes de evolución de astenia, pérdida ponderal de $15 \mathrm{~kg}$, debilidad muscular, disnea de moderados esfuerzos, disfagia para sólidos y disfonía. Ante la clínica compatible con miopatía inflamatoria con elevación de enzimas musculares (GOT, GPT, CPK y aldolasa) y antecedentes de esclerodermia con ANA positivos se realiza estudio específico autoinmune de miopatías inflamatorias resultando únicamente positivos los Ac anti-PM1 (PM-SCL) con alta sospecha diagnóstica de Síndrome Overlap (polimiosistis - esclerodermia). Se completa el estudio con electromiograma que muestra datos sugestivos de miopatía inflamatoria que se confirma en la biopsia muscular con hallazgos de polimiositis. La TC de tórax-abdomen, colono-TC, gastroscopia y mamografía no evidenciaron neoplasia. Tras confirmación diagnóstica de Síndrome Overlap (PM y SSc) iniciamos tratamiento con corticoides con pobre respuesta precisando ingreso en UCI con IOT por insuficiencia respiratoria severa. Posteriormente se administran inmunoglobulinas iv sin respuesta, por lo que se pauta tratamiento con bolos de ciclofosfamida iv con mejoría clínica progresiva. Tras completar un total de 6 bolos mensuales de ciclofosfamida iv con remisión clínica completa se mantiene inmunosupresión con azatioprina y se procede a descenso lento de dosis de esteroides. Actualmente continua asintomática.

CONCLUSIÓN: El término de escleromiositis se utiliza para definir a pacientes con condiciones clínicas e inmunológicas de esclerodermia y polimiositis o dermatomiositis. Aunque los Ac anti PM1 no son exclusivos del Sd overlap un porcentaje significativo de los pacientes con este diagnóstico presentan positividad a dichos anticuerpos. El curso de la enfermedad es generalmente benigno y la mayoría de los pacientes responden al tratamiento con corticoides. Pueden existir formas graves que precisen inmunoglobulinas iv o inmunosupresores como en nuestro caso.

\section{SINDROME PERIÓDICO ASOCIADO AL RECEPTOR DEL FACTOR DE NECROSIS TUMORAL (TRAPS): DESCRIPCIÓN DE DOS CASOS}

González Vázquez L, García Román M, Valle Feijoo L, Puerta Louro R, De la Fuente Aguado J. MEDICINA INTERNA, POVISA.

INTRODUCCIÓN: El síndrome periódico asociado al receptor del factor de necrosis tumoral (TRAPS) es una enfermedad hereditaria autosómica dominante, incluida dentro de los síndromes hereditarios de fiebre periódica. Se caracteriza por episodios inflamatorios prolongados, recurrentes, en los que se objetiva fiebre y parámetros analíticos inflamatorios elevados que pueden acompañarse de clínica articular, cutánea, ocular y abdominal. Suele iniciarse en la edad pediátrica, pero cada vez se diagnostican más casos en adultos.

OBJETIVO: describir las características clínicas, diagnósticas, el tratamiento y evolución de los casos de TRAPS diagnosticados en nuestro hospital.

RESULTADOS: Caso 1: mujer de 49 años que presenta fiebre inicialmente cada 3 ó 4 días y posteriormente diaria de predominio vespertino de dos años de evolución. El cuadro se acompañaba de lesiones cutáneas eritematosas redondeadas, algunas papulosas, que empeoran con la fiebre y se localizan en tronco y extremidades. Edema periorbitario intermitente, poliartralgias, episodios de dolor torácico opresivo intermitentes, dolor abdominal y diarrea líquida intermitente. La analítica no mostraba alteraciones con hemograma, bioquímica, hormonas tiroideas y reactantes de fase normales. Estudio de autoinmunidad: negativo. Serologías de VIH, VHB, VHC: negativas. Hemocultivos, urocultivos, co- procultivos, parásitos en heces: negativos en distintas ocasiones. Se realizaron diferentes pruebas de imagen como radiografía de tórax, ecografía abdominal y TAC cervico-tóraco-abdómino-pélvico sin alteraciones. Gastroscopia y colonoscopia: sin alteraciones reseñables. Se solicitó estudio genético confirmándose la mutación pArg121Gln en forma heterocigota (R92Q), confirmando el diagnostico de TRAPS. Se inició Etanercept $25 \mathrm{mg}$ dos veces por semana con desaparición de la fiebre y mejoría sintomática. Precisó aumento de dosis a $50 \mathrm{mg}$ por brote cutáneo.

Caso 2: mujer de 48 años con episodios desde los 20 años de dolor abdominal difuso y fiebre de 8-10 días de evolución, con artritis en codos, mialgias y eritema en muslos. Se había diagnosticado de Fiebre Mediterránea Familiar (sin estudio genético) y había tomado colchicina con mejoría inicial. En la analítica destacaba creatinina de $2 \mathrm{mg} / \mathrm{dl} \mathrm{y} \mathrm{proteinuria} \mathrm{en} \mathrm{rango} \mathrm{nefrótico.} \mathrm{Se} \mathrm{realizó} \mathrm{biopsia} \mathrm{rectal} \mathrm{que}$ mostró positividad a la tinción con rojo Congo, compatible con depósito amiloide. Se solicitó estudio genético que confirmó el diagnóstico de TRAPS y se inició tratamiento con etanercept a dosis de 25 $\mathrm{mg}$ dos veces por semana. Presentó mejoría clínica, con desaparición de la fiebre y de los episodios de dolor abdominal, así como resolución de la proteinuria.

CONCLUSIONES: aunque el TRAPS suele debutar en la infancia, se debe considerar su diagnóstico en adultos con episodios de fiebre recurrente que se acompañen de lesiones cutáneas y afectación articular. La complicación más grave es el desarrollo de amiloidosis secundaria, que debe descartarse en caso de proteinuria. El tratamiento con etanercept ha sido efectivo tanto como para controlar los síntomas clínicos, como para revertir la proteinuria.

\section{STEINERT EN OURENSE: REVISIÓN DE DISTROFIA MIOTÓNICA EN EL CHUO}

López Mato P, González Noya A, Latorre Díez A, Barreiro Rivas A, Fernández Regal I, Pérez Carral V, Naval Calviño MG, De Toro Santos $M$ MEDICINA INTERNA, COMPLEJO HOSPITALARIO UNIVERSITARIO DE OURENSE (CHUO). INTRODUCCIÓN: La distrofia miotónica tipo I, también conocida como enfermedad de Steinert, es una patología muscular de herencia autosómica dominante con mutación descrita en el gen DMPK. A nive clínico presenta debilidad muscular con miotonía (retraso en la relajación tras contracción voluntaria), así como atrofia en musculatura facial, ptosis palpebral y alopecia precoz, denominando el conjunto facies miopática. Además, se asocian otras patologías como cataratas, alteraciones de conducción cardíaca o trastornos endocrinológicos. El diagnóstico se realiza mediante una clínica y estudio electromiográfico (EMG) compatibles, pudiendo solicitar confirmación genética (amplificación repetitiva en secuencias de 3-4 nucleótidos).

OBJETIVOS: Analizar las características epidemiológicas y clínicas de los pacientes diagnosticados de enfermedad de Steinert, así como las patologías más frecuentemente asociadas.

MATERIAL Y MÉTODOS: Estudio descriptivo de los casos registrados en CHUO entre enero de 2004 y abril de 2015, obtenidos a través de nuestro servicio de Documentación Clínica.

RESULTADOS: Se registraron 11 casos, con una edad media de 54 años, siendo 55\% mujeres. Se documentaron antecedentes familiares en 9 pacientes, confirmando alteración genética en 3 de ellos. La edad media al diagnóstico fueron 42 años y todos los pacientes presentaban clínica y EMG característicos. El exitus se produio en $27 \%$ pacientes, debido a complicaciones respiratorias y con una edad media de fallecimiento de 65 años. A nivel pulmonar, sólo 3 pacientes tenían espirometría, y 6 pacientes precisaron aporte 02 , con ventilación mecánica no invasiva (VMNI) en $50 \%$ casos. 4 pacientes tuvieron infección respiratoria, de etiología broncoaspirativa en la mitad de casos; sólo 1 paciente precisó nutrición enteral por dicho motivo. A nivel endocrinológico, 18\% eran pacientes diabéticos y $72 \%$ presentaban dislipemia; se detectó hipogonadismo en 1 caso. Sobre la patología cardíaca, 18\% de pacientes padecía disfunción sistólica, y a nivel electrocardiográfico se detectó en $45 \%$ casos bloqueo $\mathrm{AV} 1^{\circ}$ grado, $27 \%$ bloqueo de rama izquierda y $9 \%$ bloqueo trifascicular; se colocó marcapasos a 2 de ellos. 7 pacientes presentaban cataratas. El 54\% manifestaban alteraciones neuropsiquiátricas, y en 9 pacientes la limitación funcional era manifiesta.

CONCLUSIONES: La enfermedad de Steinert es una patología multisistémica con importante repercusión en la calidad de vida de los pacientes. Aunque las principales comorbilidades orgánicas son las alteraciones ECG y las cataratas, no debemos olvidar las complicaciones respiratorias (principal causa de exitus) y las alteraciones en el ámbito neuropsiquiátrico, que dificultan el manejo y seguimiento de estos pacientes.

\section{TRATAMIENTO CORTO DE LAS NEUMONÍAS ADQUIRIDAS EN LA COMUNIDAD: ESTUDIO RETROSPECTIVO}

Suárez-Gil R, López-Reboiro ML, Mengual-Macenlle N, Ventura-Valcárcel P, Fernández-Piñeiro JC, RomayLema EM, García-Garrota F, Pita J, Corredoira-Sánchez J.

MEDICINA INTERNA, PATOLOGIA INFECCIOSA, MICROBIOLOGÍA, NEUMOLOGÍA, HOSPIATL LUCUS AUGUST. INTRODUCCIÓN: La Neumonía Adquirida en la Comunidad (NAC) es una entidad importante con una incidencia del $5-11 \%$ y una mortalidad que en algunas series llegar hasta el $50 \%$. La antibioterapia empleada está bien definida, no es así el tiempo de duración de la misma. Existen estudios en la bibliografía que apoyan tratamientos de 5 a 7 días.

OBJECTIVOS: Caracterizar la población susceptible de recibir un ciclo corto de antibioterapia y ver la evolución.

MATERIAL Y MÉTODOS: Se realizó un estudio retrospectivo en los pacientes valorados por el servicio de Patología Infecciosa del HULA durante los años 2004-2005. Se incluyen los pacientes diagnosticados de neumonía clínicamente bacteriana (típica) y se excluyen los pacientes con sospecha de neumonía atípica, con neutropenia o neoplasia hematológica, aquellos en estado crítico subsidiarios de ingreso en UCl, en los que haya otro posible foco de infección y portadores de prótesis endovasculares. Se inicia tratamiento antibiótico durante 5 días y se reevalúa la situación clínica diariamente; al $5^{\circ}$ día si el paciente está asintomático y estable se suspende el tratamiento, si no es así, se continúa hasta la curación clínica. Se hace seguimiento de todos los pacientes al alta durante 1 mes. Recogemos datos de filiación (edad y sexo), comorbilidades, causas de inmunosupresión, clínica, pruebas radiológicas y de laboratorio, tratamiento antibiótico instaurado y evolución (Fracaso terapéutico y prolongación del tratamiento).

RESULTADOS: Se incluyeron 36 pacientes de una edad media de 61 años ( $47 \%>65$ años) y un $74 \%$ de varones. Los factores de predisponentes fueron fumadores (42\%), EPOC (22\%), IC (20\%), DM (8\%), Inmunosupresión (16\%). La Mayoría presentaron la clínica cardinal (fiebre, tos, espectoración). El $75 \%$ presentaban un FINE entre II y IV. Se realizó diagnóstico microbiológico en el 50\% de los casos resultando todos neumoncocos.

En los 36 pacientes se pautó antibioterapia (ceftriaxona 58\%, amoxicilina/clavulánico 33\%) de 5 días, que más prolongada en 4 casos por aparición en los primeros días de derrame pleural. Los otros 32 pacientes finalizaron la pauta prescrita. El 91\% presentó defervescencia antes de 48 horas. Dos pacientes presentaron recidiva del cuadro: uno de ellos a las 48 horas y otro a los 7 días. CONCLUSIONES: La pauta corta de antibiótico durante 5 días parece una opción eficaz en una población seleccionada de pacientes, pero nuestro estudio está muy limitado por ser una muestra pequeña y no disponer de un grupo control, pero es útil para la generación de hipótesis y futuros estudios 


\section{TRESCIENTOS PACIENTES CON ENFERMEDAD TROMBOEMBOLICA VENOSA}

Fernández Bouza E, Mella Pérez C, Buño Ramilo B, Vázquez Vázquez B, Barbagelata López C, Sesma Sánchez P. MEDICINA INTERNA, COMPLEXO HOSPITALARIO UNIVERSITARIO DE FERROL.

INTRODUCCIÓN: la enfermedad tromboembólica venosa (ETV) es frecuente en nuestras consultas; conocer las características de los pacientes puede contribuir a un mejor manejo.

OBJETIVOS: analizar datos epidemiológicos y clínicos de pacientes atendidos en una consulta de ETV. MATERIAL Y MÉTODOS: se registraron las condiciones de los 300 primeros pacientes derivados a una consulta monográfica tras haber sufrido un episodio de ETV.

RESULTADOS: entre Julio-2012 y Marzo-2015 se recogieron 300 casos. El 54\% (162) fueron mujeres. El 71\%(215) precisaron ingreso hospitalario. El 54. 6\%(164) tuvieron trombosis venosa profunda (TVP), 39. 3\% (118) embolia pulmonar (EP) y 18 (6\%) ambas). La localización de la TVP fue femoral 43. 6\%(79), poplítea 26.5\%(48), ilíaca 7.7\%(14), tibio-peronea 3. 3\%(6), subclavia y miembros superiores $4.9 \%$ (9) y $8.3 \%$ (25) otras. Fueron sintomáticas el $89 \%$ de las TVP e incidentales el 10. 9\%. La afectación de miembros inferiores fue bilateral en 1. $7 \%$ (3). La EP fue central en $44 \%(60)$, periférica en $53 \%(73)$ y no se registró en $3(1 \%)$. Fue bilateral en $83(61 \%)$ y unilateral en $53(38.9 \%)$. Se consideró masiva en 8 . $2 \%(12)$, submasiva en $29 \%(21.3)$ y leve en $66.9 \%(91)$. Tres EP(2. $2 \%$ ) se diagnosticaron con gammagrafía de ventilación- perfusión y el resto con TAC. En $25 \%$ de casos (73) se hizo estudio de trombofilia positivo en 21. 9\%: un anticoagulante lúpico, un déficit de antitrombina, 4 heterocigosis para factor V Leiden, 1 homocigosis y 4 heterocigosis para mutación en gen de protrombina y 5 elevaciones de factor VIII. Otros factores de riesgo fueron: inmovilismo 47. 3\%(142), cáncer 25. 6\%(77), ETV previa 11\%(33). cirugía $10 \%(30)$, fractura $4 \%(12)$, anovulatorios $4 \%(13)$ y gestación $0.6 \%(2)$. El cáncer fue colo-rectal $31 \%(24)$, mama 16.8\%(13), pulmón 10. $3 \%(8)$, ginecológico 6. 4(5\%), hematológico 3. 8\%(3), cerebra 2. $5 \%(2)$ y otros $28.5 \%(22)$; la histología fue: adenocarcinoma $68.8 \%(53)$, epidermoide $5.1 \%(4)$, linfoma 3. $8 \%(3)$ y otras $22 \%(17)$. El estadio fue IV en $41.5 \%$ (32), III en $27.2 \%(21)$, II en $14.2 \%(11)$, I en 6. 4\%(5) y en otros en $10.3 \%(8)$. El 55. 8\%(43) recibían tratamiento quimioterápico en el momento de evento. El tratamiento inicial fue heparina de bajo peso molecular en 94\%(283), heparina no fraccionada en $1 \%(3)$ y otros $1 \%(4)$. El $75 \%$ de pacientes (225) continuaron tratamiento con anticoagulantes orales. No se estudió la mortalidad porque las condiciones del registro hacen que ésta no sea representativa de la muerte asociada con ETV.

CONCLUSIONES: en nuestros pacientes con EP, la TVP probablemente está infradiagnosticada por no realizar ecografía doppler tras el diagnostico de EP. Al igual que en la literatura, la TVP es más frecuente que la EP. Nuestros enfermos tienen predominantemente TVP proximal y sintomática. El inmovilismo es el factor de riesgo principal. A diferencia de otras series, tenemos un alto porcentaje de ETV asociada a cáncer, fundamentalmente en estadios avanzados, achacable a las características asistenciales del centro.

\section{TROMBOPROFILAXIS EN LOS SERVICIOS MÉDICOS Y QUIRÚRGICOS. ¿LO HACEMOS MEJOR QUE LOS CIRUJANOS?}

Barbagelata C, Vares M Piñeiro P, Linares D, Arévalo A, Vázquez $B$, Rodríguez A, Freire $S$.

MEDICINA INTERNA. UNIDAD DE PREINGRESO. HOSPITAL UNIVERSTTARIO A CORUÑA.

INTRODUCCIÓN: Pese a que la cirugía mayor es un factor clásico de riesgo para la enfermedad tromboembólica (ETVE), su incidencia ha aumentado en los últimos años en las plantas médicas, alcanzando 0 incluso superando a las quirúrgicas.

OBJETIVOS: Analizar y comparar la adecuación de la profilaxis en las plantas médicas y en cirugía ge neral, la comorbilidad de los pacientes (p) y las complicaciones trombóticas y hemorrágicas presentadas durante el ingreso.

MATERIAL Y MÉTODOS: Estudio observacional prospectivo comparativo de los p ingresados en el Hospital Universitario de A Coruña durante una semana del 2015 en cirugía general frente a los ingresados en medicina interna. Para valorar la adecuación de la TP se utilizó lq escala de PADUA para los p médicos y la de CAPRINI para los quirúrgicos. Se aplicó un análisis descriptivo con el paquete estadístico SPSS versión 19. 0. 4. Se incluyó un total de 93 p médicos y 54 quirúrgicos. La edad medida (DS) fue de 66 (17) años en los p médicos y de 55 (20) en los quirúrgicos. La comorbilidad fue significativamente mayor en los p médicos (tabla 1). El motivo principal de ingreso en los p médicos fue la infección respiratoria (25\%) y en los quirúrugicos la patología biliar no tumoral (24\%). El 33\% de los p quirúrgicos no fueron intervenidos y al $29.6 \%$ se les realizó cirugía mayor ( $>45 \mathrm{~min}$ ). Se inició TP en el $76 \%$ de los $p$ médicos y en el 79 $6 \%$ de los quirúrgicos. El $77.4 \%$ de los p fueron clasificados como de bajo riesgo según la escala PADUA (iniciándose TP inadecuada en el 75\% de los casos) y el 22. 6\% como de alto riesgo (no se inició TP sí indicada en el 19\%). Los principales motivos para no iniciarla fueron el alto riesgo hemorrágico y la enfermedad renal crónica estadio 4. El riesgo estimado según CAPRINI fue: muy bajo (9. 3\%), bajo (38. $9 \%$ ), moderado (27.8\%), alto (24.1\%). En los p con riesgo muy bajo/ bajo se inició profilaxis inadecuada en el 65. 38\%; sólo $3 p$ con indicación de TP no la recibieron, sin que se evidenciase un factor causa objetivo. La TP utilizada fue exclusivamente farmacológica en ambos servicios. En los médicos se utilizo enoxaparina en el $84.81 \%$ de los casos y tinzaparina en los restantes; en los quirúrgicos, enoxaparina en el 100\%. Al alta no se inició TP en ninguno de los p médicos; sí se inició en un 20. 4\% de los quirúrgicos, (36\% presentaban cáncer activo). La duración fue variable (50\% 1 semana, 20\% 2 semanas, $10 \% 3$ semanas, $20 \% 4$ semanas). En ninguno de los $p$ se objetivaron complicaciones hemorrágicas $n$ trombóticas durante el ingreso.

CONCLUSIONES: 1) Existe una sobreutilización de la profilaxis tanto en los servicios médicos como en los quirúrgicos. 2) El porcentaje de sobreutilización es similar en ambos servicios. 3) La ausencia de TP en los casos sí indicados presentaba una mayor justificación en los p médicos. 4) La indicación de TP a alta y su duración, debe ser revisada.

\section{TROMBOPROFILAXIS EN LOS SERVICIOS MEDICOS. ¿ES ADECUADA} SEGÚN LAS ESCALAS?

Vares M, Barbagelata C, Vázquez $R$ Arévalo A, González V, Llinares D, Rodríguez A, Freire S. MEDICINA INTERNA, HOSPITAL UNIVERSITARIO A CORUÑA.

INTRODUCCIÓN: El 49\% de los casos de enfermedad tromboembólica venosa (ETEV) aparecen el hospital. La ETEV constituye la primera causa de muerte prevenible en el paciente (p) hospitalizado. Para la predicción del riesgo de ETEV en $p$ médicos disponemos de las escalas de PADUA y PRETEMED, existiendo pocos datos comparativos entre ambas.

OBJETIVO: Analizar la adecuación de la TP en los servicios médicos según las escalas descritas y evaluar el grado de concordancia entre ambas

MATERIAL Y MÉTODO: Estudio observacional prospectivo de los p ingresados en los servicios médicos del Hospital Universitario de A Coruña durante una semana del mes de junio de 2014. Para valorar e riesgo de ETV se utilizaron las escalas de PADUA y PRETEMED. El riesgo hemorrágico fue medido según el registro IMPROVE. Se aplicó un análisis descriptivo con el paquete estadístico SPSS versión 19. 0. La asociación entre las escalas se evaluó mediante el test de la 2 y el test exacto de Fisher.

RESULTADOS: Se incluyeron un total de 93 p. Se inició TP en el 76\% de los casos. El 77. 4\% de los p fueron clasificados como de bajo riesgo según la escala PADUA y el 22. 6\% como de alto riesgo. En los $p$ con bajo riesgo se inició TP inadecuada en el 75\% de los casos; en los p de alto riesgo no se inició TP si estando indicada en el 19\%. Según PRETEMED el 68. 8\% de los p fueron de bajo riesgo y el 31 $2 \%$ de alto riesgo. La TP se inició erróneamente en el $71.9 \%$ de los p de bajo riesgo y no se inició en el
13. 8\% de los de alto riesgo. Los motivos médicos por los que no se inició TP cuando las escalas sí lo indicaban fue: alto riesgo hemorrágico (2p), filtrado glomerular ( $F G$ ) menor de 30 (1p) y mal pronóstico en menos de $24 \mathrm{~h}$. Un 7. 5\% de los p presentaba un FG (MDRD) menor de $30 \mathrm{~mL} / \mathrm{min} / \mathrm{m} 2$. De estos, sólo se inició TP en el $28 \%$ estando indicada en el $42 \%$. En cuanto a la concordancia entre ambas escalas: el $61.3 \%$ y el $15.1 \%$ de los $p$ fueron respectivamente clasificados como de bajo y alto riesgo por las dos escalas; el 16. 1\% fueron de bajo riesgo según PADUA y de alto riesgo según PRETEMED; el 7.5\% fue de alto grado según PADUA y de bajo grado según PRETEMED. La TP utilizada fue exclusivamente farmacológica. Se utilizó enoxaparina en el $84.81 \%$ de los casos y tinzaparina en los restantes. Las dosis de enoxaparina empleadas fueron: $20 \mathrm{~mL} / 24 \mathrm{~h}$ (11. 1\%), $40 \mathrm{~mL} / 24 \mathrm{~h}$ (82. 5\%), $60 \mathrm{~mL} / 24 \mathrm{~h}(4.8 \%)$. La pauta de enoxaparina $20 \mathrm{~mL} / 24 \mathrm{~h}$ fue inadecuada en todos los $p$. Ningún $p$ presentó complicaciones trombóticas o hemorrágicas durante el ingreso.

CONCLUSIONES: 1) Existe una sobreutilización de la TP en los servicios médicos. 2) Es necesario implementar la utilización de las escalas descritas en la práctica clínica. 3) La enfermedad renal estadio 4 y el alto riesgo hemorrágico fueron los principales motivos por los que no se inició TP en p de alto riesgo. 4 La no adecuación de la TP a las indicaciones de las escalas y la ausencia de complicaciones durante el ingreso limita el estudio comparativo entre ambas.

\section{TROMBOSIS DE VENA OVÁRICA DERECHA EN PUERPERIO. A PROPOSITO DE 5 CASOS}

Alves ED, Velo A, Rios-Prego M, Brea R, Encabo A, Caro C, Anibarro L, Nuñez M. MEDICINA INTERNA, COMPLEJO HOSPITALARIO UNIVERSITARIO DE PONTEVEDRA.

INTRODUCCIÓN: La trombosis de la vena ovárica (TVO) es una complicación rara y potencialmente grave. Su aparición es más frecuente en el puerperio. Ocurre en la vena ovárica derecha en el 80-90\% de los casos. Su sintomatología es inespecífica, aunque habitualmente cursa con dolor en fosa ilíaca derecha (FID) y fiebre. El diagnóstico puede realizarse con ecografía, tomografía computarizada (TC). El tratamiento se basa en anticoagulación y antibióticos de amplio espectro.

OBJETIVOS: Valorar la presentación (tiempo del post parto/cesárea al diagnóstico, asociación con cesárea y clínica), el método diagnóstico, la localización y el tratamiento.

Métodos: Revisión retrospectiva de pacientes con el diagnóstico de TV0 en el Complejo Hospitalario de Pontevedra (CHOP) entre Enero 2004 - Diciembre 2014.

RESULTADOS: 5 puérperas fueron diagnosticadas de TVO en los servicio de medicina interna y ginecología del CHOP. La edad media fue 28,5 años. En el 100\% de las pacientes se realizó cesárea; el tiempo medio transcurrido desde la cesárea al desarrollo de TVO fue 10,8 días. La presentación clínica fue: 3 casos con fiebre y dolor en FID, 1 caso fiebre y 1 con dolor en fosa ilíaca derecha. El diagnóstico fue predominantemente mediante TC (4 casos); 1 caso se sospechó con ecografía que luego se confirmó con TC. El 100\% de los casos tenían afectada la vena ovárica derecha y en el $80 \%$ de los casos se evidencio co-afectación de la vena cava inferior. El estudio de trombofilia se realizó en el 100\% de los casos 2 de ellas alteraciones con: 1 mutación heterocigota del factor $\mathrm{V}$ de Leiden y 1 proteína $\mathrm{C}$ libre disminuida. En todos los casos se inició al momento del diagnóstico heparina de bajo peso molecular (HBPM) y antibioterapia de amplio espectro, con evolución favorable. Posteriormente se procedió al cambio a ACO en 3 casos, los otros dos casos se mantuvieron con HBPM. El tiempo medio de anticoagulación fue de 5,4 meses con un intervalo de duración que fue entre 4 meses hasta de forma indefinida En este caso se procedió a anticoagulación indefinida por trombosis de vena femoral común de miembro inferior derecho al mes del diagnóstico, a pesar de estar con tratamiento anticoagulante. No hubo recurrencias de enfermedad tromboembólica venosa (ETV) en un período de seguimiento medio de un año posterior a la suspensión de tratamiento anticoagulante.

CONCLUSIÓN: En puérperas el diagnóstico de trombosis de vena ovárica es infrecuente. № obstante, hay que tenerlo en cuenta en mujeres puérperas con dolor en FID y fiebre. En nuestros casos se asocia a la finalización del embarazo con cesárea y habitualmente se acompaña de trombosis de la vena cava inferior. En ocasiones las pacientes pueden presentar trombofilias por lo que es importante el estudio de trombofilias. El tratamiento anticoagulante debe iniciarse precozmente con HBPM y posteriormente cambiar a ACO con una duración media de 6 meses.

\section{VALOR PREDICTIVO DE HAS BLED Y ATRIA PARA EL RIESGO DE HEMORRAGIA EN PACIENTES ANTICOAGULADOS CON DABIGATRAN}

Álvarez Otero J, Lamas Ferreiro JL, Puerta Louro R, González González L, Araújo Fernández S, De la Fuente Aguado J.

MEDICINA INTERNA, POVISA

INTRODUCCIÓN: Dabigatran es un anticoagulante inhibidor directo de la trombina indicado para la prevención del ictus isquémico en pacientes con fibrilación auricular. Una de sus potenciales complicaciones son las hemorragias, que pueden en ocasiones amenazar la vida del paciente. Existen diversas escalas para valorar el riesgo hemorrágico que presentan los pacientes que necesitan ser anticoagulados, siendo 2 de las más utilizadas HAS-BLED y ATRIA, aunque ambas escalas fueron validadas utilizando datos de pacientes a tratamiento mayoritariamente con warfarina.

OBJETIVOS: El objetivo de este estudio fue determinar el valor predictivo de las escalas HAS-BLED y ATRIA para el riesgo de hemorragia en pacientes anticoagulados con dabigatran.

MATERIAL Y MÉTODOS: Se trata de un estudio descriptivo y retrospectivo en el que se incluyeron todos los pacientes que iniciaron tratamiento anticoagulante con dabigatrán entre los meses de noviembre de 2011 y septiembre de 2012. Se estimó el riesgo de hemorragia grave que presentaba cada paciente en el momento de inicio del tratamiento con dabigatran mediante las escalas HAS-BLED y ATRIA. Se establecieron 2 variables dicotómicas con el resultado de cada escala: HAS-BLED de alto riesgo (puntuación igual o mayor a 3) y ATRIA de alto riesgo (puntuación igual o mayor a 5). Asimismo, se determinó la incidencia de complicaciones hemorrágicas hasta Junio de 2013. Finalmente se estimó la sensibilidad, especificidad, valor predictivo positivo (NPP) y valor predictivo negativo (NPN) para cada una de las escalas de riesgo hemorrágico en su forma dicotómica así como el valor discriminativo para sangrado mayor de las mismas mediante curvas ROC

RESULTADOS: Se incluyeron 316 pacientes con edad media de 76 años $( \pm 8,37)$ y predominio de varones (53\%). El $54 \%$ de los pacientes estaban a tratamiento con Dabigatran a dosis de $150 \mathrm{mg} / 12 \mathrm{~h}$ y el $46 \%$ con $110 \mathrm{mg} / 12 \mathrm{~h}$. Las complicaciones por sangrado ocurrieron en 40 pacientes (10,91/100 pacientesaño): 32 presentaron hemorragia menor (8,73/100 pacientes-año) y 8 mayor (2,18/100 pacientes-año). Un 34,6\% de los pacientes presentaron HAS-BLED de alto riesgo, variable que mostró una sensibilidad, especificidad, VPP y VPN del $75 \%, 66 \%, 5 \%$ y 99\% respectivamente, con un área bajo la curva de 0,7 (IC95\%: 0,4-0,9: $P$ 0,1). Un 5\% de los pacientes presentaron ATRIA de alto riesgo, variable que mostró una sensibilidad, especificidad, VPP y VPN del 16\%,95\%,7\%,98\%, con un área bajo la curva de 0,55 (IC95\%: 0,3-0,8; P 0,6)

CONCLUSIONES: A pesar de que tanto el HAS-BLED como el ATRIA demostraron un VPN alto, ambas escalas presentaron un bajo valor discriminativo calculado mediante curvas ROC, a diferencia de los estudios publicados con anticoagulantes distintos del dabigatran, por lo que consideramos necesario el desarrollo de nuevas escalas que permitan una valoración más adecuada del riesgo hemorrágico en aquellos pacientes en los que se plantee el tratamiento con dicho fármaco. 


\section{VARIABLES PRONÓSTICAS EN INSUFICIENCIA CARDIACA PRESERVADA}

Páez-Guillán E, García-Villafranca A, Macía-Rodríguez C, Alende-Castro V. Mateo-Mosquera L, Bermúdez Ramos $M$, Martínez-Braña L, Lado Lado F

MEDICINA INTERNA, COMPLEXO HOSPITALARIO UNIVERSITARIO DE SANTIAGO DE COMPOSTELA.

INTRODUCCIÓN: La insuficiencia cardíaca supone un problema habitual en la población de edad avanzada, esto supuso la creación de unidades específicas para manejo y seguimiento de dichos pacientes. OBJETIVO: Analizar las características y los factores asociados a mortalidad a los 5 años del diagnóstico en pacientes con insuficiencia cardíaca (IC) con fracción de eyección del ventrículo izquierdo (FEVI) preservada.

MATERIAL Y MÉTODOS: Estudio retrospectivo en el que se incluyeron los pacientes con IC con FEVI conservada a seguimiento en consulta específica de IC de medicina interna durante el periodo desde enero 2007 a diciembre 2011. Se recogieron variables epidemiológicas, clínicas y analíticas. Se realizó un análisis descriptivo y univariante para determinar los factores asociados a mortalidad a 5 años.

RESULTADOS: Se incluyeron 209 paciente (59,8\% mujeres) con una edad media de $78,9 \pm 7,2$ años. El $41,5 \%$ tenía una clase funcional II de la NYHA. La etiología de la IC fue hipertensiva en el $64,1 \%$, isqué- mica en el $11,5 \%$, valvular en el $10,0 \%$ y Cor pulmonale en el 7,7 \%. La mortalidad a los 5 años fue del $48,0 \%$. El número de reingresos a los 5 años se distribuyó de la siguiente forma: no necesitaron ingreso el $49,2 \%$ de los pacientes; el 25,4\% de los pacientes ingresaron en 1 ocasión; el 10,9\% en 2 ocasiones y el $14,5 \%$ en más de 2 ocasiones. Las comorbilidades más frecuentes fueron: la HTA (82,8\%), la fibrilación auricular (56,9\%), la insuficiencia renal grado III (49,8\%) y la DM (35,4\%). Los tratamientos utilizados con más frecuencia fueron diuréticos de asa $(93,1 \%)$, estatinas $(64,1 \%)$, IECAS $(55,2 \%), \beta$-bloqueantes $(55,1 \%)$ y antiagregantes $(54,1 \%)$.

Los principales factores asociados a mortalidad a 5 años fueron: fármacos ahorradores de K (p: 0,057), nitratos (p: 0,022) y digoxina (p: 0,005). Se encontraron como factores asociados a menor mortalidad: $\beta$-bloqueante (p: 0,053$)$, diuréticos de asa ( $p: 0,013)$, anticoagulantes orales $(p: 0,038)$ y las estatinas (p: 0,007).

CONCLUSIONES: - La insuficiencia cardíaca con fracción de eyección preservada presenta una elevada mortalidad a lo largo del seguimiento.

- Los pacientes a seguimiento en la consulta específica de IC presentan un índice bajo de reingreso.

- Tratamientos como los diuréticos de asa, los anticoagulantes y las estatinas se han asociado a menor mortalidad a 5 años. 